\title{
Phosphoinositides: Roles in the Development of Microglial-Mediated Neuroinflammation and Neurodegeneration
}

\author{
Thomas Ernest James Phillips ${ }^{\star \dagger}$ and Emily Maguire ${ }^{\star \dagger}$ \\ UK Dementia Research Institute at Cardiff University, Cardiff, United Kingdom
}

\section{OPEN ACCESS}

Edited by:

Małgorzata Kujawska,

Poznan University of Medical

Sciences, Poland

Reviewed by:

Souvarish Sarkar,

Brigham and Women's Hospital and

Harvard Medical School,

United States

Tibor Rohacs,

Rutgers New Jersey Medical School, United States

*Correspondence: Emily Maguire

maguiree1@cardiff.ac.uk

Thomas Ernest James Phillips

phillipsT10@cardiff.ac.uk

tThese authors have contributed equally to this work and share first authorship

Specialty section: This article was submitted to Non-Neuronal Cells,

a section of the journal

Frontiers in Cellular Neuroscience

Received: 12 January 2021 Accepted: 08 March 2021

Published: 26 March 2021

Citation:

Phillips TEJ and Maguire E (2021) Phosphoinositides: Roles in the Development of Microglial-Mediated Neuroinflammation and Neurodegeneration. Front. Cell. Neurosci. 15:652593. doi: 10.3389/fncel.2021.652593
Microglia are increasingly recognized as vital players in the pathology of a variety of neurodegenerative conditions including Alzheimer's (AD) and Parkinson's (PD) disease. While microglia have a protective role in the brain, their dysfunction can lead to neuroinflammation and contributes to disease progression. Also, a growing body of literature highlights the seven phosphoinositides, or PIPs, as key players in the regulation of microglial-mediated neuroinflammation. These small signaling lipids are phosphorylated derivates of phosphatidylinositol, are enriched in the brain, and have well-established roles in both homeostasis and disease.Disrupted PIP levels and signaling has been detected in a variety of dementias. Moreover, many known AD disease modifiers identified via genetic studies are expressed in microglia and are involved in phospholipid metabolism. One of these, the enzyme PLC $\gamma 2$ that hydrolyzes the PIP species $\mathrm{PI}(4,5) \mathrm{P}_{2}$, displays altered expression in $\mathrm{AD}$ and $\mathrm{PD}$ and is currently being investigated as a potential therapeutic target. Perhaps unsurprisingly, neurodegenerative conditions exhibiting PIP dyshomeostasis also tend to show alterations in aspects of microglial function regulated by these lipids. In particular, phosphoinositides regulate the activities of proteins and enzymes required for endocytosis, toll-like receptor signaling, purinergic signaling, chemotaxis, and migration, all of which are affected in a variety of neurodegenerative conditions. These functions are crucial to allow microglia to adequately survey the brain and respond appropriately to invading pathogens and other abnormalities, including misfolded proteins. $A D$ and $P D$ therapies are being developed to target many of the above pathways, and although not yet investigated, simultaneous PIP manipulation might enhance the beneficial effects observed. Currently, only limited therapeutics are available for dementia, and although these show some benefits for symptom severity and progression, they are far from curative. Given the importance of microglia and PIPs in dementia development, this review summarizes current research and asks whether we can exploit this information to design more targeted, or perhaps combined, dementia therapeutics. More work is needed to fully characterize the pathways discussed in this review, but given the strength of the current literature, insights in this area could be invaluable for the future of neurodegenerative disease research.

Keywords: microglia, neurodegeneration, neuroinflammation, phosphoinositols, Alzheimer's disease, Parkinson's disease, phagocytosis, chemotaxis 


\section{INTRODUCTION}

Fifty million people worldwide currently present with neurodegenerative conditions, with $60-70 \%$ of these suffering from Alzheimer's disease (AD) (World Alzheimer Report, 2015). Microglia, tissue-specific macrophages that reside in the central nervous system (CNS), are becoming increasingly recognized as important in the development of numerous dementia pathologies (Bachiller et al., 2018). Unlike most macrophages, microglial precursors emerge from the embryonic yolk sac and migrate into the CNS during the first trimester of development before their final maturation (Kierdorf and Prinz, 2013).

During development, microglia have key roles in shaping neuronal networks and modulating both the number of synapses and the strength of synaptic transmission (Colonna and Butovsky, 2017). Following CNS injury, microglial phagocytosis of various substrates including microbes, dead cells, and protein aggregates helps maintain healthy brain homeostasis (Gabandé-Rodríguez et al., 2020). Furthermore, these cells secrete messenger molecules such as cytokines, chemokines, and neurotrophic factors (Lee et al., 2002). Cytokine secretion regulates inflammatory responses, whilst chemokines initiate chemotaxis and migration, stimulating microglia and other immune cells to become activated and migrate to the site of injury (Lee et al., 2002). Both phagocytosis and cytokine/chemokine secretion can be triggered via activation of microglial toll-like receptors (TLRs), which promote inflammation in response to activation by pathogen-associated molecular patterns (PAMPs) and other stimuli (Fiebich et al., 2018). Microglia are also key modulators of purinergic signaling, with activation of these pathways influencing both inflammation and phagocytosis (Calovi et al., 2019).

Phosphoinositides (PIPs), in brief, are acidic membrane lipids derived from phosphatidylinositol. These lipids, known to support key cellular functions in the brain, are increasingly recognized as important in neurodegenerative processes and microglial function (Raghu et al., 2019).

This review aims to summarize the role of microglia in a variety of neurodegenerative conditions, as well as known phosphoinositide disturbances within these conditions. This will be followed by discussions on how alterations in phosphoinositides and their regulatory enzymes could affect specific microglial functions and thereby contribute to disease progression. Finally, for each microglial function discussed, we will explore how phosphoinositide-modifying therapies could potentially be used to ameliorate disease phenotypes.

\section{ROLES OF MICROGLIA IN DEMENTIA}

\section{Alzheimer's Disease}

AD, first characterized by Alois Alzheimer in 1907 (Alzheimer et al., 1995), presents with widespread brain atrophy, amyloid plaques (large extracellular deposits of amyloid-beta $(\mathrm{A} \beta)$ protein aggregates), neurofibrillary tangles (consisting of phosphorylated Tau), neuronal and synapse loss, and dystrophic neurites (Lane et al., 2018). Clinically, these pathologies result in memory loss, language difficulties, executive dysfunction, psychiatric symptoms, and behavioral disturbances, along with general difficulties managing activities of daily living (Burns and Iliffe, 2009). AD can be either familial ( $<0.5 \%$ of cases) or sporadic. Familial cases arise following mutations in the genes encoding either presenilin 1 (PSEN1), presenilin 2 (PSEN2), or amyloid precursor protein (APP; Bateman et al., 2011).

Within AD, we know that $58-79 \%$ of sporadic cases are linked to the patient's genes (Gatz et al., 2006). Genetics studies strongly suggest microglia as a leading driver of $\mathrm{AD}$ pathology, with many of the implicated genes either largely or solely expressed in microglia (McQuade and Blurton-Jones, 2019). The importance of microglia is supported by observations of proliferation and activation of microglia around amyloid plaques (Hickman et al., 2008). Whether this microglial response reduces disease progression, enhances $\mathrm{AD}$ pathology, or both is currently the subject of much debate. $\mathrm{AD}$ microglia elicit a range of functional changes including increased cytokine/chemokine production and inflammasome activation, increased synapse engulfment, and phagocytosis of injured but functional neurons (McQuade and Blurton-Jones, 2019). The role of microglia in $\mathrm{A} \beta$ clearance within $\mathrm{AD}$ is also unclear. Whilst microglial phagocytosis of $A \beta$ appears crucial in clearing plaques (Simard et al., 2006), other studies have shown that pharmacological depletion of microglia prevents plaque formation in the first place (Sosna et al., 2018).

Nitric oxide (NO) curative therapy currently exists for the treatment of AD (Weller and Budson, 2018). This may be due to a large research focus in the past on the "amyloid hypothesis" which postulates that all $\mathrm{AD}$ pathologies arise due to $A \beta$ accumulation and plaque formation, and consequently that the best way to treat the disease is to target $A \beta$ directly (Oxford et al., 2020).

\section{Parkinson's Disease}

Parkinson's disease (PD), first described by James Parkinson in 1817 (Parkinson, 2002), is the second most common neurodegenerative disease, affecting about 6.1 million people worldwide (2018). PD patients experience rigidity, bradykinesia, resting tremors, and postural instability (Gopalakrishna and Alexander, 2015), with 30\% also experiencing dementia (Hanagasi et al., 2017).

Symptoms arise following the degeneration of dopaminergic neurons in the substantia nigra, which produce the neurotransmitter dopamine. Neuronal loss occurs following the formation of intraneuronal "Lewy bodies" which consist of aggregated bundles of misfolded $\alpha$-synuclein (Lecours et al., 2018). Variants in the SNCA gene, which encodes for $\alpha$-synuclein, present as the most well-established genetic risk factor for PD (Campêlo and Silva, 2017). Around 5\% of PD cases are caused by mendelian gene changes (e.g., SNCA) and are therefore classed as familial. The remainder of PD cases arises following a complex interplay of aging, genetic susceptibility, and environmental factors (Pang et al., 2019).

Within the PD brain, microglia are thought to lose beneficial, whilst gaining detrimental, functions (Lecours et al., 2018). Positron emission tomography (PET) studies in patients, as 
well as work by McGeer and colleagues on post-mortem tissue, demonstrate increased microglial activation in PD brains (McGeer et al., 1988; Ouchi et al., 2005; Gerhard et al., 2006). Moreover, increased inflammatory cytokines, released by microglia, are observed within the brains and cerebrospinal fluid (CSF) of PD patients (Vawter et al., 1996; Nagatsu et al., 2000). CSF from PD patients is toxic to dopaminergic neurons; in part due to the aforementioned high inflammatory cytokine concentration (Nagatsu and Sawada, 2005). Furthermore, and similarly to AD, PD microglia appear to phagocytose injured but functional neurons, thereby exacerbating neurodegeneration (Brown and Neher, 2012). These microglial phenotypes seem to occur following exposure to aggregated $\alpha$-synuclein (Zhang et al., 2005).

3, 4-dihydroxy-L-phenylalanine, the precursor to dopamine, acts as the "gold standard" PD treatment. Nevertheless, while this drug ameliorates many PD-associated motor defects, long-term use often results in debilitating dyskinesia and other motor fluctuations (Lane, 2019).

\section{Huntington's Disease}

Microglia have also been implicated in the pathology of Huntington's disease (HD; Yang H.-M. et al., 2017). HD is an autosomal dominant trinucleotide repeat disorder caused by an expansion in the Huntington protein (HTT; MacDonald et al., 1993). More than 40 repeats result in disease, characterized primarily by dysfunction and death of neurons within the striatum of the brain. For patients, this results in progressive motor, cognitive, and psychiatric disturbances (Bates et al., 2015).

PET studies on human HD post-mortem brains have demonstrated increased activation of microglia in HD compared with controls (Pavese et al., 2006; Politis et al., 2012), with this activation occurring up to 15 years before the predicted age of onset (Tai et al., 2007). The degree of microglial activation appears to correlate positively with the degree of cell death within a given brain region, as well as symptom severity (Sapp et al., 2001). Moreover, mutated Huntington protein (mHTT) expression appears to impact microglial function directly (Yang H.-M. et al., 2017). Effects include increased cytokine production and transcriptional dysregulation (Crotti et al., 2014; Träger et al., 2014; Miller et al., 2016). There are currently no curative therapies available for HD (McColgan and Tabrizi, 2018).

\section{Amyotrophic Lateral Sclerosis}

Amyotrophic lateral sclerosis (ALS) is a degenerative disease primarily characterized by muscle weakness and wasting, with $10-15 \%$ of patients also suffering from frontotemporal dementia (FTD). FTD results in progressive degeneration of frontal and anterior temporal lobes, with patients experiencing behavioral changes alongside impairments in executive functioning and, often, language. ALS is familial in 15\% of cases, where it is caused by changes in one of more than 20 currently identified genes (Masrori and Van Damme, 2020). The most common cause (of both ALS and FTD) in North America and Europe is a hexanucleotide GGGGCC expansion in the c9orf72 gene (Dejesus-Hernandez et al., 2011;
Renton et al., 2011). The function of the c9orf72 protein is currently unknown, although it is suspected to be involved in endocytic trafficking and autophagy (Braems et al., 2020). Within cells, cytoplasmic aggregations of TDP-43 occur in 95\% of ALS patients (Masrori and Van Damme, 2020). Sporadic ALS likely occurs following complex interactions between risk loci-several of which have been identified via genome-wide association studies (GWAS) - and the environment (Ajroud-Driss and Siddique, 2015).

As with other dementias, the role of microglia in ALS appears to be highly complex. C9orf72 knock-out mice, while showing no motor-neuron degeneration, show altered immune responses in microglia and macrophages, highlighting the importance of these myeloid cells in ALS pathogenesis (O'Rourke et al., 2016). Furthermore, another ALS risk gene, TBK1, is involved in the production of inflammatory cytokines (Ahmad et al., 2016). Finally, microglia appear to be activated in ALS patients' brains, with this activation occurring before the onset of clinical symptoms (Geloso et al., 2017). More research must be undertaken to fully elucidate the role of microglia in ALS pathology.

\section{Summary}

Neurodegenerative conditions pose serious health and economic costs to our society. If left unchecked, cases are expected to triple by 2050 (Prince et al., 2013). At present, treatment is limited by a lack of effective therapies for many forms of neurodegenerative disease, despite decades of research aimed at developing such therapies. It is becoming clear that microglia, the primary mediators of neuroinflammation, play important roles in the pathologies of many forms of neurodegeneration. Further research exploring the roles of microglia to target them therapeutically may well hold the key to releasing the deadlock on treatment development.

\section{ROLES OF PHOSPHOINOSITIDES IN DEMENTIA}

\section{What are Phosphoinositides?}

Phosphoinositides are signaling lipids derived from phosphatidylinositol, which is comprised of diacylglycerol (DAG) moiety linked to a D-myo-inositol ring via a phosphodiester linkage. Specific kinases and phosphatases add or remove phosphate groups from the 3, 4, or 5 positions of the myo-inositol ring, generating seven PIP species. These are monophosphorylated $\mathrm{PI}(3) \mathrm{P}, \mathrm{PI}(4) \mathrm{P}$, and $\mathrm{PI}(5) \mathrm{P}$; bisphosphorylated $\mathrm{PI}(3,4) \mathrm{P}_{2}, \mathrm{PI}(3,5) \mathrm{P}_{2}$, and $\mathrm{PI}(4,5) \mathrm{P}_{2}$; and trisphosphorylated $\mathrm{PI}(3,4,5) \mathrm{P}_{3}$ (Figure 1). These lipids are enriched in the brain, with each residing on specific cellular membranes (Figure 1). In brief, PI(4)P, PI(3,4,5)P3, PI(3,4)P2, $\mathrm{PI}(5) \mathrm{P}$, and $\mathrm{PI}(4,5) \mathrm{P} 2$ can be found on the plasma membrane, $\mathrm{PI}(3) \mathrm{P}$ and $\mathrm{PI}(3,5) \mathrm{P} 2$ are concentrated within the endocytic system, and $\mathrm{PI}(5) \mathrm{P}$ is found within the nucleus. The distribution of PIPs is both dynamic and highly regulated, allowing for a rapid generation or reduction of specific species at precise locations. This function is achieved via tight spatial and temporal restrictions of the aforementioned PIP metabolism enzymes. 

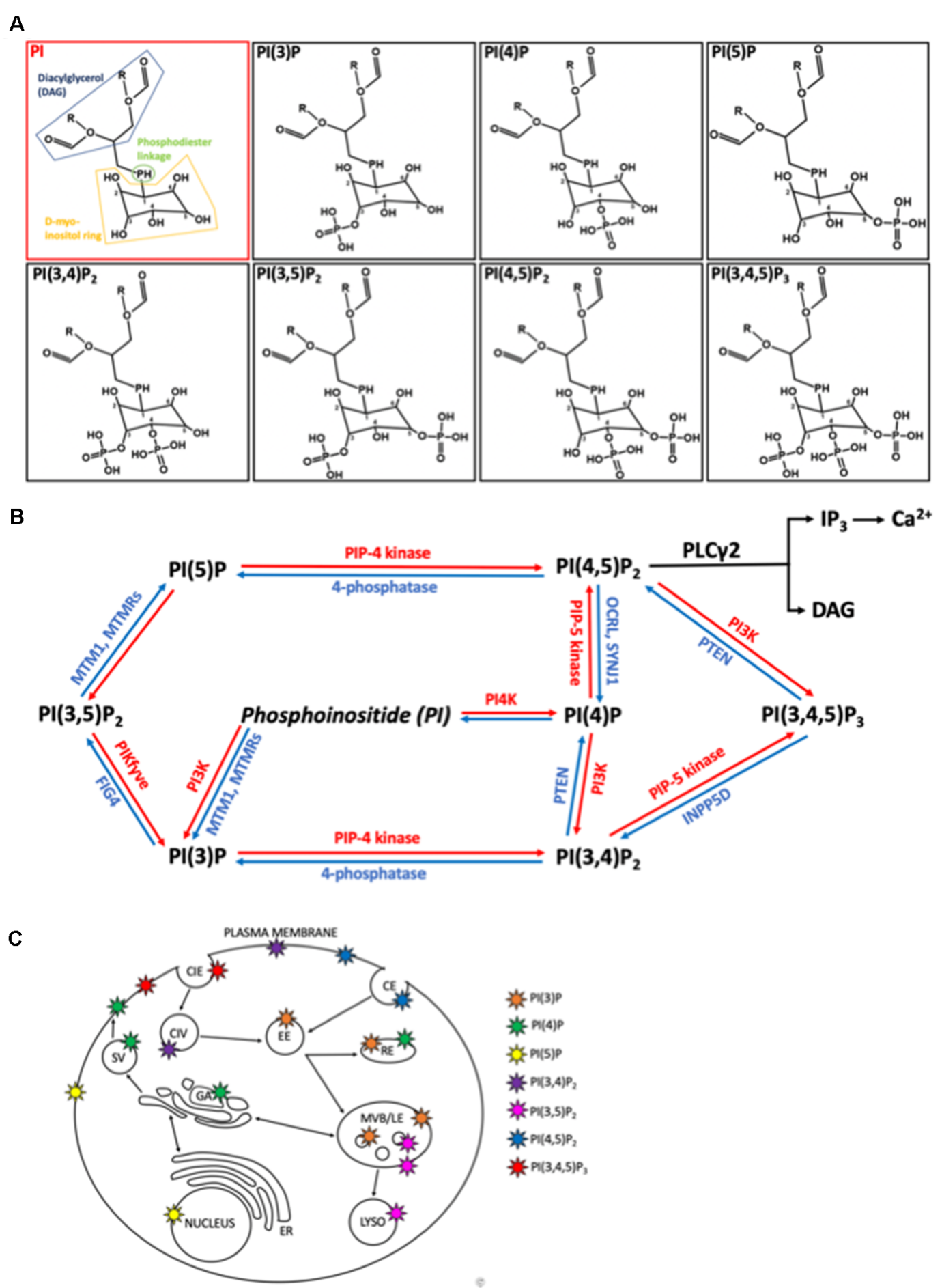

FIGURE 1 | Structure, metabolism, and location of phosphatidylinositides (PIPs) within mammalian cells. (A) Structures of phosphatidylinositol (PI) and it is seven phosphoinositide (PIP) derivatives, generated by phosphorylation of the inositol ring at positions 3,4 or 5. Pl consists of diaglycerol (DAG, blue) bound to a D-myo-inositol ring (yellow) via a phosphodiester linkage (green). O, oxygen; $\mathrm{H}$, hydrogen; $\mathrm{P}$, phosphate; R, non-polar fatty acid tails. (B) Metabolic pathways regulating the interconversion of PIP species. Lipid kinases (red) phosphorylate the inositol ring at points 3, 4, or 5 to generated more phosphorylated PIPs while lipid phosphatases remove phosphate groups. MTM1, myotubularin1; MTMR, myotubularin-related protein; FIG4, Factor-Induced Gene 4; PTEN, phosphatase and tensin homolog; OCRL, inositol phosphatase 5-phosphatase; SYNJ1, synaptojanin 1; INPP5D, Src homology 2 (SH2) domain containing inositol polyphosphatase 5-phosphatase 1. (C) Primary locations of the different PIPs within the cell are shown by the colored stars. CIE, clathrin independent endocytosis; CIV, clathrin independent endocytic vesicle, CE, clathrin dependent endocytosis; EE, early endosome; RE, recycling endosome; SV, secretory vesicle; GA, golgi apparatus; ER, endoplasmic reticulum; MVB/LE, multi-vesicular body/late endosome; LYSO, lysosome. 
Despite their low abundance, these lipids are involved in crucial cellular functions, including signal transduction, cytoskeletal reorganization, membrane dynamics, vesicular trafficking, and cell death (Phan et al., 2019). Known functions of the different PIP species in the brain are summarized in Table 1. All species appear to be involved in endocytic trafficking events (e.g., autophagy and phagocytosis), whilst others exhibit key roles in chemotaxis $\left(\mathrm{PI}(4,5) \mathrm{P}_{2}\right.$ and $\left.\mathrm{PI}(3,4,5) \mathrm{P}_{3}\right)$, and synaptic function ( $\left.\mathrm{PI}(3) \mathrm{P}, \mathrm{PI}(4,5) \mathrm{P}_{2}, \mathrm{PI}(3,5) \mathrm{P}_{2}, \mathrm{PI}(3,4,5) \mathrm{P}_{3}\right)$.

Perhaps unsurprisingly given their key roles in the brain, PIPs have been implicated in a wide variety of dementia's, including $\mathrm{AD}, \mathrm{PD}, \mathrm{HD}$, and ALS. Precise perturbances of PIP species and their suspected effects on neurodegenerative disease are later discussed and summarized in Table 1.

\section{Phosphoinositide Dyshomeostasis in Neurodegenerative Disease-General}

Growing evidence suggests that phosphoinositide dyshomeostasis plays a role in the development of a variety of dementias. Phosphoinositides, which are relatively enriched in the brain (Hawthorne and Pickard, 1979), regulate the activity of several neurotransmitters and neuropeptides (Lo Vasco, 2018). Furthermore, phosphoinositides have key roles in $\mathrm{Ca}^{2+}$ signaling (Bezprozvanny, 2009) and autophagy (Palamiuc et al., 2020), which are disrupted in numerous neurodegenerative conditions.

One key protein linking phosphoinositol metabolism with several dementias is synaptojanin 1 (SYNJ1). This phosphoinositide phosphatase hydrolyzes $\mathrm{PI}(4,5) \mathrm{P}_{2}$, with SYNJ1 knock-out mice showed increased $\mathrm{PI}(4,5) \mathrm{P}_{2}$ in neurons alongside defects in synaptic vesicle recycling (Cremona et al., 1999). Overexpression of SYNJ1 has been seen in AD patients (Miranda et al., 2018), and downregulating SYNJ1 increases clearance of amyloid plaques while improving behavioral deficits in AD mice (McIntire et al., 2012; Zhu et al., 2013). In addition to roles in $\mathrm{AD}$, mutations in SYNJ1 have been associated with early-onset atypical-Parkinson's disease, suggesting that SYNJ1 manipulation may also prove beneficial in PD (Drouet and Lesage, 2014; Ben Romdhan et al., 2018; Xie et al., 2019).

Another subset of phosphoinositide conversion enzymes with key links to dementia is the phosphoinositide-3-kinases (PI3K). PI3K promotes downstream signaling via $\mathrm{AKT}$ and mTOR and activating these pathways plays a vital regulatory role in the development of oxidative stress, in apoptosis, and in autophagy (Chong et al., 2012). Within AD, excessive activation of downstream PI3K signaling has been suggested to be responsible for some neurodegenerative processes, whereas, in $\mathrm{PD}$, under-activation of these pathways has been observed to influence pathology (Heras-Sandoval et al., 2014). Activation of the Akt/PI3K signaling pathway is crucial to the initiation of neuroinflammation by microglia in response to LPS (Cianciulli et al., 2020). Although more work needs to be done to further characterize signaling dysfunctions within these conditions, targeting these pathways using established PI3K inhibitors and activators could provide potential therapeutics in the future (Yang et al., 2016, 2019).

Together, these studies demonstrate how disruptions in phosphoinositide metabolism can be crucial to the development of neurodegenerative phenotypes. The following sections will go into more detail about phosphoinositide dyshomeostasis in specific neurodegenerative conditions. Table 2 summarizes the differing roles of PIP species in neurodegenerative conditions.

\section{Phosphoinositide Dyshomeostasis in Alzheimer's Disease}

Quite a large body of research outlines phosphoinositide dyshomeostasis in $\mathrm{AD}$. The first study to highlight this was published in 1987 by Stokes and Hawthorne. They revealed reduced PIP4 and $\mathrm{PI}(4,5) \mathrm{P}_{2}$ within the $\mathrm{AD}$ cortex when compared with controls (Stokes and Hawthorne, 1987). Within AD brains, studies have observed not only changes in PIP levels but also changes in the expression of regulatory enzymes (Lo Vasco, 2018).

Alterations in membrane phospholipid composition within $\mathrm{AD}$ following PIP dysregulation could result in changes to membrane structure and fluidity, which in turn is likely to influence the development of various characteristic $\mathrm{AD}$ pathologies (Zhu et al., 2015). Also, A $\beta$ binding to the cellular prion protein (PrPC) has been demonstrated to activate mGlurR5 and phospholipase C (PLC) signaling pathways (Um et al., 2013). These pathways are both regulated by and regulate phosphoinositide levels, with $\mathrm{PI}(4,5) \mathrm{P}_{2}$ being the substrate of PLC enzymes. PLC activation leads to downstream cytosolic $\mathrm{Ca}^{2+}$ increase, which contributes to characteristic AD memory impairment (Berridge, 2013, 2014). The above observations are supported by previous studies in familial $\mathrm{AD}$ cortical neurons which demonstrated a clear link between $\mathrm{A} \beta$ and $\mathrm{PI}(4,5) \mathrm{P}_{2}$ metabolism, with $\mathrm{A} \beta$ addition reducing $\mathrm{PI}(4,5) \mathrm{P}_{2}$ levels, perhaps via activation of $\mathrm{PLC}$ enzymes (Berman et al., 2008). This could also occur via $\mathrm{A} \beta$-mediated inhibition of the $\mathrm{PI}(4) \mathrm{P}$ synthesis enzyme PI4K, as $\mathrm{PI}(4) \mathrm{P}$ often acts as a precursor for $\mathrm{PI}(4,5) \mathrm{P}_{2}$ (Wu et al., 2004; Figure 1B). Moreover, evidence suggests that hyperphosphorylated tau, a key hallmark of $\mathrm{AD}$, may be generated by protein kinases known to be activated by PLC enzymes (Ial and Grundke-Ial, 2005).

Finally, many known $\mathrm{AD}$ risk genes (e.g., Phospholipase $\mathrm{C}$ Gamma 2 (PLCG2), inositol polyphosphate 5-phosphatase D (INPP5D), Phospholipase D3 (PLD3), CD2-associated protein (CD2AP), Phosphatidylinositol Binding Clathrin Assembly Protein (PICALM), Sodium/potassium/calcium exchanger 4 (SLC24A4)) are involved in phospholipid metabolism (Tan et al., 2019; Sims et al., 2020), providing further evidence of the importance of these pathways in disease pathology. The $\mathrm{AD}$ protective $\mathrm{R} 522$ mutation in PLCG2, which also protects against dementia with Lewy bodies and FTD (van der Lee et al., 2019), appears to protect via increased PLC $\gamma 2$ activity (Magno et al., 2019).

\section{Phosphoinositide Dyshomeostasis in Parkinson's Disease}

Several studies have highlighted the specific roles of phosphoinositide dyshomeostasis in $\mathrm{PD}$ pathology. In one of these studies, PD and control membranes were prepared 
TABLE 1 | Known functions of phosphoinositide (PIP) species within the brain and roles in neurodegeneration.

\begin{tabular}{ll}
\hline PIP species & Known functions in the brain \\
\hline $\mathrm{PI}(3) \mathrm{P}$ & $\begin{array}{l}\text { Key regulator of endocytic trafficking, } \\
\text { fusion, and autophagy. }\end{array}$ \\
& $\begin{array}{l}\text { Regulates GABAergic neurotransmission at } \\
\text { inhibitory post-synapses. }\end{array}$ \\
& Potential roles in myelin formation. \\
$\mathrm{PI}(4) \mathrm{P}$ & $\begin{array}{l}\text { Key role in multiple steps of phagocytosis } \\
\text { and other uptake systems. }\end{array}$
\end{tabular}

$\mathrm{PI}(5) \mathrm{P}$

$\mathrm{PI}(3,4) \mathrm{P}_{2}$

$\mathrm{PI}(4,5) \mathrm{P}_{2}$

$\mathrm{PI}(3,5) \mathrm{P}_{2}$
Roles in AKT/mTOR signaling, autophagy, and apoptosis.

Regulates chromatin function and transcription in the nucleus.

Potential regulators of endosomal trafficking.

Involved in the maturation of late-stage clathrin-coated pits and fast endophilin-mediated endocytosis.

Roles in actin-mediated neurite initiation and dendrite morphogenesis.

Electrical signaling at the plasma membrane (including neurons).

Roles in the recycling of synaptic vesicles and synaptic plasticity.

Many neurotransmitters utilize the G-protein coupled PLC mediated hydrolysis of $\mathrm{PI}(4,5) \mathrm{P}_{2}$ as a key step in signal transduction.

Regulates $\sim 100$ ion channels and transporters.

Regulates cytoskeletal function in neurons.

Key regulators of TLR and purinergic signaling.

Key role in actin remodeling during chemotaxis.

Key role in multiple steps of phagocytosis and other uptake systems.

Regulates membrane trafficking, endocytic vesicle fission/fusion, organelle $\mathrm{pH}$, intracellular ion channel function.
Roles in neurodegenerative disease

Inhibiting PIP-4 kinase (phosphorylates

$\mathrm{PI}(3) \mathrm{P})$ reduces $\mathrm{mHTT}$ and rescues

neurodegeneration in HD drosophila.

Excess PI3K (generates PI(3)P) activity in $A D$, reduced activity in $P D$.

Pathophysiological concentrations of $A \beta$ inhibit PI4K (generates PI(4)P) activity, both in vitro and in vivo.

PI4K inhibition reduces brain pathology in Drosophila models of $A D$.

VAPB, a causal gene for ALS, exerts deleterious effects in the brain by altering PI(4)P levels and distribution.

Reduced in AD cortex.

Inhibiting PIP-4 kinase [phosphorylates $\mathrm{PI}(5) \mathrm{P}]$ reduces $\mathrm{mHTT}$ and rescues neurodegeneration in HD drosophila.

Mutations in the $\mathrm{PI}(3,4) \mathrm{P}_{2}$ synthesis enzyme INPP5D increase genetic AD risk.

Excess $\mathrm{Pl} 3 \mathrm{~K}$ [generates $\mathrm{PI}(3,4) \mathrm{P}_{2}$ ] activity in $A D$, reduced activity in $P D$.

A genetic variant in $\mathrm{PLC} \gamma 2$, which breaks down $\mathrm{PI}(4,5) \mathrm{P}_{2}$, protects against $A D$.

Decreased $\mathrm{PI}(4,5) \mathrm{P}_{2}$ metabolism via $\mathrm{PLC} \gamma 2$ in $\mathrm{PD}$, increased $\mathrm{PI}(4,5) \mathrm{P}_{2}$ in $\mathrm{PD}$ substantia nigra.

Overexpression of SYNJ1, which hydrolyzes $\mathrm{PI}(4,5) \mathrm{P}_{2}$, acts as a risk factor for $\mathrm{AD}$ and appears to contribute to plaque pathology and behavioral deficits in mouse models.

Mutations in SYNJ1 associated with early-onset PD.

The $\mathrm{PI}(3,5) \mathrm{P}_{2}$ synthesis enzyme FIG4 acts as a risk factor for ALS.

\section{References}

Heras-Sandoval et al. (2014), Al-Ramahi et al. (2017), Papadopoulos et al. (2017) and Raghu et al. (2019)

Stokes and Hawthorne (1987), Wu et al. (2006), Levin et al. (2017), Zhang X. et al. (2017), Genevini et al. (2019) and Baba et al. (2020)

Boal et al. (2015), Bulley et al. (2015), Vicinanza et al. (2015), Al-Ramahi et al. (2017) and Jacobsen et al. (2019)

Lambert et al. (2013), Heras-Sandoval et al. (2014), Hawkins and Stephens (2016), Jing et al. (2016), Zhang S.-X. et al. (2017) and Casamento and Boucrot (2020)

Wallace and Claro (1993), McIntire et al. (2012), Zhu et al. (2013), Drouet and Lesage (2014), Sims et al. (2017), Miranda et al. (2018), Sekar and Taghibiglou (2018), Ben Romdhan et al. (2018), Bernier et al. (2013b), Le et al. (2014), Hille et al. (2015), Dickson and Hille (2019), Raghu et al. (2019), Xie et al. (2019) and Desale and Chinnathambi (2021)

Regulates synaptic strength. 
TABLE 1 | Continued

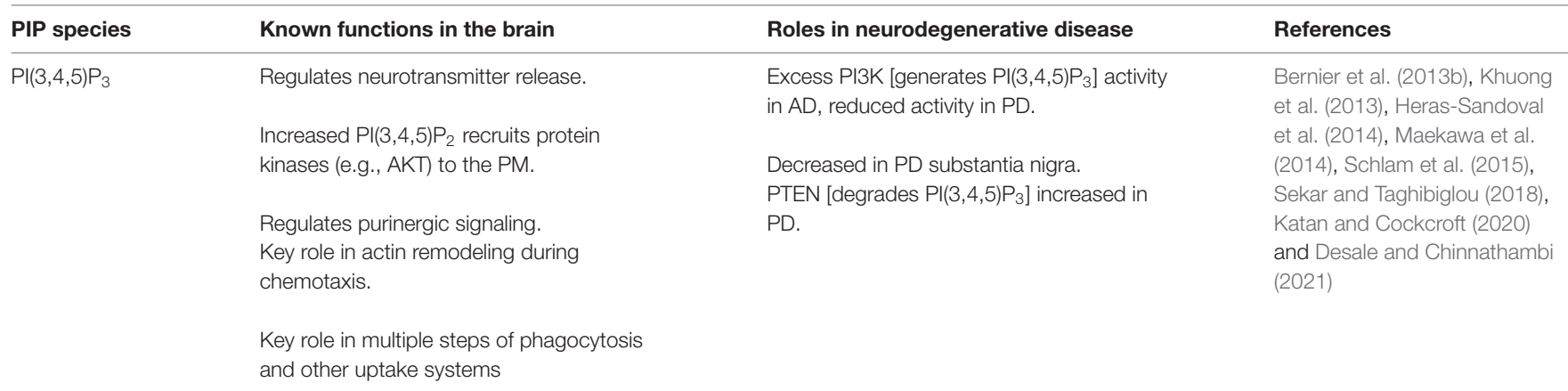

mHTT, mutant Huntington protein; AD, Alzheimer's disease; HD, Huntington's disease; PD, Parkinson's disease; ALS, amyotrophic lateral sclerosis; $A \beta$, amyloid $\beta$; VAPB, VAMP associated protein B and C; AKT, Protein kinase B mammalian target of rapamycin; TLR, toll-like receptor; SYNJ1, synaptojanin 1; FIG4, Factor induced gene 4; PLC, phospholipase C.

TABLE 2 | The role of PIP species in different neuroinflammatory conditions.

\begin{tabular}{|c|c|c|c|}
\hline Disease & PIP Species & Suspected roles in pathology & References \\
\hline \multirow[t]{4}{*}{ Alzheimer's disease } & $\mathrm{PI}(4) \mathrm{P}$ & $\begin{array}{l}\text { Key role in uptake systems including } \\
\text { phagocytosis. }\end{array}$ & $\begin{array}{l}\text { Stokes and Hawthorne } \\
\text { (1987), Wu et al. (2006), } \\
\text { Levin et al. (2017) and } \\
\text { Zhang S.-X. et al. (2017) }\end{array}$ \\
\hline & $\mathrm{PI}(3,4) \mathrm{P}_{2}$ & $\begin{array}{l}\text { Mutations in the } \mathrm{PI}(3,4) \mathrm{P}_{2} \text { synthesis enzyme } \\
\text { INPP5D increase genetic } \mathrm{AD} \text { risk. }\end{array}$ & $\begin{array}{l}\text { Lambert et al. (2013), } \\
\text { Hawkins and Stephens } \\
\text { (2016) and Jing et al. (2016) }\end{array}$ \\
\hline & $\mathrm{Pl}(4,5) \mathrm{P}_{2}$ & $\begin{array}{l}\text { Excess } \mathrm{PI} 3 \mathrm{~K} \text { (generates } \mathrm{PI}(3,4) \mathrm{P}_{2} \text { ) activity in } A D \text {. } \\
\text { A genetic variant in } \mathrm{PLC} \gamma 2 \text {, which breaks down } \\
\mathrm{PI}(4,5) \mathrm{P}_{2} \text {, protects against } A D_{2} \text {, acts as a risk } \\
\text { factor for } A D \text {. }\end{array}$ & $\begin{array}{l}\text { Mclntire et al. (2012) and } \\
\text { Sims et al. (2017) }\end{array}$ \\
\hline & $\mathrm{Pl}(3,4,5) \mathrm{P}_{3}$ & $\begin{array}{l}\left.\text { Excess PI3K (generates } \mathrm{PI}(3,4,5) \mathrm{P}_{3}\right) \text { activity in } \\
\text { AD. }\end{array}$ & $\begin{array}{l}\text { Heras-Sandoval et al. } \\
\text { (2014) }\end{array}$ \\
\hline Parkinson'S disease & $\mathrm{Pl}(4,5) \mathrm{P}_{2}$ & $\begin{array}{l}\text { Reduced PLC activity and } \mathrm{PI}(4,5) \mathrm{P}_{2} \text { metabolism } \\
\text { in } \mathrm{PD} \text { cortex, perhaps following the }\end{array}$ & $\begin{array}{l}\text { Sekar and Taghibiglou } \\
\text { (2018) }\end{array}$ \\
\hline
\end{tabular}

$\mathrm{PI}(3,4,5) \mathrm{P}_{3} \quad$ Excess PI3K (generates $\left.\mathrm{PI}(3,4,5) \mathrm{P}_{3}\right)$ reduced activity in $\mathrm{PD}_{3}$ ) increased in $\mathrm{PD}$.

Huntington'S disease $\quad \mathrm{Pl}(3) \mathrm{P}$

$\mathrm{PI}(5) \mathrm{P}$

$\mathrm{PI}(4) \mathrm{P}$

Amyotrophic lateral sclerosis

$\mathrm{PI}(3,5) \mathrm{P}_{2}$
Inhibiting PIP-4 kinase (phosphorylates PI(3)P) reduces $\mathrm{mHTT}$ and rescues neurodegeneration in HD drosophila.

Inhibiting PIP-4 kinase (phosphorylates PI(5)P) reduces $\mathrm{MHTT}$ and rescues neurodegeneration in HD drosophila.

ALS risk gene VAPB is proposed to affect neurite extension during differentiation via regulation of $\mathrm{PI}(4) \mathrm{P}$ distribution.

Non-synonymous variants in the $\mathrm{PI}(3,5) \mathrm{P}_{2}$ phosphatase FIG4 found in $1-2 \%$ of ALS patients. LOF leads to reduced levels of $\mathrm{PI}(3,5) \mathrm{P}_{2}$ and is suspected to affect autophagy.
Bernier et al. (2013b), Sekar and Taghibiglou (2018) and Katan and Cockcroft (2020)

Al-Ramahi et al. (2017)

Al-Ramahi et al. (2017)

Genevini et al. (2019)

Chow et al. (2007, 2009) and Nguyen et al. (2019)

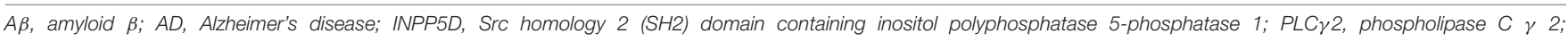
SYNJ1, synaptojanin 1; PD, Parkinson's disease; PTEN, phosphatase and tensin homolog; mHTT, mutated Huntington protein; HD, Huntington's disease; ALS, amyotrophic lateral sclerosis; VAPB, vesicle-associated membrane protein-associated protein B; FIG4, Factor induced gene 4; LOF, Ioss of function.

from the post-mortem prefrontal cortex and incubated with $\mathrm{PI}(4,5) \mathrm{P}_{2}$ before the addition of dopamine to activate PLC. These membranes demonstrated reduced PLC activity, characterized by decreased $\mathrm{PI}(4,5) \mathrm{P}_{2}$ metabolism, within the $\mathrm{PD}$ samples (Wallace and Claro, 1993). A major characteristic of PD and other neurodegenerative diseases, including $\mathrm{AD}$, is the 
accumulation of $\alpha$-synuclein containing inclusions in the brain (Visanji et al., 2019). $\alpha$-synuclein has been shown to preferentially localize to $\mathrm{PI}(4,5) \mathrm{P}_{2}$ containing membranes, where it appears to inhibit PLC enzyme activity and subsequent $\mathrm{Ca}^{2+}$ release (Narayanan et al., 2005), potentially explaining the results of the earlier research by Wallace and Claro (1993).

In addition to altered PLC signaling, levels of phosphatase and tensin homolog (PTEN), another phosphoinositide phosphatase, are also altered in PD. Interestingly, in this same study, $\mathrm{PI}(3,4,5) \mathrm{P}_{3}$ was found to be decreased, and $\mathrm{PI}(4,5) \mathrm{P}_{2}$ increased, in substantia nigra samples from $\mathrm{PD}$ patient brains compared to age-matched controls (Sekar and Taghibiglou, 2018). Within $\mathrm{PD}$, changing phosphoinositide levels could potentially be mediated by the aforementioned $\alpha$-synuclein inhibition of $\mathrm{PI}(4,5) \mathrm{P}_{2}$ degrading PLC enzymes, as well as upregulation of the $\mathrm{PI}(3,4,5) \mathrm{P}_{3}$ degradation enzyme PTEN.

\section{Phosphoinositide Dyshomeostasis in Huntington's Disease}

Phosphoinositide dyshomeostasis has also been observed in HD. For one, HTT and mHTT can be seen to interact with a variety of PIPs at membranes (Kegel et al., 2005). Interestingly, HTT interacts primarily with $\mathrm{PI}(3,4) \mathrm{P}_{2}, \mathrm{PI}(3,5) \mathrm{P}_{2}$, and $\mathrm{PI}(3,4,5) \mathrm{P}_{3}$, whilst mHTT associates more strongly with $\mathrm{PI}(3,5) \mathrm{P}_{2}$ than the wild-type HTT, whilst also binding to $\mathrm{PI}(3) \mathrm{P}, \mathrm{PI}(4) \mathrm{P}, \mathrm{PI}(5) \mathrm{P}$, and $\mathrm{PI}(4,5) \mathrm{P}_{2}$. Changing binding affinities affects the recruitment of the Huntington protein to specific cellular membranes where distinct PIP species are located. This is likely to affect the formation of growth factor signaling complexes within mHTT cells (Kegel et al., 2009).

Studies by Al-Ramahi et al. (2017) further highlighted the roles of PIPs in HD and even demonstrated the potential of PIP regulation as a therapeutic target. This work focused on the enzyme PIP4 kinase, which phosphorylates PI(5)P and PI(3)P (Figure 1). They found that inhibiting this enzyme reduces mHTT in both patient fibroblasts and neuronal cell models. Moreover, this same study demonstrated how inhibition of PIP4 kinase rescued mHTT-induced neurodegeneration in two Drosophila HD models. This protective effect was speculated to occur via increased $\mathrm{PI}(3,5) \mathrm{P}_{2}$. $\mathrm{PI}(5) \mathrm{P}, \mathrm{PI}(3) \mathrm{P}$, and $\mathrm{PI}(3,5) \mathrm{P}_{2}$ all have key roles in autophagy, known to be affected in HD (Al-Ramahi et al., 2017).

\section{Phosphoinositide Dyshomeostasis in Amyotrophic Lateral Sclerosis}

Several studies have highlighted a potential role for phosphoinositol dyshomeostasis in the pathogenesis of ALS. Firstly, non-synonymous variants in the PIP phosphatase FactorInduced Gene 4 (FIG4) appear in 1-2\% of all ALS patients (Chow et al., 2009). FIG4 regulates $\mathrm{PI}(3,5) \mathrm{P}_{2}$ homeostasis, with loss of function leading to a considerable reduction in the levels of this phospholipid (Chow et al., 2007). This has been speculated to affect autophagic function (Nguyen et al., 2019). Another ALS risk gene linked to PIP homeostasis is vesicle-associated membrane protein-associated protein B (VAPB; Genevini et al., 2019). Through its various binding partners, this crucial ER adaptor protein has roles in lipid exchange, membrane traffic, $\mathrm{Ca}^{2+}$ signaling, cytoskeletal organization, autophagy, mitochondrial function, and neurite extension. When mutated in ALS, VAPB aggregates, forming intracellular inclusions which greatly affect ER structure. VAPB depletion appears to disrupt neurite extension during differentiation via reduced PI4P, presumably following its key roles regulating PI4P distribution (Genevini et al., 2019).

\section{Summary}

Phosphoinositides have key roles in the brain, and therefore it should come as no surprise that both their levels and distribution are affected by a wide variety of neurodegenerative diseases. In several cases, this dyshomeostasis has been directly linked to disease pathology, thereby highlighting the potential of phosphoinositide-based therapies when looking to treat these devastating and often incurable conditions.

Having discussed both the function of microglia and PIPs in neurodegenerative disorders, the next section will explore the potential outcomes of PIP dyshomeostasis on specific microglial functions. The functions covered are TLR signaling, purinergic signaling, endocytosis, chemotaxis, and migration.

\section{PIP EFFECTS ON MICROGLIAL FUNCTIONS AND IMPLICATIONS FOR NEURODEGENERATION}

\section{Role of PIPs in TLR Signaling TLR Signaling in Microglia}

Toll-like receptors (TLRs) recognize conserved pathogenassociated molecular patterns (PAMPs) of bacteria, viruses, yeast, fungi, and parasites (Takeuchi et al., 2002). The human genome encodes 9 TLRs (TLR1-9), all of which are expressed in microglia (Bsibsi et al., 2002; Olson and Miller, 2004; Zhang et al., 2013). Within the brain, TLR expression is highest in glial cells (Lehnardt et al., 2002; Babcock et al., 2006), further demonstrating the importance of these signaling pathways regarding microglial function. TLR2 and 4 have been most studied in and appear to have the most relevance regarding neurodegenerative disease (Azam et al., 2019).

Upon activation, TLRs dimerize and recruit toll/interleukin 1 (TIR)-domain-containing adaptor proteins. These adaptor proteins are myeloid differentiation primary response protein 88 (MyD88, TLRs 1-2 and 4-9), TIR-domain containing adaptor protein (TIRAP, TLR 2 and 4), TIR domaincontaining adaptor-interferon $\beta$ (TRIF, TLR3 and 4), and TRIF-related adapter molecule (TRAM, TLR4; Takeda et al., 2003; Yamamoto et al., 2003a; Le et al., 2014). Following activation, MyD88 allows the nuclear translocation of NF- $\mathrm{B}$ via recruitment of tumor-necrosis-factor-receptor-associatedfactor 6 (TRAF6) and members of the IL-1R-associated kinases (IRAK) family. This results in proinflammatory cytokine and cyclooxygenase-2 (COX-2) production (Zhang et al., 1999; Takeda and Akira, 2004; Broad et al., 2007; Kawai and Akira, 2010). TLR-mediated TRIF and TRAM activation result in the induction of interferon-inducible genes, NF- $\kappa \mathrm{B}$ dependent signaling pathways, and chemokine production (Schafer et al., 1998; Fitzgerald et al., 2003; Melchjorsen and Paludan, 2003; 
Yamamoto et al., 2003b; Pålsson-McDermott and O’Neill, 2004). In addition to the activation of inflammatory pathways, TLR signaling has been suggested to enhance phagocytosis (Tricker and Cheng, 2008).

\section{Roles of Phosphoinositides in TLR Signaling}

Phosphoinositides, in particular $\mathrm{PI}(4,5) \mathrm{P}_{2}$, have been shown to act as key regulators of TLR4 signaling (Le et al., 2014). TLR4 is important in the immune response to LPS, heat-shock proteins, extracellular matrix proteins, and various neurodegenerationrelated protein aggregates (Azam et al., 2019). Activation and subsequent dimerization of TLR4 induce the formation of a MyD88 and TIRAP protein complex (Yamamoto et al., 2002). TIRAP requires $\mathrm{PI}(4,5) \mathrm{P}_{2}$ binding to its $\mathrm{N}$-terminal region to initiate translocation to the plasma membrane, allowing for downstream signal transduction and cytokine production (Kagan and Medzhitov, 2006). This activation also results in increased $\mathrm{PI}(4,5) \mathrm{P}_{2}$ at the plasma membrane (Kagan and Medzhitov, 2006), and conversely depleting $\mathrm{PI}(4,5) \mathrm{P}_{2}$ stifles downstream TLR4 signaling (Wan et al., 2010). In primary microglia, BV2 microglia-like cells and primary astrocytes, this appears to occur via upregulation of the $\mathrm{PI}(4,5) \mathrm{P}_{2}$ synthesis enzyme PIP-5 kinase following TLR4 activation (Jou et al., 2006; Lee et al., 2010a,b; Nguyen et al., 2013). In this way, phosphoinositide dyshomeostasis in neurodegenerative conditions could have substantial effects on TLR activity.

In addition to modulating adaptor protein localization, $\mathrm{PI}(4,5) \mathrm{P}_{2}$ can also have indirect effects on TLR signaling. Activated TLR4 is subsequently internalized via clathrinand dynamin-mediated endocytosis, where it initiates further downstream signaling pathways within early endosomes (Kagan et al., 2008). Endocytosis is tightly regulated by plasma membrane PI $(4,5) \mathrm{P}_{2}$ levels (Bohdanowicz and Grinstein, 2013), and studies have demonstrated how $\mathrm{PI}(4,5) \mathrm{P}_{2}$ degradation by PLC 22 is critical for TLR4 endocytosis (Zanoni et al., 2011; Schappe et al., 2018). In this way, changing $\mathrm{PI}(4,5) \mathrm{P}_{2}$ levels in the context of various neurodegenerative disorders will affect TLR4 internalization and consequent signaling activation.

Furthermore, TLR9 can be seen to induce autophagosome/lysosomal fusion-a key event in autophagy_via the $\mathrm{PI}(4,5) \mathrm{P}_{2}$ phosphatase oculocerebrorenal syndrome of lowe (ORCL). TLR9 signaling activates ORCL in lysosomes, which in turn reduces $\mathrm{PI}(4,5) \mathrm{P}_{2}$ levels. $\mathrm{PI}(4,5) \mathrm{P}_{2}$ is an inhibitor of TRPML1: an ion channel responsible for autophagy induction (De Leo et al., 2016). Via this mechanism, TLR9 dyshomeostasis, which has been observed in several neurodegenerative diseases including $\mathrm{AD}$ and $\mathrm{PD}$ (Fiebich et al., 2018), could result in altered $\mathrm{PI}(4,5) \mathrm{P}_{2}$ levels, and perhaps result in autophagy dyshomeostasis. Substantial evidence demonstrates autophagy dysregulation in both $\mathrm{AD}$ and PD (Liu and Li, 2019; Hou et al., 2020).

\section{TLR Signaling Within the Neurodegenerative Disease}

Aging, a key risk factor for numerous neurodegenerative diseases (Hou et al., 2019), results in TLR dysregulation, characterized by both impaired signaling and inappropriate activation (Shaw et al., 2011). TLRs have highly established roles in numerous neurodegenerative conditions (Fiebich et al., 2018). For one,
TLRs are upregulated in AD (Liu et al., 2005), ALS (Casula et al., 2011; Lee et al., 2015), and PD brains (Kouli et al., 2019). Furthermore, within human and mouse AD brains, upregulation of TLRs (TLR 2, 4, 5, 7, 9) has been observed within microglia surrounding amyloid plaques (Liu et al., 2005; Walter et al., 2007; Jana et al., 2008; Letiembre et al., 2009). Also, neurodegenerationrelated proteins like A $\beta$ (Jana et al., 2008; Richard et al., 2008; Caldeira et al., 2017) and $\alpha$-synuclein (Beraud et al., 2011; Daniele et al., 2015) have been demonstrated to increase microglial TLR expression.

When closely examining links between TLRs and neurodegenerative disease, it quickly becomes apparent that the relationship between signaling and pathology is often complex. Increasing or decreasing the expression of various TLRs can have both protective and detrimental outcomes in a wide variety of neurodegenerative conditions (Rietdijk et al., 2016; Azam et al., 2019).

The importance of TLR signaling in preventing the development of $\mathrm{AD}$ is highlighted by studies demonstrating how activation of TLR 2, 4, and 9 signaling can reduce brain pathology and plaque build-up (Tahara et al., 2006). Furthermore, TLR 4 and 2 knock-out mice demonstrate increased amyloid plaque burden and cognitive decline (Song et al., 2011; Zhou et al., 2019). The above affects appear to occur via reduced microglial phagocytosis of amyloid plaques. Conversely, TLR4 polymorphisms which reduce receptor signaling have been observed to be protective against LOAD (Minoretti et al., 2006). Moreover, numerous studies have demonstrated how downregulating TLR signaling $(2,4,6)$ can protect against AD development (Chen et al., 2016; Rietdijk et al., 2016; Zhang et al., 2016; Rangasamy et al., 2018; Long et al., 2019). The observed discrepancies in outcome when modulating TLR signaling in $\mathrm{AD}$ may reflect differences in disease progression at the time of treatment. TLR signaling inhibition to prevent excess neuroinflammation may be more effective at later stages of the disease, whilst activation to prevent the initial build-up of amyloid plaques appears to be beneficial at earlier stages (Go et al., 2016; Pourbadie et al., 2018).

Numerous studies demonstrate upregulated TLR signaling within PD. TLR upregulation within the PD brain is suspected to be responsible for the observed $\alpha$-synuclein-induced microglial activation (Kouli et al., 2019). Within the HD field, however, so far only one study has examined the role of TLR signaling in disease pathogenesis. This study demonstrated how homozygous deficiency of TLR2 or 3 or heterozygous deficiency of TLR4 was able to extend lifespan in an HD mouse model (Griffioen et al., 2018). Although preliminary, this data suggests that further research into TLR signaling in $\mathrm{HD}$, and perhaps investigating TLR inhibitors, would be a promising research avenue. In contrast to observations in PD and HD, TLR signaling in ALS appears to slow disease progression, with myD $88 \mathrm{KO} / \mathrm{ALS}$ mice showing accelerated disease onset and reduced survival (Kang and Rivest, 2007). Another study demonstrated the importance of the TRIF pathway in protecting motor neurons within the ALS brain (Komine et al., 2018). These observations suggest that perhaps activating TLRs in ALS could provide some therapeutic benefit. 


\section{Targeting TLRs to Treat Neurodegenerative Disease-Focus on TLR4/PI(4,5) $\mathrm{P}_{2}$}

Having summarized the well-characterized roles of TLRs and phosphoinositols in neurodegenerative conditions, the next question is whether we can exploit this knowledge when considering potential therapeutics. As TLRs have been implicated in the pathology of numerous diseases, both neurodegenerative and otherwise, many studies have characterized the effects of both natural and synthetic TLR agonists and antagonists (Gambuzza et al., 2014; Ain et al., 2020). Given the particular importance of phosphoinositides, namely $\mathrm{PI}(4,5) \mathrm{P}_{2}$, in TLR4 signaling, this review will focus on TLR4 as a therapeutic target for neurodegenerative disease.

TLR4 activation to increase engulfment of misfolded protein could act as a promising treatment strategy within the early-AD brain. Potential candidates to activate TLR4 include the non-toxic LPS derivative monophosphoryl lipid A (Yousefi et al., 2019). As previously discussed, during later disease stages it is likely that inhibiting effects of TLR4 can protect against further neurodegeneration. Potential TLR4-pathway inhibitors that have shown promise against early $\mathrm{AD}$ phenotypes include the omega-3-polyunsaturated fatty acid alpha-linolenic acid (Ali et al., 2020), geniposidic acid (Zhou et al., 2020), and Alpinia oxyphylla-Schisandra chinensis (Qi et al., 2019). TLR4 inhibitors have also been investigated to treat PD. One such compound is vinpocetine, which appears to reduce TLR expression and improve the cognition of PD patients; although whether or not this improvement occurs specifically via effects on TLR signaling is yet to be determined (Ping et al., 2019).

As TLR signaling, particularly TLR4 signaling, is highly influenced by changing $\mathrm{PI}(4,5) \mathrm{P}_{2}$ levels, it may be possible to boost any protective effects by combining TLR-targeting and $\mathrm{PI}(4,5) \mathrm{P}_{2}$ manipulating compounds. This could involve co-treating with drugs to increase $\mathrm{PI}(4,5) \mathrm{P}_{2}$ levels when activating TLR4 and reducing $\mathrm{PI}(4,5) \mathrm{P}_{2}$ when inhibiting TLR4. There are several options available for manipulating $\mathrm{PI}(4,5) \mathrm{P}_{2}$ levels (Idevall-Hagren and De Camilli, 2015). One way would be by activating or inhibiting PLC $\gamma 2$ : the enzyme that breaks down $\mathrm{PI}(4,5) \mathrm{P}_{2}$.

To conclude this section, TLR signaling, a key function of microglia, is dysregulated in numerous neurodegenerative conditions. This potentially allows for the possibility of using the same drug to treat multiple disorders. TLR signaling has strong links to phosphoinositide metabolism, another function known to be disrupted in the same conditions. These links could be exploited when investigating potential therapeutics.

\section{Roles of PIPs in Purinergic Signaling Purinergic Signaling in Microglia}

The purinergic signaling system has wide-ranging implications for CNS function. This system consists of enzymes, transporters, receptors, and other proteins which facilitate the recognition, secretion, and degradation of extracellular nucleotides and nucleosides. Within the CNS, nucleotides [such as adenosine triphosphate (ATP), adenosine diphosphate (ADP), and uridine diphosphate (UDP)] are released from cells in exosomes. ATP is often released from damaged cells following CNS injury (Neary et al., 1994). Following the release, nucleotides are rapidly degraded by ectonucleotidases, generating both other nucleotides and adenosine. Adenosine binds to P1 purinergic receptors (A1, A2A, A2B, and A3), which are widely expressed across the CNS. Adenosinergic signaling within microglia has key roles regarding activation. Nucleotides bind to ionotropic $\mathrm{P} 2 \mathrm{X}(\mathrm{P} 2 \mathrm{X} 1-7)$ and metabotropic P2Y (P2Y1, 2, 4, 6, 11-14) receptors, which are again widely expressed, and act as key mediators in neuronal-glial signaling networks. ATP binding to $\mathrm{P} 2 \mathrm{X}$ receptors opens a non-selective $\mathrm{Na}^{+}, \mathrm{K}^{+}$, and $\mathrm{Ca}^{2+}$ cation pore. $\mathrm{P} 2 \mathrm{Y}$ receptors are activated by a variety of nucleotides and share the seven-transmembrane-domain topology of G-protein coupled receptors. Activated P2Y 1, $2,4,6$, and 11 receptors use $G_{q} / G_{11}$ to activate PLC and initiate $\mathrm{Ca}^{2+}$ release from the ER, which in turn induces storeoperated $\mathrm{Ca}^{2+}$ entry via Orail and TRPC (Lim et al., 2017). P2Y 12-14 couple to $\mathrm{G}_{\mathrm{i}} / 0$, which activate $\mathrm{G}$ protein-gated, inwardly rectifying potassium (GIRK) channels to modulate downstream ion channels (Abbracchio et al., 2009; Erb and Weisman, 2012).

Microglia express the $\mathrm{P} 1$ receptors $\mathrm{A} 1, \mathrm{~A} 2 \mathrm{~A}$ and A3 (Haskó et al., 2005), and the $\mathrm{P} 2$ receptors $\mathrm{P} 2 \mathrm{X} 4, \mathrm{P} 2 \mathrm{X} 7, \mathrm{P} 2 \mathrm{Y} 6, \mathrm{P} 2 \mathrm{Y} 12$, and P2Y13 (Calovi et al., 2019). A1R expression on microglia appears to reduce activation; A2AR expression occurs in response to immune-stimuli, results in cytokine and nitric oxide (NO) release, and affects neuronal survival; A3R expression promotes chemokine release (Boison et al., 2010). Increased P2X7R expression in microglia leads to microgliosis, $\mathrm{NO}$ and reactive oxygen species release, ATP release, NLRP3 inflammasome assembly, caspase-1 cleavage, chemokine, and cytokine release (Choi et al., 2007; Takenouchi et al., 2009; Shieh et al., 2014; He et al., 2017; Munoz et al., 2017; Yue et al., 2017). Persistent P2X7 activation also leads to the formation of a large non-selective pore that appears to reduce microglial viability and increase cytotoxicity (Seeland et al., 2015; Monif et al., 2016). Effects of P2X4R expression in microglia are not particularly well understood, although it also appears to promote activation and inflammation (Calovi et al., 2019). Furthermore, prolonged P2X4 activation appears to result in a large non-selective pore in a similar way to $\mathrm{P} 2 \mathrm{X} 7$, although this pore appears non-cytotoxic (Bernier et al., 2012a). P2Y12R is established as a marker for healthy, ramified microglia (Mildner et al., 2017), is downregulated during activation (Haynes et al., 2006), and has key roles in cell migration and chemotaxis (Ohsawa et al., 2010). The roles of P2Y12R in chemotaxis will be further explored in a later section. Moreover, P2Y12R, alongside P2Y13R, have roles in inflammatory cytokine production and release from microglia (Liu et al., 2017). P2Y6, via UDP, initiates microglial phagocytosis (Neher et al., 2014), whilst also promoting neuroinflammation via cytokine (Yang X. et al., 2017), chemokine (Kim et al., 2011; Morioka et al., 2013), and NO production (Quintas et al., 2014).

The above information demonstrates the crucial role of purinergic signaling regarding a wide variety of microglial functions. 


\section{Roles of Phosphoinositides in Purinergic Signaling}

All known P2X channels (except P2X5) have been demonstrated to be regulated by phosphoinositide signaling, with PIPs proving crucial cofactors for channel activity (Bernier et al., 2013b). This review will discuss in detail only $\mathrm{P} 2 \mathrm{X} 4$ and $\mathrm{P} 2 \mathrm{X} 7$ regulation by PIPs, as these are the P2X channels expressed in microglia (Calovi et al., 2019).

$\mathrm{PI}(4,5) \mathrm{P}_{2}$ and $\mathrm{PI}(3,4,5) \mathrm{P}_{3}$ have been demonstrated to increase $\mathrm{P} 2 \mathrm{X} 4$ channel activity. Activity, including P2X4-mediated $\mathrm{Ca}^{2+}$ entry, can be stopped by depleting either $\mathrm{PI}(4,5) \mathrm{P}_{2}$ or $\mathrm{PI}(3,4,5) \mathrm{P}_{3}$ and rescued by intracellular injection of these lipids (Bernier et al., 2008). As previously mentioned, prolonged ATP-mediated $\mathrm{P} 2 \mathrm{X} 4$ stimulation leads to the formation of a highly permeable pore, and this process is also inhibited by $\mathrm{PI}(4,5) \mathrm{P}_{2}$ depletion (Bernier et al., 2012a). PIP binding appears to affect P2X activity by inducing a conformational change that affects channel gating (Bernier et al., 2008, 2012b). Specific lysine residues of the P2X4 C-terminal region appear crucial for PIP-P2X4 interactions, with mutation of these residues inhibiting $\mathrm{PI}(4,5) \mathrm{P}_{2}$ and $\mathrm{PI}(3,4,5) \mathrm{P}_{3}$ binding. The seemingly non-specific nature of the P2X binding site within the P2X4R means that it is likely regulated by a host of PIP species (Bernier et al., 2013b).

Pharmacological inhibition of $\mathrm{PI}(4,5) \mathrm{P}_{2}$ synthesis has been demonstrated to reduce P2X7R current density (Zhao et al., 2007). Similar to P2X4, specific positively charged residues within P2X7R were found to be directly responsible for this $\mathrm{PI}(4,5) \mathrm{P}_{2}$ mediated receptor activation (Zhao et al., 2007), although in this case interactions may be indirect (Bernier et al., 2012b). Indirect interactions of $\mathrm{PI}(4,5) \mathrm{P}_{2}$ and other PIP-sensitive receptors via linker proteins has previously been characterized, and P2X7R has been shown to interact with $\alpha$-actinin (Kim et al., 2001): a known linker protein which facilitates the interaction between $\mathrm{PI}(4,5) \mathrm{P}_{2}$ and glutamate receptors (Kim et al., 2008).

Increasing evidence suggests the $\mathrm{PI}(4,5) \mathrm{P}_{2}$ degradative enzyme PLC $\gamma 2$ as an indirect regulator of numerous P2X channels via modulation of $\mathrm{PI}(4,5) \mathrm{P}_{2}$ levels (Bernier et al., 2013b). This enzyme-driven channel regulation via PIP synthesis/degradation has been demonstrated for several other types of receptor, for example, PIP degradation by PLC modulates TRPM7, GIRK, and KCNQ channel activity (Caulfield et al., 1994; Kobrinsky et al., 2000; Runnels et al., 2002; Cho et al., 2005; Brown et al., 2007). Moreover, stimulating PLC $\gamma 2-$ mediated $\mathrm{PI}(4,5) \mathrm{P}_{2}$ hydrolysis via activation of platelet-derived growth factor receptor led to reduced P2X7R activity, with $\mathrm{PI}(4,5) \mathrm{P}_{2}$ addition reversing this effect in macrophages (Zhao et al., 2007). This theory is further supported by observations that UDP-mediated activation of P2Y6 leads to PLC activation within microglia, followed by reduced $\mathrm{P} 2 \mathrm{X} 4 \mathrm{R}$ activity, presumably due to falling $\mathrm{PI}(4,5) \mathrm{P}_{2}$ levels (Bernier et al., 2013a). As P2Y receptors often signal via PLC $\gamma 2$, which is in turn regulated by $\mathrm{PI}(4,5) \mathrm{P}_{2}$ levels (Erb and Weisman, 2012), P2Y signaling is also likely to be tightly linked to phosphoinositide homeostasis within microglia.

In addition to interaction with P2X channels, ATP and $\mathrm{PI}(4,5) \mathrm{P}_{2}$ binding has been demonstrated to co-regulate key intracellular signaling proteins. This includes focal adhesion kinase, which has been demonstrated to impact microglial mobility (Choi et al., 2015). Furthermore, ATP-sensitive potassium channels or $\mathrm{K}_{\mathrm{ATP}}$ channels, which have key roles regarding initiation of inflammation by microglia (Rodriguez et al., 2013), are also co-regulated by $\mathrm{PI}(4,5) \mathrm{P}_{2}$ binding (Li et al., 2017).

The above evidence demonstrates a clear regulatory function of phosphoinositide species, particularly $\mathrm{PI}(4,5) \mathrm{P}_{2}$, with regards to purinergic signaling. This means that PIP dyshomeostasis within neurodegenerative disease will likely have substantial implications regarding microglial purinergic signaling and downstream phenotypes.

\section{Purinergic Signaling and Neurodegenerative Disease}

Purinergic signaling has well-established roles within numerous neurodegenerative disorders including $\mathrm{AD}, \mathrm{PD}, \mathrm{HD}$, and ALS (Puchaowicz et al., 2014).

$\mathrm{P} 1$ receptors are seen to be upregulated early in disease progression within the most affected areas of PD patient brains (Villar-Menéndez et al., 2014). Also, two polymorphisms in the $\mathrm{A} 2 \mathrm{~A}$ receptor appear to reduce $\mathrm{PD}$ risk (Popat et al., 2011). This dysregulation is also seen in $\mathrm{AD}$, with increased $\mathrm{A} 2 \mathrm{~A}$ receptor expression observed in the cortex and hippocampal microglia in post-mortem brains (Angulo et al., 2003). Following these observations, many clinical trials are currently underway investigating A1 receptor antagonists as a therapeutic target for Parkinson's disease, with some showing promise (Tóth et al., 2019). In vitro and in vivo studies suggest similar neuroprotective effects of A1 modulators in $\mathrm{AD}$, with antagonism of A2ARs appearing to reduce amyloid plaque formation (Woods et al., 2016). One such A2A receptor antagonist is caffeine (Fredholm et al., 1999): known to reduce the risk of a variety of neurodegenerative conditions (Eskelinen and Kivipelto, 2010). Within ALS however, activation of $\mathrm{A} 2 \mathrm{~A}$ receptors appears protective, with caffeine negatively affecting neurological phenotypes, although this effect is stage-dependent (Sebastião et al., 2018). A similar effect, alongside downregulation of the $\mathrm{A} 2 \mathrm{~A}$ receptor, is seen in $\mathrm{HD}$ (Blum et al., 2018).

$\mathrm{P} 2 \mathrm{X}$ receptors are also acknowledged to play important roles in neurodegenerative disease development. P2X7R is the most widely studied regarding its roles in neurodegeneration, following observations that it is upregulated in microglia from a variety of conditions including $\mathrm{AD}$ and $\mathrm{PD}$ (McLarnon et al., 2006; Durrenberger et al., 2012). Within AD, increased microglial purinergic signaling via the P2X7R appears to contribute to both altered $\mathrm{A} \beta$ metabolism, a heightened inflammatory response, and synaptotoxicity (Woods et al., 2016). Though not as well studied as P2X7, P2X4 also appears to be dysregulated in the $\mathrm{AD}$ brain and is seen to increase following exposure to A $\beta$ (Varma et al., 2009). These observations, alongside known roles of the P2X4R in eliciting inflammatory responses (Calovi et al., 2019), suggest potential roles in AD pathology. Within PD, P2X7 receptors are thought to contribute to pathology via increased synaptotoxicity, neurotoxicity, and gliosis (Carmo et al., 2014). Though current research on purinergic signaling in PD has focused on P2X7, P2X4 has also been implicated in $\mathrm{PD}$ pathology. Altered $\mathrm{P} 2 \mathrm{X} 4$ signaling in $\mathrm{PD}$ is thought to 
interfere with dopaminergic signaling, therefore contributing to observed difficulty with motor control and sensorimotor gating in PD mouse models (Khoja et al., 2016). P2X7R expression is also increased within HD mouse brains, and treating with a P2X7R antagonist inhibits neuronal loss while improving motor coordination (Díaz-Hernández et al., 2009). Within ALS, in contrast to that observed in AD, PD, and $\mathrm{HD}, \mathrm{P} 2 \mathrm{X} 4$, and P2X7 expression appear to protect against neurodegeneration (Oliveira-Giacomelli et al., 2018). Indeed, allosteric P2X4 activation increases the lifespan of ALS-mice (Andries et al., 2007) and P2X7R knock-out ALS mice show accelerated neurodegeneration (Apolloni et al., 2013).

P2Y receptors are also dysregulated in a variety of neurodegenerative conditions. Within AD microglia, P2Y signaling can be seen to affect microglial migration, chemokine and cytokine production, endocytosis, phagocytosis, $A \beta$ metabolism, and oxidative stress responses (Erb et al., 2015). UDP-mediated P2Y6 signaling appears to increase phagocytosis of viable neurons by activated microglia. Perhaps unsurprisingly given the above observations, the P2Y6R has been suggested to contribute to microglial activation, inflammation, and phagocytosis of viable neurons in PD. P2Y6R appears to increase in PD models, and antagonists of this receptor appear to delay neuronal death following inflammation (Yang X. et al., 2017; Oliveira-Giacomelli et al., 2019). To our knowledge, no research has been done currently investigating UDP/P2Y6R signaling in AD models, although this would likely be a fruitful avenue in future studies. P2Y12, alongside its roles in chemotaxis, has been suggested to be important for synaptic plasticity and synaptic pruning (Sipe et al., 2016). As increased synaptic pruning is emerging as a key phenotype of neurodegenerative diseases, including $A D$ and $\mathrm{PD}$, this receptor may have roles in the pathology of a variety of neurodegenerative disorders (Lee and Chung, 2019). Microglial P2Y13R expression has been shown to induce astrocyte proliferation, which could also have implications for neurodegeneration, although no studies have specifically looked at this in this receptor context of neurodegenerative diseases (Quintas et al., 2018).

Whist more work needs to be done to thoroughly characterize the roles of microglial purinergic signaling in neurodegenerative disease, these signaling pathways have clear implications regarding dementia pathology.

\section{Targeting Purinergic Signaling to Treat Neurodegenerative Disease}

Drugs targeting purinergic signaling are showing great promise regarding the treatment of a variety of neurodegenerative disorders.

Several A2A receptor antagonists have been characterized and investigated in clinical trials on PD patients, showing various degrees of success. So far, however, despite the benefits of $\mathrm{A} 2 \mathrm{~A}$ antagonism seen in vivo and in vitro in $\mathrm{AD}$ models, no compounds have moved to clinical trials as of yet for this condition. Several P2Y receptor antagonists exist, although to date none have been investigated as potential treatments for neurodegenerative diseases (Von Kügelgen and
Hoffmann, 2016). A variety of A2A receptor agonists are available, although many appear to have adverse side effects (Guerrero, 2018).

P2X7 antagonists appear to reduce pathologies in several neurodegenerative disorders, including $\mathrm{AD}$ and $\mathrm{PD}$ (Burnstock and Knight, 2018). Many have been previously tested in clinical trials for the treatment of non-neurological disorders, such as rheumatoid arthritis and Crohn's disease (Cao et al., 2019). Following its promise as a potential wide-ranging therapeutic target, numerous highly potent, stable, centrally penetrant P2X7R antagonists are currently being developed and tested for a wide range of conditions (Rech et al., 2016). P2X4 antagonists have proved harder to generate, although some are now available and are likely to be investigated in future studies for beneficial effects on neurodegenerative disorders (Stokes et al., 2017).

Given the potential of P2XR7 and P2XR4 inhibition as potential therapeutic targets for neurodegenerative disorders, and that these channels are activated by PIPs, it may be the case that dual P2X and PIP synthesis inhibition could act as a potential therapeutic. As mentioned in the previous section on TLR signaling, there are several options available for modulating PIP levels (Idevall-Hagren and De Camilli, 2015). Moreover, given that PLC $\gamma 2$ hydrolysis of $\mathrm{PI}(4,5) \mathrm{P}_{2}$ can be seen to modulate P2X activity (Bernier et al., 2013b), potentially activating PLC $\gamma 2$, alongside direct purinergic signaling modulation, could be protective against neurological disease progression.

In summary, purinergic signaling, a key regulator of microglial function, is dysregulated in numerous neurodegenerative disorders. This process has strong links to phosphoinositide metabolism. These links could be exploited when investigating potential therapeutics.

\section{Role of PIPs in Microglial Endocytosis Endocytic Systems in Microglia}

Microglia, like all tissue-resident macrophages, are dedicated phagocytes tasked with immune surveillance and the elimination of pathogens. These cells can recognize, engulf and destroy foreign bodies. In addition to their immuno-protective role, microglia also perform important housekeeping tasks such as removing apoptotic cells and mediating synaptic pruning during development (Wake et al., 2011). Microglia survey their environment by constantly patrolling a set region for indications of danger or damage (Madry et al., 2018). Large particles are internalized via phagocytosis, whilst other endocytic uptake methods (e.g., micro and macro-pinocytosis) are utilized for the uptake of fluid-phase material and soluble antigens (Solé-Domènech et al., 2016). Micropinocytosis includes receptor-mediated uptake methods, such as clathrin-mediated and caveolae-mediated endocytosis (Mettlen et al., 2018; Li et al., 2019).

During phagocytosis and macropinocytosis, large vacuoles are known as phagosomes, and macropinosomes form via actin rearrangement (May and Machesky, 2001). These vacuoles engulf the target material following the invagination of the plasma membrane. The vacuole is then brought into the cytoplasm 
where it fuses with the lysosome, which degrades the captured material (Gray et al., 2016). Phagocytosis and macropinocytosis can be artificially divided into two phases. First the formation of the vacuole, and then its progression and maturation through the endocytic pathway. Similar molecular machinery is involved in phagocytic and macropinocytic systems. These processes involve complex signaling cascades, which lead to cytoskeletal reorganization and membrane remodeling. Both systems begin with Rho GTPase activation and the extension of actin-driven membrane protrusions (West et al., 2000), followed by activation of PI3K which results in large-scale membrane remodeling (Araki et al., 1996).

Clathrin-mediated endocytosis is the major entry route for extracellular hormones and signaling factors and serves to regulate the internalization of transmembrane receptors as well as the recycling of pre-and postsynaptic membrane proteins (Le Roy and Wrana, 2005). Caveolae are invaginations of the plasma membrane generated by caveolins, proteins with a membrane-integral hairpin anchor, and cavins, cytoplasmic proteins that are required for the stabilization of caveolae (Parton and del Pozo, 2013). Following their internalization, caveolae display multiple additional roles within the cell, participating in mechano-sensing, compartmentalized signaling, and lipid metabolism (Del Pozo et al., 2020).

The following sections discuss the role of PIPs in the above described endocytic processes and speculated involvement of these lipids is summarized in Table 3.

\section{Roles of Phosphoinositides in Phagocytosis}

When microglia initially encounter phagocytic targets, extracellular signals must be conveyed across the plasma membrane to initiate the complex cellular behaviors that culminate in uptake. It is becoming increasingly apparent that PIPs play a prominent role in relaying this information. Indeed, both the detection of ligands by transmembrane phagocytic receptors and the ruffling of membranes during macropinocytosis are accompanied by local changes in PIP composition (Gillooly et al., 2001). PIPs also coordinate phagosome maturation, whereby membrane fusion and fission events lead to the acquisition of degradative properties (Vieira et al., 2002).

$\mathrm{PI}(4,5) \mathrm{P}_{2}$ and its metabolites (Figure 2) are pivotal to the control of numerous events in phagocytosis including the rearrangement of the actin cytoskeleton (Rohatgi et al., 2000), receptor mobility (Jaumouillé and Grinstein, 2011), integrin activation (Martel et al., 2001), and ion channel activity (Suh and Hille, 2005). To control these disparate events it is important that $\mathrm{PI}(4,5) \mathrm{P}_{2}$ levels change only locally during phagocytosis and that each event occurs in discrete locations (Kutateladze, 2010). Work by Botelho et al. (2000) characterized an accumulation of $\mathrm{PI}(4,5) \mathrm{P}_{2}$ in emerging pseudopods during the early stages of phagosome formation, followed by a drop in levels at the base of the phagocytic cup as the pseudopodia extend. Following phagosome sealing and severing, phagosomal $\mathrm{PI}(4,5) \mathrm{P}_{2}$ decreases precipitously and is no longer detectable by fluorescence microscopy (Botelho et al., 2000). This decrease appears to initially occur via PI3K-mediated phosphorylation of $\mathrm{PI}(4,5) \mathrm{P}_{2}$ into $\mathrm{PI}(3,4,5) \mathrm{P}_{3}$. PI3K also serves as a signal for the recruitment of PLC $\gamma$, which then acts as the predominant method for reducing $\mathrm{PI}(4,5) \mathrm{P}_{2}$ levels within phagosomes (Falasca et al., 1998).

$\mathrm{PI}(4,5) \mathrm{P}_{2}$ promotes the activation of several actin-regulatory proteins which encourage filament assembly and inhibit disassembly (Saarikangas et al., 2010). This leads to an increase in the number of barbed ends and also induces de novo actin nucleation by activating nucleation-promoting factors (Miki et al., 1996). Also, ezrin, radixin, and moesin (ERM) proteins, which link the cytoskeleton to the plasma membrane, are known to be partially controlled by $\mathrm{PI}(4,5) \mathrm{P}_{2}$ levels (Bretscher et al., 2002). As such the localized increase in $\mathrm{PI}(4,5) \mathrm{P}_{2}$ that occurs after the activation of phagocytic receptors results in reorganization of the actin cytoskeleton, driving the extension of pseudopodia around the surface of phagocytic targets (Coppolino et al., 2002). Blocking this local increase in $\mathrm{PI}(4,5) \mathrm{P}_{2}$ appears to prevent the formation of phagocytic cups and therefore inhibits phagocytosis (Coppolino et al., 2002). Interestingly, dismantling of actin at the base of the cup and particle internalization are also blocked if high $\mathrm{PI}(4,5) \mathrm{P}_{2}$ levels are sustained by promoting PIP5K-mediated synthesis or by inhibiting PLC $\gamma$-driven degradation (Scott et al., 2005). This suggests that the reduction of $\mathrm{PI}(4,5) \mathrm{P}_{2}$ is linked to actin disassembly, which is in turn required for the completion of phagocytosis.

In addition to the consequences that $\mathrm{PI}(4,5) \mathrm{P}_{2}$ metabolism has on cytoskeletal dynamics, the breakdown of this PIP to its secondary metabolites also has important ramifications in the phagocytic process. PLC $\gamma$-mediated hydrolysis of $\mathrm{PI}(4,5) \mathrm{P}_{2}$ leads to the formation of DAG and $\operatorname{Ins}(1,4,5) \mathrm{P}_{3}\left(\mathrm{IP}_{3}\right)$. DAG generation coincides in space and time with the disappearance of $\mathrm{PI}(4,5) \mathrm{P}_{2}$. Interestingly, though neither DAG nor $\mathrm{IP}_{3}$ is essential for particle engulfment, inhibition of PLC $\gamma$ blocks the phagocytic response (Botelho et al., 2000; Scott et al., 2005). This suggests that it's the disappearance of $\mathrm{PI}(4,5) \mathrm{P}_{2}$, rather than the formation of its metabolites that is required for phagocytosis. However, DAG recruitment of PKC isoforms and increased $\mathrm{Ca}^{2}$ levels in the cytoplasm is required for later stages of phagocytosis (Ueyama et al., 2004; Nunes et al., 2012; Schlam et al., 2013; Bengtsson et al., 1993).

Like other 3-polyphosphoinositides, $\mathrm{PI}(3,4,5) \mathrm{P}_{3}$ levels are scarce in unstimulated cells. However, $\mathrm{PI}(3,4,5) \mathrm{P}_{3}$ is quickly generated following activation of immune receptors. The metabolism of $\mathrm{PI}(3,4,5) \mathrm{P}_{3}$ is strictly and dynamically regulated, and in general restricted to the cytosolic side of the cell membrane (Palmieri et al., 2010). During phagocytosis, the spatiotemporal dynamics of $\mathrm{PI}(3,4,5) \mathrm{P}_{3}$ synthesis mirror those of $\mathrm{PI}(4,5) \mathrm{P}_{2}$ breakdown, consistent with a role for class I $\mathrm{PI} 3 \mathrm{~K}$ in mediating the conversion of $\mathrm{PI}(4,5) \mathrm{P}_{2}$ to $\mathrm{PI}(3,4,5) \mathrm{P}_{3}$. PI3K is recruited to and activated at sites of phagocytosis following particle engagement (Marshall et al., 2001). Synthesis of phagosomal $\mathrm{PI}(3,4,5) \mathrm{P}_{3}$ is detectable shortly after phagocytic targets are engaged, and this PIP continues to accumulate as the phagocytic cup progresses. While $\mathrm{PI}(3,4,5) \mathrm{P}_{3}$ is still detectable after sealing, its presence in the phagosomal compartment is short-lived, and its concentration declines sharply within 
TABLE 3 | Suspected involvement of PIP species in various forms of endocytosis.

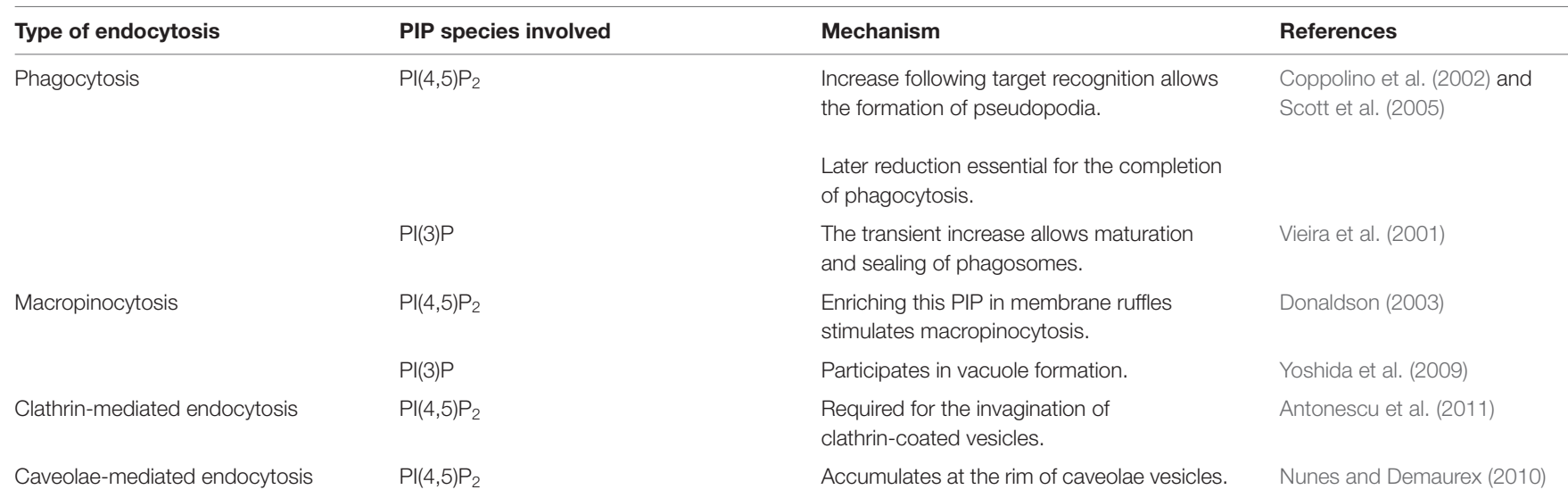

\section{A}

\section{Particle sensing and capture}

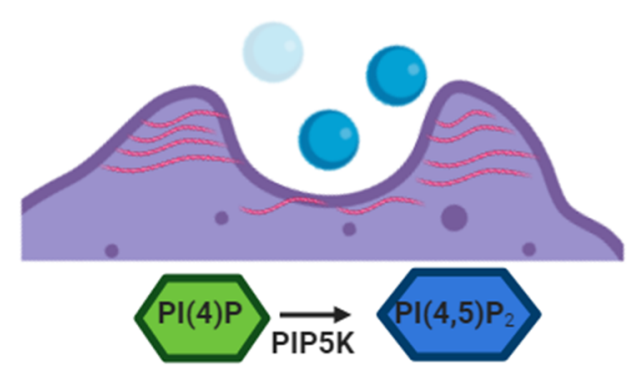

B

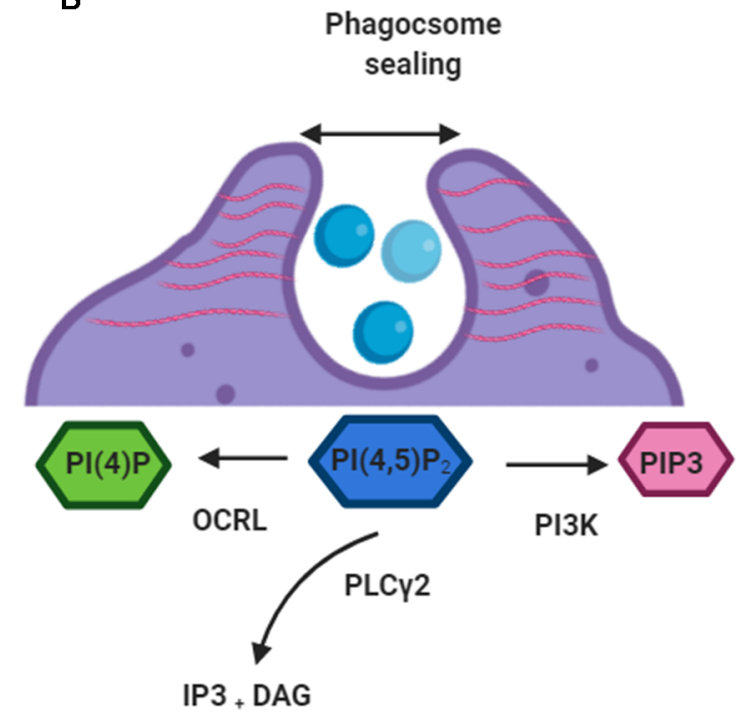

FIGURE 2 | Roles of $\mathrm{PI}(4,5) \mathrm{P}_{2}$ in early phagocytosis. (A) When a target is detected by a phagocytic cell PI(4)P is converted to PI(4,5) $\mathrm{P}_{2}$ by PIP5K. PIP5K associates with the plasma membrane along its positively charged surface. $\mathrm{P}(4,5) \mathrm{P}_{2}$ mediates linkage of actin networks (red) to integral plasmalemmal proteins through intermediary ezrin, radixin, and moesin (ERM) proteins. (B) When the phagosome sealing begins depletion of $\mathrm{PI}(4,5) \mathrm{P}_{2}$ from the base of the cup leads to the removal of actin filaments. $\mathrm{PI}(4,5) \mathrm{P}_{2}$ is converted by kinases (PI3K), phosphatases (OCRL), and phospholipases (PLC $\gamma$ ). This allows the movement of the closed vacuole into the cell.

1-2 min. Notably, SHIP accumulates at the phagosomal membrane (Marshall et al., 2001), where it promotes the breakdown of $\mathrm{PI}(3,4,5) \mathrm{P}_{3}$ to $\mathrm{PI}(3,4) \mathrm{P}_{2}$ (Marshall et al., 2001; Kamen et al., 2007). Perhaps unsurprisingly given its key and early role in the phagocytic process, near-complete inhibition of phagocytosis is seen in macrophages treated with PI3K inhibitors (Cox et al., 1999).

Though its cellular concentration is comparatively low, the PIP PI(3)P is also critically involved in the maturation of phagosomes. In mammalian cells, $\mathrm{PI}(3) \mathrm{P}$ is found mainly at the cytoplasmic leaflet of early endosomes and in intraluminal vesicles of multivesicular bodies (Kaminska et al., 2016). However, sealing of the phagosome and its internalization is followed by a striking yet transient accumulation of this PIP, which lasts for about $10 \mathrm{~min}$ and coincides with the centripetal movement of the phagosomal vacuole (Vieira et al., 2001).

\section{Roles of Phosphoinositides in Other Forms of Endocytosis}

A central role for PIPs as spatial landmarks for membrane trafficking in other forms of endocytosis has emerged (Cremona and De Camilli, 2001; De Matteis and Godi, 2004). Despite only constituting $<10 \%$ of the total cellular phospholipids, PIPs act as key regulators of intracellular membrane traffic and cell signaling. Together with their corresponding vesicle adaptors and transmembrane cargo proteins, phosphoinositides can be seen as part of a system for directing membrane trafficking pathways (Wenk and De Camilli, 2004). PI(4,5) $\mathrm{P}_{2}$ is required for the invagination of clathrin-coated vesicles (CCVs), the 
fusion of secretory granules with the plasmalemma, and for macropinocytosis. Other PIPs have been localized to distinct intracellular membranes and it now seems that many of the key proteins involved in vesicle formation, fusion, and fission are important targets of these lipids. For one, the formation of $\mathrm{PI}(4,5) \mathrm{P}_{2}$-enriched membrane ruffles by overexpression of Arf6-GTP stimulates clathrin-independent macropinocytosis (Donaldson, 2003). Several enzymatic activities appear to contribute to $\mathrm{PI}(4,5) \mathrm{P}_{2}$ degradation, which is required for the uncoating of CCVs (Cremona et al., 1999). Among these are PLC 8 , inositol 5-phosphatases including synaptojanin, SHIP, OCRL, 5-phosphatase II, and proline-rich inositol polyphosphate 5-phosphatase. Moreover, $\mathrm{PI}(4,5) \mathrm{P}_{2}$ is the precursor for $\mathrm{PI}(3,4,5) \mathrm{P}_{3}$ synthesis following activation of $\mathrm{PI} 3 \mathrm{~K}$ by ligand-bound cell signaling receptors (De Matteis and Godi, 2004). How exactly the interplay between PI kinases and phosphatases is regulated is unclear.

Several studies have documented the presence of $\mathrm{PI}(3,4) \mathrm{P}_{2}$ in macropinosomes. This PIP appears to be generated by SHIP2 and broken down by INPP4B (Hasegawa et al., 2011; Welliver and Swanson, 2012; Maekawa et al., 2014). PI(3)P can also be found within early macropinosomes in myeloid cells (Yoshida et al., 2009). Unlike during phagocytosis, where PI(3)P is believed to be important for vesicle maturation, during macropinocytosis $\mathrm{PI}(3) \mathrm{P}$ has been proposed to participate in vacuolar formation. Additionally, inhibiting PI(3)P synthesis by knocking down INPP4B impairs micropinocytosis (Maekawa et al., 2014).

Whilst the core components of caveolae are not known to associate with PIPs directly, the dynamin-related ATPase EHD2 binds $\mathrm{PI}(4,5) \mathrm{P}_{2}$-rich membranes before recruitment to caveolae containing vesicles (He et al., 2004). EHD2 functions as a negative regulator of caveolae internalization by retaining this protein at the plasma membrane and this function require lipidbinding (Cheng et al., 2007). Interestingly, Nunes and Demaurex (2010) labeled PI $(4,5) \mathrm{P}_{2}$ bound to the PH-domain of PLC $\delta$ on freeze-fractured plasma membrane leaflets and reported the accumulation of $\mathrm{PI}(4,5) \mathrm{P}_{2}$ at the rim of caveolae vesicles. The precise significance of the role of PIPs in caveolin-mediated endocytosis thus remains elusive, yet caveolae do appear to be regulated by $\mathrm{PI}(4,5) \mathrm{P}_{2}$.

\section{Endocytosis and Neurodegenerative Disease}

One of the principal roles of microglia in neurodegeneration is the clearance of protein aggregates, myelin debris, and apoptotic cells in an attempt to maintain healthy brain homeostasis. Many neurodegenerative conditions present with increasing accumulation of toxic extracellular proteins such as $A \beta$ plaques in $A D$, and increased apoptosis of cells such as the loss of dopaminergic neurons in PD. It is therefore clear that alterations in microglial phago and endocytosis would have important implications regarding the progression of neurodegenerative conditions.

FcR-mediated phagocytosis and complement activation play a critical role in the removal of plaques from the $\mathrm{AD}$ brain (Lee and Landreth, 2010). Furthermore, monocyte chemotactic protein-1 (MCP-1/CCL2), coupled with its binding receptor CC-chemokine receptor 2, appear crucial mediators of the neuroinflammatory response that drives the disease process in a mouse model of $\mathrm{AD}$ (Kiyota et al., 2009, 2013; Bose and Cho, 2013). CCL2-deficient AD mice (APP/PSEN1 mice) showed decreased microglial phagocytosis of both monomeric and oligomeric $A \beta 42$ and accelerate $A \beta$ deposition (Kiyota et al., 2013). Moreover, GWAS studies (Sims et al., 2017) have found several $\mathrm{AD}$ disease risk factors that are linked to both phagocytosis and phosphoinositides including a hyperfunctional protective variant of PLC $\gamma 2$ which hydrolyzes $\mathrm{PI}(4,5) \mathrm{P}_{2}$ (Magno et al., 2019). Knockout of PLC $\gamma 2$ has been shown to reduce phagocytosis in microglia (Andreone et al., 2020). Similarly, AD-GWAS variants in TREM2, an upstream receptor in this pathway, have been shown to affect phagocytosis both positively and negatively (Kim et al., 2017). Abi3, another risk factor for $\mathrm{AD}$, is linked to actin polymerization and may also have a role in phagocytosis (Moraes et al., 2017; Conway et al., 2018). It is important to note however that despite the observed protective roles of microglial phagocytosis in the neurodegenerative brain increasing phagocytosis in microglia may not always improve brain pathology. AD microglia have been shown to display disrupted microglia-mediated synaptic pruning, which correlates with decreased cognitive ability (Brucato and Benjamin, 2020).

In addition to observations in $\mathrm{AD}$, in vitro studies of microglia treated with monomeric $\alpha$-synuclein as a model of PD exhibit enhanced phagocytosis (Park et al., 2008). Using proteomic technology, Liu et al., have shown that a variety of types of membrane proteins were potentially involved in microglial internalization of $\alpha$-synuclein (Liu et al., 2007). In particular, clathrin was demonstrated to play a critical role in the endocytosis of aggregated $\alpha$ - synuclein, probably in a receptor-ligand sequestration-related manner, although the exact mechanism requires further study (Liu et al., 2007). In Huntington's disease extracellular mHTT is cleared by microglial phagocytosis (Crotti and Glass, 2015). Moreover, within FTD and ALS, mutations in phagocytosis-associated genes expressed by microglia in the CNS have been identified as risk factors. These genes include missense mutations in TREM2 (Cady et al., 2014; Kleinberger et al., 2014). Also, mutations in PFN1, encoding Profilin, have been identified as a causative mutation in ALS. Profilin is important for the regulation of actin dynamics (Wu et al., 2012; Fil et al., 2017).

\section{Targeting Microglial Endocytosis to Treat Neurodegenerative Disease}

As discussed in the previous section, microglial phagocytosis plays an important role in the neuroimmune response to neurodegenerative conditions. As such it presents a tempting target for therapeutic intervention. However, it is worth remembering one of the clinical symptoms of $\mathrm{AD}$ is the chronic loss of synapses caused by microglial phagocytic engulfment (McQuade and Blurton-Jones, 2019). Moreover, AD and PD microglia can be seen to contribute to neurodegeneration via phagocytosis of injured but functional neurons (Brown and Neher, 2012; McQuade and Blurton-Jones, 2019). As such simply upregulating phagocytosis may not be useful. Ongoing geneticsbased studies however may suggest a more effective route 
allowing a more targeted approach. There is a significant amount of work to still be done in this area before any therapies can be brought to the clinic. Given the importance of PIPs throughout the phagocytic process, possibly the future therapeutics targeting phagocytosis would benefit from co-manipulation of PIP levels.

\section{Role of PIPs in Microglial Chemotaxis and Migration Chemotaxis and Migration in Microglia}

Cell migration is crucial to the function of microglia, allowing them to patrol their region of interest and respond to sites of damage. Microglia react rapidly to damage signals with a positive chemotactic response. Upon detection of these signals, microglia undergo complex molecular and cytoskeletal changes that polarize the cell towards the direction of the damage site. Once stimulated to migrate, cells form a coordinated outgrowth of protrusions and adhesions, which results in translocation of the cell body by contraction towards the adhering zones. Finally, the adhesions are disassembled and the rear of the cell is retracted (Smolders et al., 2019). As a cell advances, newly extended protrusions adhere to the extracellular substrate using integrins. Integrins are attached to interacting myosin II and actin filaments (F and G type) via adaptor proteins, which allows for the generation of traction force (Lauffenburger and Horwitz, 1996). Previous studies have demonstrated that primary rat microglia (P0-P2) do not demonstrate classic types of adhesions during migration (which uses cell adhesion molecules such as cadherins), but instead form podosomes. These are $0.4-1 \mu \mathrm{m}$ multimolecular structures with an F-actin core surrounded by a ring of adhesion and structural proteins. Through $\mathrm{Ca}^{2+}$ signaling in these podosomes, microglia are able to adhere to and degrade fibronectin substrates using matrix metalloproteinases. This allows them to transverse the extra cellular matrix (Siddiqui et al., 2012; Vincent et al., 2012).

Microglia mobility can be broadly divided into two main functional modes; surveillance and chemotaxis. Both these systems involve altering the cytoskeletal structure of the microglia using the high amounts of filamentous actin in motile bundles present in microglial cells (Capani et al., 2001; Lambrechts et al., 2004). In vivo and in situ studies using genetically targeted microglia have demonstrated that microglial tissue surveillance in the healthy CNS is almost exclusively performed by their long, thin, and highly branched processes, which extend and retract at average velocities of $2.5 \mu \mathrm{m} / \mathrm{min}$ (Davalos et al., 2005; Nimmerjahn et al., 2005; Wu et al., 2007; Li et al., 2012). Their high process motility (as well as their high cell density in the brain) allows microglia to scan the entire brain parenchyma once every few hours (Nimmerjahn et al., 2005). The mechanism of this surveillance is not fully understood but is thought to be monitored in part via signaling by astrocytes (Cotrina et al., 2000; Xiong et al., 2018) and neurones (Nimmerjahn et al., 2005; Fontainhas et al., 2011; Li et al., 2012; Gyoneva and Traynelis, 2013; Dissing-Olesen et al., 2014) as well as by fractalkine signaling (Zujovic et al., 2000; Cardona et al., 2006; Liang et al., 2009). However, it has been demonstrated that unlike chemotaxis, surveillance is not regulated by P2Y12 receptors (Haynes et al., 2006).

Microglia detect damage (via activation of $\mathrm{P} 2 \mathrm{Y} 12$ purinergic receptors or fibrinogen-sensing $\mathrm{CD} 11 \mathrm{~b} / \mathrm{CD} 18$ receptors) and immediately extend processes toward the site of injury, where they converge in less than $30 \mathrm{~min}$ to form a spherical shield preventing further spread (Davalos et al., 2005; Hines et al., 2009). As previously mentioned in this review, in vitro studies have established a key role for extracellular nucleotides like ATP/ADP as potent inducers of microglial chemotaxis (Honda et al., 2001; Franke et al., 2007; Orr et al., 2009). These nucleotides, as well as other signals like NO, are known to leak from damaged cells and so act as a signal of damage (Neary et al., 1994). Microglia use ionotropic P2X and metabotropic $\mathrm{P} 2 \mathrm{Y}$ and P1 receptors to respond to extracellular nucleotides and nucleosides (Haynes et al., 2006; Koizumi et al., 2007; Wu et al., 2007; Avignone et al., 2008; Orr et al., 2009). Within cultured rat microglia, increased membrane ruffling and chemotaxis upon ADP stimulation appears to occur via the purinergic P2Y12R. ATP/ADP-induced chemotaxis, dependent on Gi-coupled P2Y receptors, was first described in cultured microglia and later in vivo (Honda et al., 2001; Davalos et al., 2005), and knock-out of ADP-activated Gi-coupled P2Y12 greatly decreases chemotaxis (Haynes et al., 2006). Expression of the P2Y12 receptor on the surface of ramified microglia in vivo (Haynes et al., 2006) is particularly enriched at the tips of the leading processes during chemotaxis (Dissing-Olesen et al., 2014). ATP/ADP-induced $\mathrm{P} 2 \mathrm{Y} 12$ receptor activation leads to PLC and $\mathrm{Ca}^{2+}$ dependent phosphorylation of the serine/threonine kinase Akt, as well as PI3K-mediated Akt phosphorylation (Irino et al., 2008).

\section{Role of Phosphoinositides in Chemotaxis and Migration}

In vitro PI3K appears to act as one of the major signaling components of chemotaxis by allowing cells to establish polarity (Fan et al., 2017). PI3K is selectively localized at the leading edge of the membrane after exposure to a chemoattractant gradient. This creates a spatially restricted production of $\mathrm{PI}(3,4,5) \mathrm{P}_{3}$ from $\mathrm{PI}(4,5) \mathrm{P}_{2}$, which induces F-actin polymerization at the front of migrating cells (Parent et al., 1998; Haugh et al., 2000; Rickert et al., 2000). PTEN, which localizes away from the leading edge, acts reciprocally to $\mathrm{PI} 3 \mathrm{~K}$ by converting $\mathrm{PI}(3,4,5) \mathrm{P}_{3}$ to $\mathrm{PI}(4,5) \mathrm{P}_{2}$ (Wu et al., 2014; Figure 3).

$\mathrm{P} 2 \mathrm{Y} 12 \mathrm{R}$ has also been reported to be linked to a potassium channel, and ATP/ADP-induced activation of P2Y12R elicits an outward potassium current in microglia (Swiatkowski et al., 2016). Blocking this current abolishes chemotaxis to ATP, suggesting that this current plays an important role in the regulation of microglial motility.

Interaction with PIP species is crucial regarding actin assembly, with these lipids facilitating the crosslinking and linking of actin to the plasma membrane by binding with several different actin-binding proteins (ABPs; Figure 3). The $\mathrm{ABP}$ gelsolin is a key regulator of actin filament assembly and disassembly. Gelsolin caps to the barbed ends of $G$ and $\mathrm{F}$ actin filaments, where it prevents monomer exchange (endblocking or capping; Weeds et al., 1986), promotes nucleation 


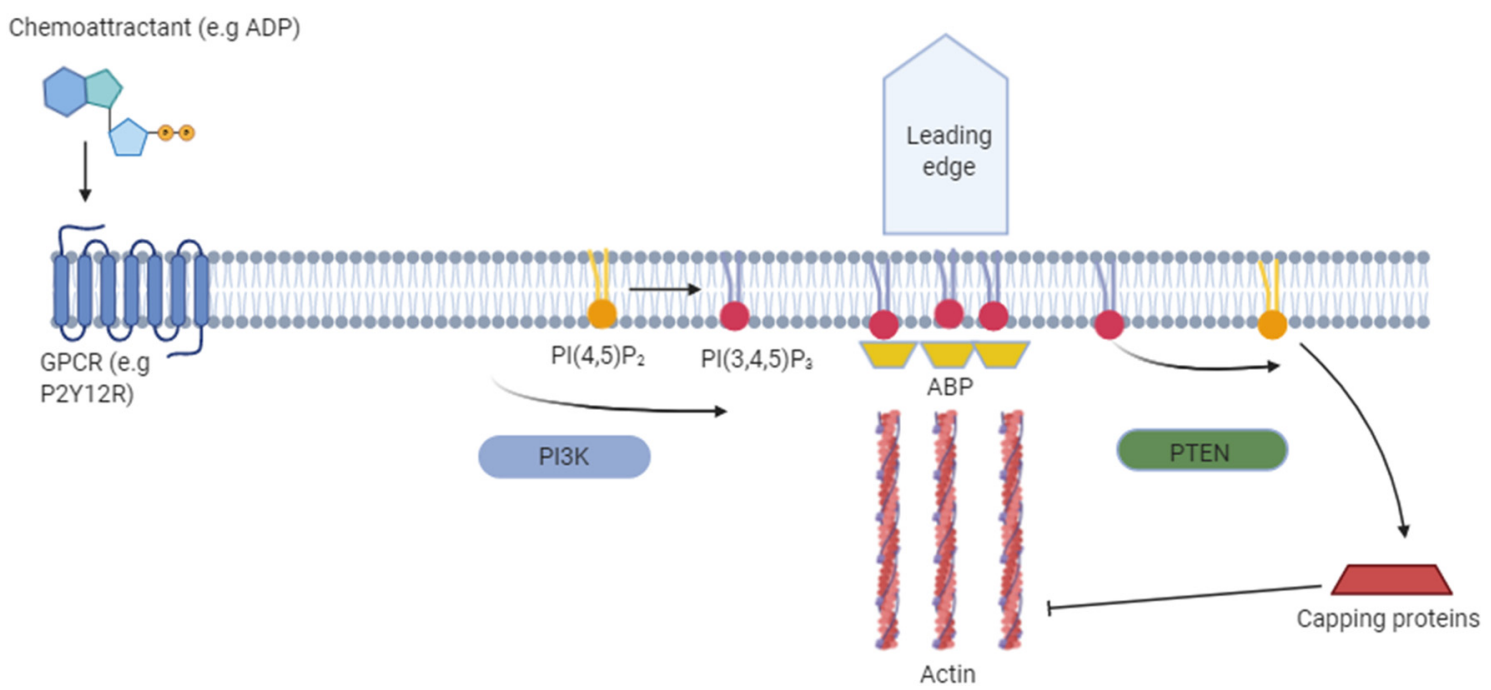

FIGURE 3 | Functional role of phosphoinositides in cell migration. The binding of a chemoattractant to G-protein coupled receptors (e.g., P2Y12R) in the cell membrane releases the $\mathrm{G} \alpha$ heterodimer from the heterotrimeric $\mathrm{G} \alpha$ proteins. Dissociated $\mathrm{G} \alpha$ proteins stimulate $\mathrm{PI}(3,4,5) \mathrm{P}_{3}$ production from $\mathrm{PI}(4,5) \mathrm{P}_{2}$ via phosphoinositide 3-kinase $(\mathrm{PI} 3 \mathrm{~K})$ and lead to membrane translocation of $\mathrm{PI}(3,4,5) \mathrm{P}_{3}$-binding actin-binding proteins (ABPs) such as myosin. This allows remodeling of the actin cytoskeleton at the leading edge, which is required for the formation of novel cell protrusions. Away from the leading edge $\mathrm{PI}(3,4,5) \mathrm{P}_{3}$ is converted back to $\mathrm{PI}(4,5) \mathrm{P}_{2}$ via phosphatase and tensin homolog $(\mathrm{PTEN}) . \mathrm{PI}(4,5) \mathrm{P}_{2}$ then inhibits actin assembly by binding capping proteins.

(the assembly of monomers into filaments) and severs existing Factins. Gelsolin binds $\mathrm{PI}(4,5) \mathrm{P}_{2}$ and $\mathrm{PI}(3,4,5) \mathrm{P}_{3}$ in vivo through two regions that contain clusters of basic residues. Overlapping binding sites means that PIP binding inhibits gelsolin from binding to the G/F-actin (Xian and Janmey, 2002). Gelsolin not only binds to charged regions on PIPs but also interacts with the fatty acid side chains and thus pulls out phospholipids from lipid bilayers. Through this mechanism, gelsolin may modulate PIP density in the plasma membrane (Liepina et al., 2003).

Cofilin proteins are a family of ABPs which are structurally and functionally related to gelsolin. These proteins bind to both $\mathrm{G}$ and F-actin and cause depolymerization at the minus end of filaments, thereby preventing their reassembly. Both $\mathrm{PI}(4,5) \mathrm{P}_{2}$ and $\mathrm{PI}(3,4,5) \mathrm{P}_{3}$ bind to cofilin and inhibit its activity (Ojala et al., 2001).

$\alpha$-Actinin belongs to the spectrin gene superfamily. This protein connects actin filaments to integrins and serves as a scaffold to integrate signaling components at adhesion sites and promote bundling of actin filaments (Otey and Carpen, 2004). These proteins contain a PIP-binding site within the calponin homology domain ( $\mathrm{CH} 1$ and $\mathrm{CH} 2)$, close to the actin-binding site. $\alpha$-actinin binds to both $\mathrm{PI}(4,5) \mathrm{P}_{2}$ and $\mathrm{PI}(3,4,5) \mathrm{P}_{3}$ with equal affinity. In vivo studies show that $\mathrm{PI}(3,4,5) \mathrm{P}_{3}$ disrupts the connection between $\alpha$-actinin and F-actin, although interestingly the opposite is seen in in vitro studies. Furthermore, the elevation of $\mathrm{PI}(3,4,5) \mathrm{P}_{3}$ appears to disrupt the link between actin and integrins, which allows for the redistribution of focal adhesion points in migrating cells (Fraley et al., 2005).

The Ezrin/radixin/moesin (ERM) protein family provides a regulated linkage between the plasma membrane and the underlying actin cytoskeleton (Tsukita and Yonemura, 1997). Several studies have indicated that the binding of ERM proteins to $\mathrm{PI}(4,5) \mathrm{P}_{2}$ and phosphorylation of a threonine residue in the F-actin binding site causes the dissociation of activated ERM proteins (Crepaldi et al., 1997; Naba et al., 2008).

Septins are a group of highly conserved GTP-binding proteins that assemble into filaments and are increasingly recognized as a crucial component of the cytoskeleton (Mostowy and Cossart, 2012). Septins act as a scaffold, allowing the recruitment of many proteins. In vitro studies have shown that purified septins bind phospholipids and that they display particular affinities for $\mathrm{PI}(4,5) \mathrm{P}_{2}$ and $\mathrm{PI}(3,4,5) \mathrm{P}_{3}$ (Tanaka-Takiguchi et al., 2009). Depletion of $\mathrm{PI}(4,5) \mathrm{P}_{2}$ and $\mathrm{PI}(3,4,5) \mathrm{P}_{3}$ in vivo disrupts septin filaments in 3T3 cells (Gilden and Krummel, 2010).

Myosin I is a monomeric, actin-based motor protein with ATPase activity that has been shown to function in the membrane-cytoskeletal interactions, including vesicle transport along actin filaments and regulation of plasma membrane tension. Myosin I molecules have a tail homology (TH) domain that contains a putative phospholipid-binding $\mathrm{PH}$ domain. Previous studies have shown that the $\mathrm{TH}$ domain preferentially binds to acidic phospholipids such as phosphatidylserine and $\mathrm{PI}(3,4,5) \mathrm{P}_{2}$. These phospholipids are relatively abundant in biological membranes and their concentrations do not appear to change a great deal in response to intracellular signaling. In contrast, $\mathrm{PI}(3,4,5) \mathrm{P}_{3}$ levels are highly regulated and function as signaling mechanisms for myosin (Chen et al., 2012).

\section{Microglial Chemotaxis and Migration Within the Neurodegenerative Disease}

Many neurodegenerative conditions present with alterations in microglial migration and distribution. Microglia follow gradients of chemokines towards damaged and dying cells, which by definition are present in these disorders. 
The net migration of microglia induced by deposits of $A \beta$ in $\mathrm{AD}$ is well documented. This process acts to concentrate microglia around $A \beta$ deposits in an attempt to neutralize or prevent further damage. Increased levels of a wide range of chemokines have been reported in $\mathrm{AD}$ patients (KoenigsknechtTalboo and Landreth, 2005). One example is MCP-1. Levels of MCP-1 within CSF increase throughout $\mathrm{AD}$ and levels correlate with disease severity (Galimberti et al., 2006). Other chemokines including IL-18, VEGF, and Fractalkine have also been shown to be elevated in patients with $\mathrm{AD}$ (Kalaria et al., 1998; D’Andrea et al., 2004; Franciosi et al., 2005). In PD $\alpha-$ synuclein aggregates released from neurons activate microglia and act as chemoattractants that direct microglial migration by acting on NADPH oxidase and several other specific downstream proteins (Wang et al., 2015). In HD mutant mHTT protein has been shown to impair immune cell migration by disrupting actin remodeling (Kwan et al., 2012). Notably, PI3K signaling, via inhibition of the Akt/Erk signaling cascade, has been shown to significantly contribute to the pathogenesis of $\mathrm{AD}, \mathrm{PD}$, and HD (Rai et al., 2019). Within ALS, microglia appear to be less mobile than controls in cellular models when using MCP-1 as a chemoattractant (Yamasaki et al., 2010).

\section{Targeting Microglial Chemotaxis and Migration to Treat Neurodegenerative Disease}

Targeting chemotaxis to treat neurodegeneration represents a very nuanced problem. While microglia do have a protective role in many forms of neurodegenerative disease, they also have a detrimental role. While an increased number of microglia may be able to reduce damage and clear extracellular proteins they can also initiate a large, potentially damaging neuroinflammatory response. As such promoting chemotaxis to encourage microglia response to damage may be counterproductive while at the same time reducing the neuroimmune response is also unadvised. A few therapies linked to chemotaxis have been investigated, however. TREM2 is a receptor upstream of PLC $\gamma 2$ in microglia. Sequence variations in TREM2 have been demonstrated to increase the risk of AD (Sims et al., 2017, 2020). TREM2 is currently being investigated as a target for $\mathrm{AD}$ therapies (Long et al., 2019) and dysregulation of TREM2 has been shown to reduce chemotaxis (Mazaheri et al., 2017). TGFbeta has

\section{REFERENCES}

Abbracchio, M. P., Burnstock, G., Verkhratsky, A., and Zimmermann, H. (2009). Purinergic signaling in the nervous system: an overview. Trends Neurosci. 32, 19-29. doi: 10.1016/j.tins.2008.10.001

Ahmad, L., Zhang, S. Y., Casanova, J. L., and Sancho-Shimizu, V. (2016). Human TBK1: a gatekeeper of neuroinflammation. Trends Mol. Med. 22, 511-527. doi: 10.1016/j.molmed.2016.04.006

Ain, Q. U., Batool, M., and Choi, S. (2020). Tlr4-targeting therapeutics: structural basis and computer-aided drug discovery approaches. Molecules 25:627. doi: 10.3390/molecules25030627

Ajroud-Driss, S., and Siddique, T. (2015). Sporadic and hereditary amyotrophic lateral sclerosis (ALS). Biochim. Biophys. Acta 1852, 679-684. doi: 10.1016/j. bbadis.2014.08.010

Al-Ramahi, I., Giridharan, S. S. P., Chen, Y. C., Patnaik, S., Safren, N., Hasegawa, J., et al. (2017). Inhibition of Pip $4 \mathrm{k} \gamma$ ameliorates the pathological effects of mutant huntingtin protein. eLife 6:e29123. doi: 10.7554/eLife. 29123 been shown to downregulate microglia chemotaxis (Huang et al., 2010) and has been investigated as a treatment of AD (Chao et al., 1994). Given the key roles of PIPs in chemotaxis, perhaps co-manipulation of these lipids could enhance therapeutic effects.

\section{CONCLUSION}

The microglial function is severely impaired in a variety of ways within neurodegenerative conditions, with these cells typically showing heightened activation states from early stages of disease development, often before symptom onset. Alongside disturbances in microglial homeostasis, disruptions in phosphoinositide levels and metabolism are also seen in many of these same conditions. These PIPs appear to play important roles in the regulation of numerous key microglial functions. Together, these observations suggest that the observed microglial dysfunction may arise in part as a result of this lipid dyshomeostasis.

Further research into both the role of microglia and PIP dyshomeostasis within neurodegenerative disease could provide us with much-needed therapeutics for treating these presently incurable conditions. It may be that co-manipulating microglial functions alongside PIP levels could allow us to boost the effectiveness of targeted therapeutics, thus bringing us closer to the ultimate goal of a world without dementia.

\section{AUTHOR CONTRIBUTIONS}

TP and EM contributed equally to the researching and drafting of the work presented here. All authors contributed to the article and approved the submitted version.

\section{FUNDING}

TP and EM are funded through the UK Dementia Research Institute [grant number 514201 (TP) and grant number 519688 (EM)] with support from the MRC, Alzheimer's Society, and Alzheimer's Research UK. This work was supported by the UK Dementia Research Institute at Cardiff University.

Ali, W., Ikram, M., Park, H. Y., Jo, M. G., Ullah, R., Ahmad, S., et al. (2020) Oral administration of $\alpha$ linoleic acid rescues $A \beta$-induced glia-mediated neuroinflammation and cognitive dysfunction in C57BL/6N mice. Cells 9:667. doi: $10.3390 /$ cells 9030667

Alzheimer, A., Stelzmann, R. A., Schnitzlein, H. N., and Murtagh, F. R. (1995). An English translation of Alzheimer's 1907 paper, "Uber eine eigenartige erkankung der hirnrinde". Clin. Anat. 8, 429-431. doi: 10.1002/ca.980080612

Andreone, B. J., Przybyla, L., Llapashtica, C., Rana, A., Davis, S. S., Van Lengerich, B., et al. (2020). Alzheimer's-associated PLC $\gamma 2$ is a signaling node required for both trem 2 function and the inflammatory response in human microglia. Nat. Neurosci. 23, 927-938. doi: 10.1038/s41593-020-0650-6

Andries, M., Van Damme, P., Robberecht, W., and Van Den Bosch, L. (2007). Ivermectin inhibits ampa receptor-mediated excitotoxicity in cultured motor neurons and extends the life span of a transgenic mouse model of amyotrophic lateral sclerosis. Neurobiol. Dis. 25, 8-16. doi: 10.1016/j.nbd.2006.08.018

Angulo, E., Casadó, V., Mallol, J., Canela, E. I., Viñals, F., Ferrer, I., et al. (2003). A1 adenosine receptors accumulate in neurodegenerative structures in Alzheimer disease and mediate both amyloid precursor protein processing 
and tau phosphorylation and translocation. Brain Pathol. 13, 440-451. doi: 10.1111/j.1750-3639.2003.tb00475.x

Antonescu, C. N., Aguet, F., Danuser, G., and Schmid, S. L. (2011). Phosphatidylinositol-(4,5)-bisphosphate regulates clathrin-coated pit initiation, stabilization, and size. Mol. Biol. Cell 22, 2588-2600. doi: 10.1091/mbc.E11-04-0362

Apolloni, S., Amadio, S., Montilli, C., Volonté, C., and D’ambrosi, N. (2013). Ablation of $\mathrm{P} 2 \mathrm{X} 7$ receptor exacerbates gliosis and motoneuron death in the SOD1-G93A mouse model of amyotrophic lateral sclerosis. Hum. Mol. Genet. 22, 4102-4116. doi: 10.1093/hmg/ddt259

Araki, N., Johnson, M. T., and Swanson, J. A. (1996). A role for phosphoinositide 3-kinase in the completion of macropinocytosis and phagocytosis by macrophages. J. Cell Biol. 135, 1249-1260. doi: 10.1083/jcb.135.5.1249

Avignone, E., Ulmann, L., Levavasseur, F., Rassendren, F., and Audinat, E. (2008). Status epilepticus induces a particular microglial activation state characterized by enhanced purinergic signaling. J. Neurosci. 28, 9133-9144. doi: 10.1523/JNEUROSCI.1820-08.2008

Azam, S., Jakaria, M., Kim, I. S., Kim, J., Haque, M. E., and Choi, D. K. (2019). Regulation of toll-like receptor (TLR) signaling pathway by polyphenols in the treatment of age-linked neurodegenerative diseases: focus on TLR4 signaling. Front. Immunol. 10:1000. doi: 10.3389/fimmu.2019. 01000

Baba, T., Alvarez-Prats, A., Kim, Y. J., Abebe, D., Wilson, S., Aldworth, Z., et al. (2020). Myelination of peripheral nerves is controlled by PI4KB through regulation of schwann cell golgi function. Proc. Natl. Acad. Sci. U S A 117, 28102-28113. doi: 10.1073/pnas.2007432117

Babcock, A. A., Wirenfeldt, M., Holm, T., Nielsen, H. H., Dissing-Olesen, L., ToftHansen, H., et al. (2006). Toll-like receptor 2 signaling in response to brain injury: an innate bridge to neuroinflammation. J. Neurosci. 26, 12826-12837. doi: 10.1523/JNEUROSCI.4937-05.2006

Bachiller, S., Jiménez-Ferrer, I., Paulus, A., Yang, Y., Swanberg, M., Deierborg, T., et al. (2018). Microglia in neurological diseases: a road map to braindisease dependent-inflammatory response. Front. Cell. Neurosci. 12:488. doi: $10.3389 /$ fncel.2018.00488

Bateman, R. J., Aisen, P. S., De Strooper, B., Fox, N. C., Lemere, C. A., Ringman, J. M., et al. (2011). Autosomal-dominant Alzheimer's disease: a review and proposal for the prevention of Alzheimer's disease. Alzheimers Res. Ther. 3:1. doi: 10.1186/alzrt59

Bates, G. P., Dorsey, R., Gusella, J. F., Hayden, M. R., Kay, C., Leavitt, B. R., et al. (2015). Huntington disease. Nat. Rev. Dis. Primers 1:15005. doi: 10.1038/nrdp. 2015.5

Ben Romdhan, S., Sakka, S., Farhat, N., Triki, S., Dammak, M., and Mhiri, C. (2018). A novel SYNJ1 mutation in a tunisian family with juvenile Parkinson's disease associated with epilepsy. J. Mol. Neurosci. 66, 273-278. doi: 10.1007/s12031-018-1167-2

Bengtsson, T., Jaconi, M. E., Gustafson, M., Magnusson, K. E., Theler, J. M., Lew, D. P., et al. (1993). Actin dynamics in human neutrophils during adhesion and phagocytosis is controlled by changes in intracellular free calcium. Eur. J. Cell Biol. 62, 49-58.

Beraud, D., Twomey, M., Bloom, B., Mittereder, A., Ton, V., Neitzke, K., et al. (2011). $\alpha$-synuclein alters toll-like receptor expression. Front. Neurosci. 5:80. doi: 10.3389/fnins.2011.00080

Berman, D. E., Dall'armi, C., Voronov, S. V., Mcintire, L. B., Zhang, H., Moore, A. Z., et al. (2008). Oligomeric amyloid- $\beta$ peptide disrupts phosphatidylinositol-4,5-bisphosphate metabolism. Nat. Neurosci. 11, 547-554. doi: 10.1038/nn.2100

Bernier, L. P., Ase, A. R., Boue-Grabot, E., and Seguela, P. (2012a). P2x4 receptor channels form large noncytolytic pores in resting and activated microglia. Glia 60, 728-737. doi: 10.1002/glia.22301

Bernier, L. P., Blais, D., Boue-Grabot, E., and Seguela, P. (2012b). A dual polybasic motif determines phosphoinositide binding and regulation in the P2X channel family. PLoS One 7:E40595. doi: 10.1371/journal.pone.0040595

Bernier, L. P., Ase, A. R., Boue-Grabot, E., and Seguela, P. (2013a). Inhibition of P2X4 function by P2Y6 udp receptors in microglia. Glia 61, 2038-2049. doi: $10.1002 /$ glia.22574

Bernier, L. P., Ase, A. R., and Seguela, P. (2013b). Post-translational regulation of P2X receptor channels: modulation by phospholipids. Front. Cell. Neurosci. 7:226. doi: 10.3389 /fncel.2013.00226
Bernier, L. P., Ase, A. R., Chevallier, S., Blais, D., Zhao, Q., Boue-Grabot, E., et al. (2008). Phosphoinositides regulate P2X4 ATP-gated channels through direct interactions. J. Neurosci. 28, 12938-12945. doi: 10.1523/JNEUROSCI.3038-08. 2008

Berridge, M. J. (2013). Dysregulation of neural calcium signaling in Alzheimer disease, bipolar disorder and schizophrenia. Prion 7, 2-13. doi: 10.4161/pri. 21767

Berridge, M. J. (2014). Calcium regulation of neural rhythms, memory and Alzheimer's disease. J. Physiol. 592, 281-293. doi: 10.1113/jphysiol.2013.257527

Bezprozvanny, I. (2009). Calcium signaling and neurodegenerative diseases. Trends Mol. Med. 15, 89-100. doi: 10.1016/j.molmed.2009. 01.001

Blum, D., Chern, Y., Domenici, M. R., Buée, L., Lin, C. Y., Rea, W., et al. (2018). The role of adenosine tone and adenosine receptors in Huntington's disease. J. Caffeine Adenosine Res. 8, 43-58. doi: 10.1089/caff.2018.0006

Boal, F., Mansour, R., Gayral, M., Saland, E., Chicanne, G., Xuereb, J. M., et al. (2015). TOM1 is a PI5P effector involved in the regulation of endosomal maturation. J. Cell Sci. 128, 815-827. doi: 10.1242/jcs.166314

Bohdanowicz, M., and Grinstein, S. (2013). Role of phospholipids in endocytosis, phagocytosis, and macropinocytosis. Physiol. Rev. 93, 69-106. doi: 10.1152/physrev.00002.2012

Boison, D., Chen, J. F., and Fredholm, B. B. (2010). Adenosine signaling and function in glial cells. Cell Death Differ. 17, 1071-1082. doi: 10.1038/cdd. 2009.131

Bose, S., and Cho, J. (2013). Role of chemokine CCL2 and its receptor CCR2 in neurodegenerative diseases. Arch. Pharm. Res. 36, 1039-1050. doi: 10.1007/s12272-013-0161-z

Botelho, R. J., Teruel, M., Dierckman, R., Anderson, R., Wells, A., York, J. D., et al. (2000). Localized biphasic changes in phosphatidylinositol-4,5-bisphosphate at sites of phagocytosis. J. Cell Biol. 151, 1353-1368. doi: 10.1083/jcb.151.7.1353

Braems, E., Swinnen, B., and Van Den Bosch, L. (2020). C9orf72 loss-of-function: a trivial, stand-alone or additive mechanism in C9 ALS/FTD? Acta Neuropathol. 140, 625-643. doi: 10.1007/s00401-020-02214-x

Bretscher, A., Edwards, K., and Fehon, R. G. (2002). ERM proteins and merlin: integrators at the cell cortex. Nat. Rev. Mol. Cell Biol. 3, 586-599. doi: $10.1038 / \mathrm{nrm} 882$

Broad, A., Kirby, J. A., and Jones, D. E. (2007). Toll-like receptor interactions: tolerance of MyD88-dependent cytokines but enhancement of MyD88independent interferon- $\beta$ production. Immunology 120, 103-111. doi: 10.1111/j.1365-2567.2006.02485.x

Brown, D. A., Hughes, S. A., Marsh, S. J., and Tinker, A. (2007). Regulation of $M(K v 7.2 / 7.3)$ channels in neurons by PIP(2) and products of PIP(2) hydrolysis: significance for receptor-mediated inhibition. J. Physiol. 582, 917-925. doi: 10.1113/jphysiol.2007.132498

Brown, G. C., and Neher, J. J. (2012). Eaten alive! Cell death by primary phagocytosis: 'phagoptosis'. Trends Biochem. Sci. 37, 325-332. doi: 10.1016/j. tibs.2012.05.002

Brucato, F. H., and Benjamin, D. E. (2020). Synaptic pruning in Alzheimer's disease: role of the complement system. Glob. J. Med. Res. 20:10.34257/gjmrfvol20is6pg1. doi: 10.34257/gjmrfvol20is6pg1

Bsibsi, M., Ravid, R., Gveric, D., and Van Noort, J. M. (2002). Broad expression of toll-like receptors in the human central nervous system. J. Neuropathol. Exp. Neurol. 61, 1013-1021. doi: 10.1093/jnen/61.11.1013

Bulley, S. J., Clarke, J. H., Droubi, A., Giudici, M. L., and Irvine, R. F. (2015). Exploring phosphatidylinositol 5-phosphate 4-kinase function. Adv. Biol. Regul. 57, 193-202. doi: 10.1016/j.jbior.2014.09.007

Burns, A., and Iliffe, S. (2009). Alzheimer's disease. BMJ 338:B158 doi: 10.1136/bmj.b158

Burnstock, G., and Knight, G. E. (2018). The potential of P2X7 receptors as a therapeutic target, including inflammation and tumour progression. Purinergic Signal. 14, 1-18. doi: 10.1007/s11302-017-9593-0

Cady, J., Koval, E. D., Benitez, B. A., Zaidman, C., Jockel-Balsarotti, J., Allred, P., et al. (2014). TREM2 variant p.R47H as a risk factor for sporadic amyotrophic lateral sclerosis. JAMA Neurol. 71, 449-453. doi: 10.1001/jamaneurol.2013.6237

Caldeira, C., Cunha, C., Vaz, A. R., Falcao, A. S., Barateiro, A., Seixas, E., et al. (2017). Key aging-associated alterations in primary microglia response to $\beta$ amyloid stimulation. Front. Aging Neurosci. 9:277. doi: 10.3389/fnagi.2017. 00277 
Calovi, S., Mut-Arbona, P., and Sperlagh, B. (2019). Microglia and the purinergic signaling system. Neuroscience 405, 137-147. doi: 10.1016/j.neuroscience.2018. 12.021

Campêlo, C., and Silva, R. H. (2017). Genetic variants in SNCA and the risk of sporadic Parkinson's disease and clinical outcomes: a review. Parkinsons Dis. 2017:4318416. doi: 10.1155/2017/4318416

Cao, F., Hu, L. Q., Yao, S. R., Hu, Y., Wang, D. G., Fan, Y. G., et al. (2019). P2X7 receptor: a potential therapeutic target for autoimmune diseases. Autoimmun. Rev. 18, 767-777. doi: 10.1016/j.autrev.2019.06.009

Capani, F., Ellisman, M. H., and Martone, M. E. (2001). Filamentous actin is concentrated in specific subpopulations of neuronal and glial structures in rat central nervous system. Brain Res. 923, 1-11. doi: 10.1016/s00068993(01)03189-4

Cardona, A. E., Pioro, E. P., Sasse, M. E., Kostenko, V., Cardona, S. M., Dijkstra, I. M., et al. (2006). Control of microglial neurotoxicity by the fractalkine receptor. Nat. Neurosci. 9, 917-924. doi: 10.1038/nn1715

Carmo, M. R., Menezes, A. P., Nunes, A. C., Pliássova, A., Rolo, A. P., Palmeira, C. M., et al. (2014). The P2X7 receptor antagonist brilliant blue $\mathrm{G}$ attenuates contralateral rotations in a rat model of parkinsonism through a combined control of synaptotoxicity, neurotoxicity and gliosis. Neuropharmacology 81, 142-152. doi: 10.1016/j.neuropharm.2014. 01.045

Casamento, A., and Boucrot, E. (2020). Molecular mechanism of fast endophilinmediated endocytosis. Biochem. J. 477, 2327-2345. doi: 10.1042/BCJ201 90342

Casula, M., Iyer, A. M., Spliet, W. G., Anink, J. J., Steentjes, K., Sta, M., et al. (2011). Toll-like receptor signaling in amyotrophic lateral sclerosis spinal cord tissue. Neuroscience 179, 233-243. doi: 10.1016/j.neuroscience.2011.02.001

Caulfield, M. P., Jones, S., Vallis, Y., Buckley, N. J., Kim, G. D., Milligan, G., et al. (1994). Muscarinic M-current inhibition via $\mathrm{G} \alpha \mathrm{q} / 11$ and $\alpha$-adrenoceptor inhibition of $\mathrm{Ca}^{2+}$ current via $\mathrm{G} \alpha$ o in rat sympathetic neurones. J. Physiol. 477, 415-422. doi: 10.1113/jphysiol.1994.sp020203

Chao, C. C., Hu, S., Frey, W. H. II., Ala, T. A., Tourtellotte, W. W., and Peterson, P. K. (1994). Transforming growth factor $\beta$ in Alzheimer's disease. Clin. Diagn. Lab. Immunol. 1, 109-110.

Chen, L., Hu, L., Zhao, J., Hong, H., Feng, F., Qu, W., et al. (2016). Chotosan improves $A \beta 1-42$-induced cognitive impairment and neuroinflammatory and apoptotic responses through the inhibition of TLR-4/NF- $\mathrm{KB}$ signaling in mice. J. Ethnopharmacol. 191, 398-407. doi: 10.1016/j.jep.2016.03.038

Chen, C. L., Wang, Y., Sesaki, H., and Iijima, M. (2012). Myosin I links PIP3 signaling to remodeling of the actin cytoskeleton in chemotaxis. Sci. Signal. 5:Ra10. doi: 10.1126/scisignal.2002446

Cheng, N., He, R., Tian, J., Dinauer, M. C., and Ye, R. D. (2007). A critical role of protein kinase $\mathrm{C}$ delta activation loop phosphorylation in formylmethionyl-leucyl-phenylalanine-induced phosphorylation of p47(phox) and rapid activation of nicotinamide adenine dinucleotide phosphate oxidase. J. Immunol. 179, 7720-7728. doi: 10.4049/jimmunol.179.11.7720

Cho, H., Lee, D., Lee, S. H., and Ho, W. K. (2005). Receptor-induced depletion of phosphatidylinositol 4,5-bisphosphate inhibits inwardly rectifying $\mathrm{K}+$ channels in A receptor-specific manner. Proc. Natl. Acad. Sci. U S A 102, 4643-4648. doi: 10.1073/pnas.0408844102

Choi, I., Kim, B., Byun, J. W., Baik, S. H., Huh, Y. H., Kim, J. H., et al. (2015). LRRK2 G2019S mutation attenuates microglial motility by inhibiting focal adhesion kinase. Nat. Commun. 6:8255. doi: 10.1038/ncomms9255

Choi, H. B., Ryu, J. K., Kim, S. U., and Mclarnon, J. G. (2007). Modulation of the purinergic P2X7 receptor attenuates lipopolysaccharide-mediated microglial activation and neuronal damage in inflamed brain. J. Neurosci. 27, 4957-4968. doi: 10.1523/JNEUROSCI.5417-06.2007

Chong, Z. Z., Shang, Y. C., Wang, S., and Maiese, K. (2012). A critical kinase cascade in neurological disorders: PI 3-K, Akt, and mTOR. Future Neurol. 7, 733-748. doi: 10.2217/fnl.12.72

Chow, C. Y., Landers, J. E., Bergren, S. K., Sapp, P. C., Grant, A. E., Jones, J. M., et al. (2009). Deleterious variants of FIG4, a phosphoinositide phosphatase, in patients with ALS. Am. J. Hum. Genet. 84, 85-88. doi: 10.1016/j.ajhg.2008. 12.010

Chow, C. Y., Zhang, Y., Dowling, J. J., Jin, N., Adamska, M., Shiga, K., et al. (2007). Mutation of FIG4 causes neurodegeneration in the pale tremor mouse and patients with CMT4J. Nature 448, 68-72. doi: 10.1038/nature05876
Cianciulli, A., Porro, C., Calvello, R., Trotta, T., Lofrumento, D. D., and Panaro, M. A. (2020). Microglia mediated neuroinflammation: focus on PI3K modulation. Biomolecules 10:137. doi: 10.3390/biom10010137

Colonna, M., and Butovsky, O. (2017). Microglia function in the central nervous system during health and neurodegeneration. Annu. Rev. Immunol. 35, 441-468. doi: 10.1146/annurev-immunol-051116-052358

Conway, O. J., Carrasquillo, M. M., Wang, X., Bredenberg, J. M., Reddy, J. S., Strickland, S. L., et al. (2018). ABI3 and PLCG2 missense variants as risk factors for neurodegenerative diseases in caucasians and African Americans. Mol. Neurodegener. 13:53. doi: 10.1186/s13024-018-0289-x

Coppolino, M. G., Dierckman, R., Loijens, J., Collins, R. F., Pouladi, M., JongstraBilen, J., et al. (2002). Inhibition of phosphatidylinositol-4-phosphate 5-kinase I $\alpha$ impairs localized actin remodeling and suppresses phagocytosis. J. Biol. Chem. 277, 43849-43857. doi: 10.1074/jbc.M209046200

Cotrina, M. L., Lin, J. H., López-García, J. C., Naus, C. C., and Nedergaard, M. (2000). ATP-mediated glia signaling. J. Neurosci. 20, 2835-2844. doi: 10.1523/JNEUROSCI.20-08-02835.2000

Cox, D., Tseng, C. C., Bjekic, G., and Greenberg, S. (1999). A requirement for phosphatidylinositol 3-kinase in pseudopod extension. J. Biol. Chem. 274, 1240-1247. doi: 10.1074/jbc.274.3.1240

Cremona, O., and De Camilli, P. (2001). Phosphoinositides in membrane traffic at the synapse. J. Cell Sci. 114, 1041-1052.

Cremona, O., Di Paolo, G., Wenk, M. R., Lüthi, A., Kim, W. T., Takei, K., et al. (1999). Essential role of phosphoinositide metabolism in synaptic vesicle recycling. Cell 99, 179-188. doi: 10.1016/s0092-8674(00)81649-9

Crepaldi, T., Gautreau, A., Comoglio, P. M., Louvard, D., and Arpin, M. (1997). Ezrin is an effector of hepatocyte growth factor-mediated migration and morphogenesis in epithelial cells. J. Cell Biol. 138, 423-434. doi: 10.1083/jcb. 138.2.423

Crotti, A., Benner, C., Kerman, B. E., Gosselin, D., Lagier-Tourenne, C., Zuccato, C., et al. (2014). Mutant huntingtin promotes autonomous microglia activation via myeloid lineage-determining factors. Nat. Neurosci. 17, 513-521. doi: $10.1038 / \mathrm{nn} .3668$

Crotti, A., and Glass, C. K. (2015). The choreography of neuroinflammation in Huntington's disease. Trends Immunol. 36, 364-373. doi: 10.1016/j.it.2015.04. 007

D'Andrea, M. R., Cole, G. M., and Ard, M. D. (2004). The microglial phagocytic role with specific plaque types in the Alzheimer disease brain. Neurobiol. Aging 25, 675-683. doi: 10.1016/j.neurobiolaging.2003.12.026

Daniele, S. G., Beraud, D., Davenport, C., Cheng, K., Yin, H., and MaguireZeiss, K. A. (2015). Activation of MyD88-dependent TLR1/2 signaling by misfolded $\alpha$-synuclein, a protein linked to neurodegenerative disorders. Sci. Signal. 8:ra45. doi: 10.1126/scisignal.2005965

Davalos, D., Grutzendler, J., Yang, G., Kim, J. V., Zuo, Y., Jung, S., et al. (2005). ATP mediates rapid microglial response to local brain injury in vivo. Nat. Neurosci. 8, 752-758. doi: 10.1038/nn1472

De Leo, M. G., Staiano, L., Vicinanza, M., Luciani, A., Carissimo, A., Mutarelli, M., et al. (2016). Autophagosome-lysosome fusion triggers a lysosomal response mediated by TLR9 and controlled by OCRL. Nat. Cell Biol. 18, 839-850. doi: $10.1038 /$ ncb3386

De Matteis, M. A., and Godi, A. (2004). Pi-loting membrane traffic. Nat. Cell Biol. 6, 487-492. doi: 10.1038/ncb0604-487

Dejesus-Hernandez, M., Mackenzie, I. R., Boeve, B. F., Boxer, A. L., Baker, M., Rutherford, N. J., et al. (2011). Expanded GGGGCC hexanucleotide repeat in noncoding region of C9ORF72 causes chromosome 9p-linked FTD and ALS. Neuron 72, 245-256. doi: 10.1016/j.neuron.2011.09.011

Del Pozo, M. A., Lolo, F. N., and Echarri, A. (2020). Caveolae: mechanosensing and mechanotransduction devices linking membrane trafficking to mechanoadaptation. Curr. Opin. Cell Biol. 68, 113-123. doi: 10.1016/j. ceb.2020.10.008

Desale, S. E., and Chinnathambi, S. (2021). Phosphoinositides signaling modulates microglial actin remodeling and phagocytosis in Alzheimer's disease. Cell Commun. Signal. 19:28. doi: 10.1186/s12964-021-00715-0

Dickson, E. J., and Hille, B. (2019). Understanding phosphoinositides: rare, dynamic, and essential membrane phospholipids. Biochem. J. 476, 1-23. doi: 10.1042/BCJ20180022

Dissing-Olesen, L., Ledue, J. M., Rungta, R. L., Hefendehl, J. K., Choi, H. B., and Macvicar, B. A. (2014). Activation of neuronal nmda receptors triggers 
transient ATP-mediated microglial process outgrowth. J. Neurosci. 34, 10511-10527. doi: 10.1523/JNEUROSCI.0405-14.2014

Donaldson, J. G. (2003). Multiple roles for Arf6: sorting, structuring, and signaling at the plasma membrane. J. Biol. Chem. 278, 41573-41576. doi: 10.1074/jbc. R300026200

Dong, X.-P., Shen, D., Wang, X., Dawson, T., Li, X., Zhang, Q., et al. (2010). $\mathrm{Pi}(3,5) \mathrm{P}(2)$ controls membrane trafficking by direct activation of mucolipin $\mathrm{Ca}^{2+}$ release channels in the endolysosome. Nat. Commun. 1:38.doi: $10.1038 /$ ncomms 1037

Drouet, V., and Lesage, S. (2014). Synaptojanin 1 mutation in Parkinson's disease brings further insight into the neuropathological mechanisms. Biomed. Res. Int. 2014:289728. doi: 10.1155/2014/289728

Durrenberger, P. F., Grünblatt, E., Fernando, F. S., Monoranu, C. M., Evans, J., Riederer, P., et al. (2012). Inflammatory pathways in Parkinson's disease; a bne microarray study. Parkinsons Dis. 2012:214714. doi: 10.1155/2012/214714

Díaz-Hernández, M., Díez-Zaera, M., Sánchez-Nogueiro, J., GómezVillafuertes, R., Canals, J. M., Alberch, J., et al. (2009). Altered P2X7-receptor level and function in mouse models of Huntington's disease and therapeutic efficacy of antagonist administration. FASEB J. 23, 1893-1906. doi: 10.1096/fj. 08-122275

Erb, L., Cao, C., Ajit, D., and Weisman, G. A. (2015). P2Y receptors in Alzheimer's disease. Biol. Cell 107, 1-21. doi: 10.1111/boc.201400043

Erb, L., and Weisman, G. A. (2012). Coupling of P2Y receptors to G proteins and other signaling pathways. Wiley Interdiscip. Rev. Membr. Transp. Signal. 1, 789-803. doi: $10.1002 /$ wmts.62

Eskelinen, M. H., and Kivipelto, M. (2010). Caffeine as a protective factor in dementia and Alzheimer's disease. J. Alzheimers Dis. 20, S167-S174. doi: 10.3233/JAD-2010-1404

Falasca, M., Logan, S. K., Lehto, V. P., Baccante, G., Lemmon, M. A., and Schlessinger, J. (1998). Activation of phospholipase C $\gamma$ by PI 3-kinaseinduced $\mathrm{PH}$ domain-mediated membrane targeting. EMBO J. 17, 414-422. doi: 10.1093/emboj/17.2.414

Fan, Y., Xie, L., and Chung, C. Y. (2017). Signaling pathways controlling microglia chemotaxis. Mol. Cells 40, 163-168. doi: 10.14348/molcells.2017.0011

Fiebich, B. L., Batista, C. R. A., Saliba, S. W., Yousif, N. M., and De Oliveira, A. C. P. (2018). Role of microglia TLRs in neurodegeneration. Front. Cell. Neurosci. 12:329. doi: 10.3389/fncel.2018.00329

Fil, D., DeLoach, A., Yadav, S., Alkam, D., MacNicol, M., Singh, A., et al. (2017). Mutant profilin1 transgenic mice recapitulate cardinal features of motor neuron disease. Hum. Mol. Genet. 26, 686-701. doi: 10.1093/hmg/ddw429

Fitzgerald, K. A., Rowe, D. C., Barnes, B. J., Caffrey, D. R., Visintin, A., Latz, E., et al. (2003). Lps-Tlr4 signaling to IRF-3/7 and NF- $\mathrm{\kappa B}$ involves the toll adapters TRAM and trif. J. Exp. Med. 198, 1043-1055. doi: 10.1084/jem.20031023

Fontainhas, A. M., Wang, M., Liang, K. J., Chen, S., Mettu, P., Damani, M., et al. (2011). Microglial morphology and dynamic behavior is regulated by ionotropic glutamatergic and GABAergic neurotransmission. PLoS One 6:E15973. doi: 10.1371/journal.pone.0015973

Fraley, T. S., Pereira, C. B., Tran, T. C., Singleton, C., and Greenwood, J. A. (2005). Phosphoinositide binding regulates $\alpha$-actinin dynamics: mechanism for modulating cytoskeletal remodeling. J. Biol. Chem. 280, 15479-15482. doi: $10.1074 /$ jbc.M500631200

Franciosi, S., Choi, H. B., Kim, S. U., and McLarnon, J. G. (2005). Il8 enhancement of amyloid- $\beta$ ( $\mathrm{A} \beta$ 1-42)-induced expression and production of pro-inflammatory cytokines and cox-2 in cultured human microglia. J. Neuroimmunol. 159, 66-74. doi: 10.1016/j.jneuroim.2004.10.006

Franke, H., Schepper, C., Illes, P., and Krügel, U. (2007). Involvement of P2x and P2Y receptors in microglial activation in vivo. Purinergic Signal. 3, 435-445. doi: 10.1007/s11302-007-9082-y

Fredholm, B. B., Bättig, K., Holmén, J., Nehlig, A., and Zvartau, E. E. (1999). Actions of caffeine in the brain with special reference to factors that contribute to its widespread use. Pharmacol. Rev. 51, 83-133.

Gabandé-Rodríguez, E., Keane, L., and Capasso, M. (2020). Microglial phagocytosis in aging and Alzheimer's disease. J. Neurosci. Res. 98, 284-298. doi: 10.1002/jnr.24419

Galimberti, D., Schoonenboom, N., Scheltens, P., Fenoglio, C., Bouwman, F., Venturelli, E., et al. (2006). Intrathecal chemokine synthesis in mild cognitive impairment and Alzheimer disease. Arch. Neurol. 63, 538-543. doi: 10.1001/archneur.63.4.538
Gambuzza, M. E., Sofo, V., Salmeri, F. M., Soraci, L., Marino, S., and Bramanti, P. (2014). Toll-like receptors in Alzheimer's disease: a therapeutic perspective. CNS Neurol. Disord. Drug Targets 13, 1542-1558. doi: $10.2174 / 1871527313666140806124850$

Gatz, M., Reynolds, C. A., Fratiglioni, L., Johansson, B., Mortimer, J. A., Berg, S., et al. (2006). Role of genes and environments for explaining Alzheimer disease. Arch. Gen. Psychiatry 63, 168-174. doi: 10.1001/archpsyc.63.2.168

Geloso, M. C., Corvino, V., Marchese, E., Serrano, A., Michetti, F., and D'Ambrosi, N. (2017). The dual role of microglia in ALS: mechanisms and therapeutic approaches. Front. Aging Neurosci. 9:242. doi: 10.3389/fnagi.2017. 00242

Genevini, P., Colombo, M. N., Venditti, R., Marcuzzo, S., Colombo, S. F., Bernasconi, P., et al. (2019). VAPB depletion alters neuritogenesis and phosphoinositide balance in motoneuron-like cells: relevance to VAPB-linked amyotrophic lateral sclerosis. J. Cell Sci. 132:jcs220061. doi: 10.1242/jcs.220061

Gerhard, A., Pavese, N., Hotton, G., Turkheimer, F., Es, M., Hammers, A., et al. (2006), in vivo imaging of microglial activation with [11C](R)-PK11195 PET in idiopathic Parkinson's disease. Neurobiol. Dis. 21, 404-412. doi: 10.1016/j.nbd. 2005.08 .002

Gilden, J., and Krummel, M. F. (2010). Control of cortical rigidity by the cytoskeleton: emerging roles for septins. Cytoskeleton 67, 477-486. doi: $10.1002 / \mathrm{cm} .20461$

Gillooly, D. J., Simonsen, A., and Stenmark, H. (2001). Phosphoinositides and phagocytosis. J. Cell Biol. 155, 15-18. doi: 10.1083/jcb.200109001

Go, M., Kou, J., Lim, J. E., Yang, J., and Fukuchi, K. I. (2016). Microglial response to LPS increases in wild-type mice during aging but diminishes in an Alzheimer's mouse model: implication of TLR4 signaling in disease progression. Biochem. Biophys. Res. Commun. 479, 331-337. doi: 10.1016/j.bbrc.2016.09.073

Gopalakrishna, A., and Alexander, S. A. (2015). Understanding Parkinson disease: a complex and multifaceted illness. J. Neurosci. Nurs. 47, 320-326. doi: 10.1097/JNN.0000000000000162

Gray, M. A., Choy, C. H., Dayam, R. M., Ospina-Escobar, E., Somerville, A., Xiao, X., et al. (2016). Phagocytosis enhances lysosomal and bactericidal properties by activating the transcription factor TFEB. Curr. Biol. 26, 1955-1964. doi: 10.1016/j.cub.2016.05.070

Griffioen, K., Mattson, M. P., and Okun, E. (2018). Deficiency of toll-like receptors 2, 3 or 4 extends life expectancy in Huntington's disease mice. Heliyon 4:e00508. doi: 10.1016/j.heliyon.2018.e00508

Guerrero, A. (2018). A2A adenosine receptor agonists and their potential therapeutic applications. An update. Curr. Med. Chem. 25, 3597-3612. doi: 10.2174/0929867325666180313110254

Gyoneva, S., and Traynelis, S. F. (2013). Norepinephrine modulates the motility of resting and activated microglia via different adrenergic receptors. J. Biol. Chem. 288, 15291-15302. doi: 10.1074/jbc.M113.458901

Hanagasi, H. A., Tufekcioglu, Z., and Emre, M. (2017). Dementia in Parkinson's disease. J. Neurol. Sci. 374, 26-31. doi: 10.1016/j.jns.2017.01.012

Hasegawa, J., Tokuda, E., Tenno, T., Tsujita, K., Sawai, H., Hiroaki, H., et al. (2011). SH3YL1 regulates dorsal ruffle formation by a novel phosphoinositidebinding domain. J. Cell Biol. 193, 901-916. doi: 10.1083/jcb.2010 12161

Haskó, G., Pacher, P., Vizi, E. S., and Illes, P. (2005). Adenosine receptor signaling in the brain immune system. Trends Pharmacol. Sci. 26, 511-516. doi: 10.1016/j. tips.2005.08.004

Haugh, J. M., Codazzi, F., Teruel, M., and Meyer, T. (2000). Spatial sensing in fibroblasts mediated by 3' phosphoinositides. J. Cell Biol. 151, 1269-1280. doi: $10.1083 /$ jcb.151.6.1269

Hawkins, P. T., and Stephens, L. R. (2016). Emerging evidence of signaling roles for PI( $(3,4) \mathrm{P} 2$ in class I And Ii PI3K-regulated pathways. Biochem. Soc. Trans. 44, 307-314. doi: 10.1042/BST20150248

Hawthorne, J. N., and Pickard, M. R. (1979). Phospholipids in synaptic function. J. Neurochem. 32, 5-14. doi: 10.1111/j.1471-4159.1979.tb04503.x

Haynes, S. E., Hollopeter, G., Yang, G., Kurpius, D., Dailey, M. E., Gan, W.-B., et al. (2006). The P2Y12 receptor regulates microglial activation by extracellular nucleotides. Nat. Neurosci. 9, 1512-1519. doi: 10.1038/nn1805

He, R., Nanamori, M., Sang, H., Yin, H., Dinauer, M. C., and Ye, R. D. (2004). Reconstitution of chemotactic peptide-induced nicotinamide adenine dinucleotide phosphate (reduced) oxidase activation in transgenic COS-phox cells. J. Immunol. 173, 7462-7470. doi: 10.4049/jimmunol.173.12.7462 
He, Y., Taylor, N., Fourgeaud, L., and Bhattacharya, A. (2017). The role of microglial P2X7: modulation of cell death and cytokine release. J. Neuroinflammation 14:135. doi: 10.1186/s12974-0170904-8

Heras-Sandoval, D., Pérez-Rojas, J. M., Hernández-Damián, J., and PedrazaChaverri, J. (2014). The role of PI3K/AKT/mTOR pathway in the modulation of autophagy and the clearance of protein aggregates in neurodegeneration. Cell. Signal. 26, 2694-2701. doi: 10.1016/j.cellsig.2014.08.019

Hickman, S. E., Allison, E. K., and El Khoury, J. (2008). Microglial dysfunction and defective $\beta$-amyloid clearance pathways in aging Alzheimer's disease mice. J. Neurosci. 28, 8354-8360. doi: 10.1523/JNEUROSCI.061608.2008

Hille, B., Dickson, E. J., Kruse, M., Vivas, O., and Suh, B.-C. (2015). Phosphoinositides regulate ion channels. Biochim. Biophys. Acta 1851, 844-856. doi: 10.1016/j.bbalip.2014.09.010

Hines, D. J., Hines, R. M., Mulligan, S. J., and Macvicar, B. A. (2009). Microglia processes block the spread of damage in the brain and require functional chloride channels. Glia 57, 1610-1618. doi: 10.1002/glia.20874

Honda, S., Sasaki, Y., Ohsawa, K., Imai, Y., Nakamura, Y., Inoue, K., et al. (2001). Extracellular ATP or ADP induce chemotaxis of cultured microglia through Gi/O-coupled P2Y receptors. J. Neurosci. 21, 1975-1982. doi: 10.1523/JNEUROSCI.21-06-01975.2001

Hou, Y., Dan, X., Babbar, M., Wei, Y., Hasselbalch, S. G., Croteau, D. L., et al. (2019). Ageing as a risk factor for neurodegenerative disease. Nat. Rev. Neurol. 15, 565-581. doi: 10.1038/s41582-019-0244-7

Hou, X., Watzlawik, J. O., Fiesel, F. C., and Springer, W. (2020). Autophagy in Parkinson's disease. J. Mol. Biol. 432, 2651-2672. doi: 10.1016/j.jmb.2020. 01.037

Huang, W.-C., Yen, F.-C., Shie, F.-S., Pan, C.-M., Shiao, Y.-J., Yang, C.-N., et al. (2010). TGF- $\beta 1$ blockade of microglial chemotaxis toward a $\beta$ aggregates involves SMAD signaling and down-regulation of CCL5. J. Neuroinflammation 7:28. doi: 10.1186/1742-2094-7-28

Idevall-Hagren, O., and De Camilli, P. (2015). Detection and manipulation of phosphoinositides. Biochim. Biophys. Acta 1851, 736-745. doi: 10.1016/j.bbalip. 2014.12.008

Ial, K., and Grundke-Ial, I. (2005). Metabolic/signal transduction hypothesis of Alzheimer's disease and other tauopathies. Acta Neuropathol. 109, 25-31. doi: 10.1007/s00401-004-0951-y

Irino, Y., Nakamura, Y., Inoue, K., Kohsaka, S., and Ohsawa, K. (2008). AKT activation is involved in $\mathrm{P} 2 \mathrm{Y} 12$ receptor-mediated chemotaxis of microglia. J. Neurosci. Res. 86, 1511-1519. doi: 10.1002/jnr.21610

Jacobsen, R. G., Mazloumi Gavgani, F., Edson, A. J., Goris, M., Altankhuyag, A., and Lewis, A. E. (2019). Polyphosphoinositides in the nucleus: roadmap of their effectors and mechanisms of interaction. Adv. Biol. Regul. 72, 7-21. doi: 10.1016/j.jbior.2019.04.001

Jana, M., Palencia, C. A., and Pahan, K. (2008). Fibrillar amyloid- $\beta$ peptides activate microglia via TLR2: implications for Alzheimer's disease. J. Immunol. 181, 7254-7262. doi: 10.4049/jimmunol.181.10.7254

Jaumouillé, V., and Grinstein, S. (2011). Receptor mobility, the cytoskeleton, and particle binding during phagocytosis. Curr. Opin. Cell Biol. 23, 22-29. doi: $10.1016 /$ j.ceb.2010.10.006

Jing, H., Zhu, J.-X., Wang, H.-F., Zhang, W., Zheng, Z.-J., Kong, L.-L., et al. (2016). Inpp5d Rs35349669 polymorphism with late-onset Alzheimer's disease: a replication study and meta-analysis. Oncotarget 7, 69225-69230. doi: 10.18632/oncotarget.12648

Jou, I., Lee, J. H., Park, S. Y., Yoon, H. J., Joe, E. H., and Park, E. J. (2006). Gangliosides trigger inflammatory responses via TLR4 in brain glia. Am. J. Pathol. 168, 1619-1630. doi: 10.2353/ajpath.2006.050924

Kagan, J. C., and Medzhitov, R. (2006). Phosphoinositide-mediated adaptor recruitment controls toll-like receptor signaling. Cell 125, 943-955. doi: 10.1016/j.cell.2006.03.047

Kagan, J. C., Su, T., Horng, T., Chow, A., Akira, S., and Medzhitov, R. (2008). Tram couples endocytosis of toll-like receptor 4 to the induction of interferon- $\beta$. Nat. Immunol. 9, 361-368. doi: 10.1038/ni1569

Kalaria, R. N., Cohen, D. L., Premkumar, D. R., Nag, S., Lamanna, J. C., and Lust, W. D. (1998). Vascular endothelial growth factor in Alzheimer's disease and experimental cerebral Ischemia. Brain Res. Mol. Brain Res. 62, 101-105. doi: 10.1016/s0169-328x(98)00190-9
Kamen, L. A., Levinsohn, J., and Swanson, J. A. (2007). Differential association of phosphatidylinositol 3-kinase, SHIP-1, and PTEN with forming phagosomes. Mol. Biol. Cell 18, 2463-2472. doi: 10.1091/mbc.e07-01-0061

Kaminska, J., Rzepnikowska, W., Polak, A., Flis, K., Soczewka, P., Bala, K., et al. (2016). Phosphatidylinositol-3-phosphate regulates response of cells to proteotoxic stress. Int. J. Biochem. Cell Biol. 79, 494-504. doi: 10.1016/j.biocel. 2016.08.007

Kang, J., and Rivest, S. (2007). MyD88-deficient bone marrow cells accelerate onset and reduce survival in a mouse model of amyotrophic lateral sclerosis. J. Cell Biol. 179, 1219-1230. doi: 10.1083/jcb.200705046

Katan, M., and Cockcroft, S. (2020). Phosphatidylinositol(4,5)bisphosphate: diverse functions at the plasma membrane. Essays Biochem. 64, 513-531. doi: 10.1042/EBC20200041

Kawai, T., and Akira, S. (2010). The role of pattern-recognition receptors in innate immunity: update on toll-like receptors. Nat. Immunol. 11, 373-384. doi: $10.1038 /$ ni. 1863

Kegel, K. B., Sapp, E., Alexander, J., Valencia, A., Reeves, P., Li, X., et al. (2009). Polyglutamine expansion in huntingtin alters its interaction with phospholipids. J. Neurochem. 110, 1585-1597. doi: 10.1111/j.1471-4159.2009. 06255.x

Kegel, K. B., Sapp, E., Yoder, J., Cuiffo, B., Sobin, L., Kim, Y. J., et al. (2005). Huntingtin associates with acidic phospholipids at the plasma membrane. J. Biol. Chem. 280, 36464-36473. doi: 10.1074/jbc.M5036 72200

Khoja, S., Shah, V., Garcia, D., Asatryan, L., Jakowec, M. W., and Davies, D. L. (2016). Role of purinergic P2x4 receptors in regulating striatal dopamine homeostasis and dependent behaviors. J. Neurochem. 139, 134-148. doi: $10.1111 /$ jnc. 13734

Khuong, T. M., Habets, R. L., Kuenen, S., Witkowska, A., Kasprowicz, J., Swerts, J., et al. (2013). Synaptic PI $(3,4,5) \mathrm{P} 3$ is required for syntaxinla clustering and neurotransmitter release. Neuron 77, 1097-1108. doi: 10.1016/j.neuron.2013. 01.025

Kierdorf, K., and Prinz, M. (2013). Factors regulating microglia activation. Front. Cell. Neurosci. 7:44. doi: 10.3389/fncel.2013.00044

Kim, B., Jeong, H. K., Kim, J. H., Lee, S. Y., Jou, I., and Joe, E. H. (2011). Uridine 5'-diphosphate induces chemokine expression in microglia and astrocytes through activation of the P2Y6 receptor. J. Immunol. 186, 3701-3709. doi: 10.4049/jimmunol.1000212

Kim, M., Jiang, L. H., Wilson, H. L., North, R. A., and Surprenant, A. (2001). Proteomic and functional evidence for a $\mathrm{P} 2 \mathrm{X} 7$ receptor signaling complex. EMBO J. 20, 6347-6358. doi: 10.1093/emboj/20.22.6347

Kim, S.-M., Mun, B.-R., Lee, S.-J., Joh, Y., Lee, H.-Y., Ji, K.-Y., et al. (2017). Trem 2 promotes $A \beta$ phagocytosis by upregulating C/EBP $\beta$-dependent CD36 expression in microglia. Sci. Rep. 7:11118. doi: 10.1038/s41598-01711634-X

Kim, A. Y., Tang, Z., Liu, Q., Patel, K. N., Maag, D., Geng, Y., et al. (2008). Pirt, A phosphoinositide-binding protein, functions as a regulatory subunit of TRPV1. Cell 133, 475-485. doi: 10.1016/j.cell.2008.02.053

Kiyota, T., Gendelman, H. E., Weir, R. A., Higgins, E. E., Zhang, G., and Jain, M. (2013). CCL2 affects $\beta$-amyloidosis and progressive neurocognitive dysfunction in a mouse model of Alzheimer's disease. Neurobiol. Aging 34, 1060-1068. doi: 10.1016/j.neurobiolaging.2012.08.009

Kiyota, T., Yamamoto, M., Xiong, H., Lambert, M. P., Klein, W. L., Gendelman, H. E., et al. (2009). CCL2 accelerates microglia-mediated a $\beta$ oligomer formation and progression of neurocognitive dysfunction. PLoS One 4:E6197. doi: 10.1371/journal.pone.0006197

Kleinberger, G., Yamanishi, Y., Suárez-Calvet, M., Czirr, E., Lohmann, E., Cuyvers, E., et al. (2014). TREM2 mutations implicated in neurodegeneration impair cell surface transport and phagocytosis. Sci. Transl. Med. 6:243ra86. doi: 10.1126/scitranslmed.3009093

Kobrinsky, E., Mirshahi, T., Zhang, H., Jin, T., and Logothetis, D. E. (2000). Receptor-mediated hydrolysis of plasma membrane messenger PIP2 leads to K+-current desensitization. Nat. Cell Biol. 2, 507-514. doi: 10.1038/350 19544

Koenigsknecht-Talboo, J., and Landreth, G. E. (2005). Microglial phagocytosis induced by fibrillar $\beta$-amyloid and IgGs are differentially regulated by proinflammatory cytokines. J. Neurosci. 25, 8240-8249. doi: 10.1523/JNEUROSCI.1808-05.2005 
Koizumi, S., Shigemoto-Mogami, Y., Nasu-Tada, K., Shinozaki, Y., Ohsawa, K., Tsuda, M., et al. (2007). Udp acting at P2Y6 receptors is a mediator of microglial phagocytosis. Nature 446, 1091-1095. doi: 10.1038/nature05704

Komine, O., Yamashita, H., Fujimori-Tonou, N., Koike, M., Jin, S., Moriwaki, Y., et al. (2018). Innate immune adaptor TRIF deficiency accelerates disease progression of ALS mice with accumulation of aberrantly activated astrocytes. Cell Death Differ. 25, 2130-2146. doi: 10.1038/s41418-018 -0098-3

Kouli, A., Horne, C. B., and Williams-Gray, C. H. (2019). Toll-like receptors and their therapeutic potential in Parkinson's disease and $\alpha$-synucleinopathies. Brain Behav. Immun. 81, 41-51. doi: 10.1016/j.bbi.2019.06.042

Kutateladze, T. G. (2010). Translation of the phosphoinositide code by PI effectors. Nat. Chem. Biol. 6, 507-513. doi: 10.1038/nchembio.390

Kwan, W., Träger, U., Davalos, D., Chou, A., Bouchard, J., Andre, R., et al. (2012). Mutant huntingtin impairs immune cell migration in Huntington disease. J. Clin. Invest. 122, 4737-4747. doi: 10.1172/JCI64484

Lambert, J. C., Ibrahim-Verbaas, C. A., Harold, D., Naj, A. C., Sims, R., Bellenguez, C., et al. (2013). Meta-analysis of 74,046 individuals identifies 11 new susceptibility loci for Alzheimer's disease. Nat. Genet. 45, 1452-1458. doi: 10.1038/ng.2802

Lambrechts, A., Van Troys, M., and Ampe, C. (2004). The actin cytoskeleton in normal and pathological cell motility. Int. J. Biochem. Cell Biol. 36, 1890-1909. doi: 10.1016/j.biocel.2004.01.024

Lane, E. L. (2019). L-DOPA for Parkinson's disease-a bittersweet pill. Eur. J. Neurosci. 49, 384-398. doi: 10.1111/ejn.14119

Lane, C. A., Hardy, J., and Schott, J. M. (2018). Alzheimer's disease. Eur. J. Neurol. 25, 59-70. doi: 10.1111/ene.13439

Lauffenburger, D. A., and Horwitz, A. F. (1996). Cell migration: a physically integrated molecular process. Cell 84, 359-369. doi: 10.1016/s00928674(00)81280-5

Le, O. T., Nguyen, T. T., and Lee, S. Y. (2014). Phosphoinositide turnover in toll-like receptor signaling and trafficking. BMB Rep. 47, 361-368. doi: 10.5483/bmbrep.2014.47.7.088

Le Roy, C., and Wrana, J. L. (2005). Clathrin- and non-clathrin-mediated endocytic regulation of cell signaling. Nat. Rev. Mol. Cell Biol. 6, 112-126. doi: $10.1038 / \mathrm{nrm} 1571$

Lecours, C., Bordeleau, M., Cantin, L., Parent, M., Paolo, T. D., and Tremblay, M. (2018). Microglial implication in Parkinson's disease: loss of beneficial physiological roles or gain of inflammatory functions? Front. Cell. Neurosci. 12:282. doi: $10.3389 /$ fncel.2018.00282

Lee, E., and Chung, W.-S. (2019). Glial control of synapse number in healthy and diseased brain. Front. Cell. Neurosci. 13:42. doi: 10.3389/fncel.2019.00042

Lee, C. Y., and Landreth, G. E. (2010). The role of microglia in amyloid clearance from the AD brain. J. Neural Transm. 117, 949-960. doi: 10.1007/s00702-0100433-4

Lee, J. Y., Lee, J. D., Phipps, S., Noakes, P. G., and Woodruff, T. M. (2015). Absence of toll-like receptor 4 (Tlr4) extends survival in the hSOD1 G93A mouse model of amyotrophic lateral sclerosis. J. Neuroinflammation 12:90. doi: 10.1186/s12974-015-0310-Z

Lee, S. Y., Kim, B., Jeong, H.-K., Min, K.-J., Liu, T., Park, J.-Y., et al. (2010a). Enhanced phosphatidylinositol 4-phosphate 5-kinase $\alpha$ expression and PI(4,5)P2 production in LPS-stimulated microglia. Neurochem. Int. 57, 600-607. doi: 10.1016/j.neuint.2010.07.008

Lee, S. Y., Kim, B., Yoon, S., Kim, Y. J., Liu, T., Woo, J. H., et al. (2010b). Phosphatidylinositol 4-phosphate 5-kinase $\alpha$ is induced in gangliosidestimulated brain astrocytes and contributes to inflammatory responses. Exp. Mol. Med. 42, 662-673. doi: 10.3858/emm.2010.42.9.066

Lee, Y. B., Nagai, A., and Kim, S. U. (2002). Cytokines, chemokines, and cytokine receptors in human microglia. J. Neurosci. Res. 69, 94-103. doi: 10.1002/jnr. 10253

Lehnardt, S., Lachance, C., Patrizi, S., Lefebvre, S., Follett, P. L., Jensen, F. E., et al. (2002). The toll-like receptor TLR4 is necessary for lipopolysaccharideinduced oligodendrocyte injury in the CNS. J. Neurosci. 22, 2478-2486. doi: 10.1523/JNEUROSCI.22-07-02478.2002

Letiembre, M., Liu, Y., Walter, S., Hao, W., Pfander, T., Wrede, A., et al. (2009). Screening of innate immune receptors in neurodegenerative diseases: a similar pattern. Neurobiol. Aging 30, 759-768. doi: 10.1016/j.neurobiolaging.2007. 08.018
Levin, R., Hammond, G. R., Balla, T., De Camilli, P., Fairn, G. D., and Grinstein, S. (2017). Multiphasic dynamics of phosphatidylinositol 4-phosphate during phagocytosis. Mol. Biol. Cell 28, 128-140. doi: 10.1091/mbc.E16-06-0451

Li, Y., Du, X.-F., Liu, C.-S., Wen, Z.-L., and Du, J.-L. (2012). Reciprocal regulation between resting microglial dynamics and neuronal activity in vivo. Dev. Cell 23, 1189-1202. doi: 10.1016/j.devcel.2012.10.027

Li, T., Qin, K., Li, N., Han, C., and Cao, X. (2019). An endosomal lapf is required for macrophage endocytosis and elimination of bacteria. Proc. Natl. Acad. Sci. U S A 116, 12958-12963. doi: 10.1073/pnas.1903896116

Li, N., Wu, J.-X., Ding, D., Cheng, J., Gao, N., and Chen, L. (2017). Structure of a pancreatic ATP-sensitive potassium channel. Cell 168, 101.e10-110.e10. doi: 10.1016/j.cell.2016.12.028

Liang, K. J., Lee, J. E., Wang, Y. D., Ma, W., Fontainhas, A. M., Fariss, R. N., et al. (2009). Regulation of dynamic behavior of retinal microglia by CX3CR1 signaling. Invest. Ophthalmol. Vis. Sci. 50, 4444-4451. doi: 10.1167 /iovs.08-3357

Liepina, I., Czaplewski, C., Janmey, P., and Liwo, A. (2003). Molecular dynamics study of a gelsolin-derived peptide binding to a lipid bilayer containing phosphatidylinositol 4,5-bisphosphate. Biopolymers 71, 49-70. doi: 10.1002/bip.10375

Lim, H. M., Woon, H., Han, J. W., Baba, Y., Kurosaki, T., Lee, M. G., et al. (2017). UDP-induced phagocytosis and ATP-stimulated chemotactic migration are impaired in STIM1 $1^{-/-}$microglia in vitro and in vivo. Mediators Inflamm. 2017:8158514. doi: 10.1155/2017/8158514

Liu, J., and Li, L. (2019). Targeting autophagy for the treatment of Alzheimer's disease: challenges and opportunities. Front. Mol. Neurosci. 12:203. doi: 10.3389/fnmol.2019.00203

Liu, Y., Walter, S., Stagi, M., Cherny, D., Letiembre, M., Schulz-Schaeffer, W., et al. (2005). LPS receptor (Cd14): a receptor for phagocytosis of Alzheimer's amyloid peptide. Brain 128, 1778-1789. doi: 10.1093/brain/awh531

Liu, P.-W., Yue, M.-X., Zhou, R., Niu, J., Huang, D.-J., Xu, T., et al. (2017). $\mathrm{P}_{2} \mathrm{Y}_{12}$ and $\mathrm{P}_{2} \mathrm{Y}_{13}$ receptors involved in $\mathrm{ADP} \beta$ s induced the release of Il-1 $\beta$, Il-6 and Tnf- $\alpha$ from cultured dorsal horn microglia. J. Pain Res. 10, 1755-1767. doi: 10.2147/JPR.S137131

Liu, J., Zhou, Y., Wang, Y., Fong, H., Murray, T. M., and Zhang, J. (2007). Identification of proteins involved in microglial endocytosis of $\alpha$-synuclein. J. Proteome Res. 6, 3614-3627. doi: 10.1021/pr0701512

Lo Vasco, V. R. (2018). The phosphoinositide signal transduction pathway in the pathogenesis of Alzheimer's disease. Curr. Alzheimer Res. 15, 355-362. doi: 10.2174/1567205014666170829100230

Long, H., Zhong, G., Wang, C., Zhang, J., Zhang, Y., Luo, J., et al. (2019). Trem 2 attenuates A $\beta 1-42$-mediated neuroinflammation in BV-2 cells by downregulating TLR signaling. Neurochem. Res. 44, 1830-1839. doi: 10.1007/s11064-019-02817-1

MacDonald, M. E., Ambrose, C. M., Duyao, M. P., Myers, R. H., Lin, C., Srinidhi, L., et al. (1993). A novel gene containing a trinucleotide repeat that is expanded and unstable on Huntington's disease chromosomes. Cell 72, 971-983. doi: 10.1016/0092-8674(93)90585-e

Madry, C., Kyrargyri, V., Arancibia-Cárcamo, I. L., Jolivet, R., Kohsaka, S., Bryan, R. M., et al. (2018). Microglial ramification, surveillance, and interleukin-1 $\beta$ release are regulated by the two-pore domain $\mathrm{K}^{+}$channel THIK-1. Neuron 97, 299.e6-312.e6. doi: 10.1016/j.neuron.2017.12.002

Maekawa, M., Terasaka, S., Mochizuki, Y., Kawai, K., Ikeda, Y., Araki, N., et al. (2014). Sequential breakdown of 3-phosphorylated phosphoinositides is essential for the completion of macropinocytosis. Proc. Natl. Acad. Sci. U S A 111, E978-E987. doi: 10.1073/pnas.1311029111

Magno, L., Lessard, C. B., Martins, M., Lang, V., Cruz, P., Asi, Y., et al. (2019). Alzheimer's disease phospholipase C- $\gamma$-2 (PLCG2) protective variant is a functional hypermorph. Alzheimers Res. Ther. 11:16. doi: 10.1186/s13195-0190469-0

Marshall, J. G., Booth, J. W., Stambolic, V., Mak, T., Balla, T., Schreiber, A. D., et al. (2001). Restricted accumulation of phosphatidylinositol 3-kinase products in a plasmalemmal subdomain during Fc $\gamma$ receptor-mediated phagocytosis. J. Cell Biol. 153, 1369-1380. doi: 10.1083/jcb.153.7.1369

Martel, V., Racaud-Sultan, C., Dupe, S., Marie, C., Paulhe, F., Galmiche, A., et al. (2001). Conformation, localization, and integrin binding of talin depend on its interaction with phosphoinositides. J. Biol. Chem. 276, 21217-21227. doi: 10.1074/jbc.M102373200 
Masrori, P., and Van Damme, P. (2020). Amyotrophic lateral sclerosis: a clinical review. Eur. J. Neurol. 27, 1918-1929. doi: 10.1111/ene.14393

May, R. C., and Machesky, L. M. (2001). Phagocytosis and the actin cytoskeleton. J. Cell Sci. 114, 1061-1077.

Mazaheri, F., Snaidero, N., Kleinberger, G., Madore, C., Daria, A., Werner, G., et al. (2017). TREM2 deficiency impairs chemotaxis and microglial responses to neuronal injury. EMBO Rep. 18, 1186-1198. doi: 10.15252/embr.201743922

McCartney, A. J., Zolov, S. N., Kauffman, E. J., Zhang, Y., Strunk, B. S., Weisman, L. S., et al. (2014). Activity-dependent PI(3,5)P2 synthesis controls AMPA receptor trafficking during synaptic depression. Proc. Natl. Acad. Sci. U $S$ A 111, E4896-E4905. doi: 10.1073/pnas.1411117111

McColgan, P., and Tabrizi, S. J. (2018). Huntington's disease: a clinical review. Eur. J. Neurol. 25, 24-34. doi: 10.1111/ene.13413

McGeer, P. L., Itagaki, S., Boyes, B. E., and Mcgeer, E. G. (1988). Reactive microglia are positive for HLA-DR in the substantia nigra of Parkinson's and Alzheimer's disease brains. Neurology 38, 1285-1291. doi: 10.1212/wnl.38.8.1285

McIntire, L. B., Berman, D. E., Myaeng, J., Staniszewski, A., Arancio, O., Di Paolo, G., et al. (2012). Reduction of synaptojanin 1 ameliorates synaptic and behavioral impairments in a mouse model of Alzheimer's disease. J. Neurosci. 32, 15271-15276. doi: 10.1523/JNEUROSCI.2034-12.2012

McLarnon, J. G., Ryu, J. K., Walker, D. G., and Choi, H. B. (2006). Upregulated expression of purinergic $\mathrm{P} 2 \mathrm{x}(7)$ receptor in Alzheimer disease and amyloid- $\beta$ peptide-treated microglia and in peptide-injected rat hippocampus. J. Neuropathol. Exp. Neurol. 65, 1090-1097. doi: 10.1097/01.jnen.0000240470. 97295.d3

McQuade, A., and Blurton-Jones, M. (2019). Microglia in Alzheimer's disease: exploring how genetics and phenotype influence risk. J. Mol. Biol. 431, 1805-1817. doi: 10.1016/j.jmb.2019.01.045

Melchjorsen, J., and Paludan, S. R. (2003). Induction of RANTES/CCL5 by herpes simplex virus is regulated by nuclear factor $\mathrm{\kappa} B$ and interferon regulatory factor 3. J. Gen. Virol. 84, 2491-2495. doi: 10.1099/vir.0.19159-0

Mettlen, M., Chen, P.-H., Srinivasan, S., Danuser, G., and Schmid, S. L. (2018). Regulation of clathrin-mediated endocytosis. Annu. Rev. Biochem. 87, 871-896. doi: 10.1146/annurev-biochem-062917-012644

Miki, H., Miura, K., and Takenawa, T. (1996). N-WASP, A novel actindepolymerizing protein, regulates the cortical cytoskeletal rearrangement in a PIP2-dependent manner downstream of tyrosine kinases. EMBO J. 15, 5326-5335. doi: 10.1002/j.1460-2075.1996.tb00917.x

Mildner, A., Huang, H., Radke, J., Stenzel, W., and Priller, J. (2017). P2Y 12 receptor is expressed on human microglia under physiological conditions throughout development and is sensitive to neuroinflammatory diseases. Glia 65, 375-387. doi: 10.1002/glia.23097

Miller, J. R., Lo, K. K., Andre, R., Hensman Moss, D. J., Träger, U., Stone, T. C., et al. (2016). RNA-Seq Of Huntington's disease patient myeloid cells reveals innate transcriptional dysregulation associated with proinflammatory pathway activation. Hum. Mol. Genet. 25, 2893-2904. doi: 10.1093/hmg/ddw142

Minoretti, P., Gazzaruso, C., Vito, C. D., Emanuele, E., Bianchi, M., Coen, E., et al. (2006). Effect of the functional toll-like receptor 4 Asp299Gly polymorphism on susceptibility to late-onset Alzheimer's disease. Neurosci. Lett. 391, 147-149. doi: 10.1016/j.neulet.2005.08.047

Miranda, A. M., Herman, M., Cheng, R., Nahmani, E., Barrett, G., Micevska, E., et al. (2018). Excess synaptojanin 1 contributes to place cell dysfunction and memory deficits in the aging hippocampus in three types of Alzheimer's disease. Cell Rep 23, 2967-2975. doi: 10.1016/j.celrep.2018.05.011

Monif, M., Reid, C. A., Powell, K. L., Drummond, K. J., O’Brien, T. J., and Williams, D. A. (2016). Interleukin- $1 \beta$ has trophic effects in microglia and its release is mediated by P2X7R pore. J. Neuroinflammation 13:173. doi: 10.1186/s12974-016-0621-8

Moraes, L., Zanchin, N. I. T., and Cerutti, J. M. (2017). ABI3, a component of the WAVE2 complex, is potentially regulated by PI3K/AKT pathway. Oncotarget 8, 67769-67781. doi: 10.18632/oncotarget.18840

Morioka, N., Tokuhara, M., Harano, S., Nakamura, Y., Hisaoka-Nakashima, K., and Nakata, Y. (2013). The activation of P2Y6 receptor in cultured spinal microglia induces the production of CCL2 through the MAP kinases-NF- $\mathrm{KB}$ pathway. Neuropharmacology 75, 116-125. doi: 10.1016/j.neuropharm.2013. 07.017

Mostowy, S., and Cossart, P. (2012). Septins: the fourth component of the cytoskeleton. Nat. Rev. Mol. Cell Biol. 13, 183-194. doi: 10.1038/nrm3284
Munoz, F. M., Gao, R., Tian, Y., Henstenburg, B. A., Barrett, J. E., and $\mathrm{Hu}, \mathrm{H}$. (2017). Neuronal p2x7 receptor-induced reactive oxygen species production contributes to nociceptive behavior in mice. Sci. Rep. 7:3539. doi: 10.1038/s41598-017-03813-7

Naba, A., Reverdy, C., Louvard, D., and Arpin, M. (2008). Spatial recruitment and activation of the Fes kinase by ezrin promotes HGF-induced cell scattering. EMBO J. 27, 38-50. doi: 10.1038/sj.emboj.7601943

Nagatsu, T., Mogi, M., Ichinose, H., and Togari, A. (2000). Cytokines in Parkinson's disease. J. Neural Transm. Suppl. 58, 143-151. doi: 10.1007/9783-7091-6284-2_12

Nagatsu, T., and Sawada, M. (2005). Inflammatory process in Parkinson's disease: role for cytokines. Curr. Pharm. Des. 11, 999-1016. doi: $10.2174 / 1381612053381620$

Narayanan, V., Guo, Y., and Scarlata, S. (2005). Fluorescence studies suggest a role for $\alpha$-synuclein in the phosphatidylinositol lipid signaling pathway. Biochemistry 44, 462-470. doi: 10.1021/bi0487140

Neary, J. T., Baker, L., Jorgensen, S. L., and Norenberg, M. D. (1994). Extracellular ATP induces stellation and increases glial fibrillary acidic protein content and DNA synthesis in primary astrocyte cultures. Acta Neuropathol. 87, 8-13. doi: $10.1007 / \mathrm{BF} 00386249$

Neher, J. J., Neniskyte, U., Hornik, T., and Brown, G. C. (2014). Inhibition Of UDP/P2Y6 purinergic signaling prevents phagocytosis of viable neurons by activated microglia in vitro and in vivo. Glia 62, 1463-1475. doi: 10.1002/glia. 22693

Nguyen, T. T., Kim, Y. M., Kim, T. D., Le, O. T., Kim, J. J., Kang, H. C., et al. (2013). Phosphatidylinositol 4-phosphate 5-kinase $\alpha$ facilitates toll-like receptor 4-mediated microglial inflammation through regulation of the toll/interleukin1 receptor domain-containing adaptor protein (TIRAP) location. J. Biol. Chem 288, 5645-5659. doi: 10.1074/jbc.M112.410126

Nguyen, D. K. H., Thombre, R., and Wang, J. (2019). Autophagy as a common pathway in amyotrophic lateral sclerosis. Neurosci. Lett. 697, 34-48. doi: 10.1016/j.neulet.2018.04.006

Nimmerjahn, A., Kirchhoff, F., and Helmchen, F. (2005). Resting microglial cells are highly dynamic surveillants of brain parenchyma in vivo. Science 308, 1314-1318. doi: 10.1126/science.1110647

Nunes, P., Cornut, D., Bochet, V., Hasler, U., Oh-Hora, M., Waldburger, J. M. et al. (2012). STIM1 juxtaposes ER to phagosomes, generating $\mathrm{Ca}^{2+}$ hotspots that boost phagocytosis. Curr. Biol. 22, 1990-1997. doi: 10.1016/j.cub.2012. 08.049

Nunes, P., and Demaurex, N. (2010). The role of calcium signaling in phagocytosis. J. Leukoc. Biol. 88, 57-68. doi: 10.1189/jlb.0110028

O’Rourke, J. G., Bogdanik, L., Yáñez, A., Lall, D., Wolf, A. J., Muhammad, A. K., et al. (2016). C9orf72 is required for proper macrophage and microglial function in mice. Science 351, 1324-1329. doi: 10.1126/science. aaf1064

Ohsawa, K., Irino, Y., Sanagi, T., Nakamura, Y., Suzuki, E., Inoue, K., et al. (2010). P2Y12 receptor-mediated integrin- $\beta 1$ activation regulates microglial process extension induced by ATP. Glia 58, 790-801. doi: 10.1002/glia.20963

Ojala, P. J., Paavilainen, V., and Lappalainen, P. (2001). Identification of yeast cofilin residues specific for actin monomer and PIP2 binding. Biochemistry 40, 15562-15569. doi: 10.1021/bi0117697

Oliveira-Giacomelli, Á., Albno, C. A., De Souza, H. D. N., Corrêa-Velloso, J., De Jesus Santos, A. P., Baranova, J., et al. (2019). P2Y6 and P2X7 receptor antagonism exerts neuroprotective/ neuroregenerative effects in an animal model of Parkinson's disease. Front. Cell. Neurosci. 13:476. doi: 10.3389/fncel. 2019.00476

Oliveira-Giacomelli, Á., Naaldijk, Y., Sardá-Arroyo, L., Gonçalves, M. C. B., Corrêa-Velloso, J., Pillat, M. M., et al. (2018). Purinergic receptors in neurological diseases with motor symptoms: targets for therapy. Front. Pharmacol. 9:325. doi: 10.3389/fphar.2018.00325

Olson, J. K., and Miller, S. D. (2004). Microglia initiate central nervous system innate and adaptive immune responses through multiple TLRs. J. Immunol. 173, 3916-3924. doi: 10.4049/jimmunol.173.6.3916

Orr, A. G., Orr, A. L., Li, X.-J., Gross, R. E., and Traynelis, S. F. (2009). Adenosine A2A receptor mediates microglial process retraction. Nat. Neurosci. 12, 872-878. doi: $10.1038 / \mathrm{nn} .2341$

Otey, C. A., and Carpen, O. (2004). $\alpha$-actinin revisited: a fresh look at an old player. Cell Motil. 58, 104-111. doi: $10.1002 / \mathrm{cm} .20007$ 
Ouchi, Y., Yoshikawa, E., Sekine, Y., Futatsubashi, M., Kanno, T., Ogusu, T., et al. (2005). Microglial activation and dopamine terminal loss in early Parkinson's disease. Ann. Neurol. 57, 168-175. doi: 10.1002/ana.20338

Oxford, A. E., Stewart, E. S., and Rohn, T. T. (2020). Clinical trials in Alzheimer's disease: a hurdle in the path of remedy. Int. J. Alzheimers Dis. 2020:5380346. doi: $10.1155 / 2020 / 5380346$

Palamiuc, L., Ravi, A., and Emerling, B. M. (2020). Phosphoinositides in autophagy: current roles and future insights. FEBS J. 287, 222-238. doi: $10.1111 /$ febs. 15127

Palmieri, M., Nowell, C. J., Condron, M., Gardiner, J., Holmes, A. B., Desai, J., et al. (2010). Analysis of cellular phosphatidylinositol (3,4,5)-trisphosphate levels and distribution using confocal fluorescent microscopy. Anal. Biochem. 406, 41-50. doi: 10.1016/j.ab.2010.06.033

Pålsson-McDermott, E. M., and O'Neill, L. A. (2004). Signal transduction by the lipopolysaccharide receptor, toll-like receptor-4. Immunology 113, 153-162. doi: 10.1111/j.1365-2567.2004.01976.x

Pang, S. Y.-Y., Ho, P. W., Liu, H. F., Leung, C. T., Li, L., Chang, E. E. S., et al. (2019). The interplay of aging, genetics and environmental factors in the pathogenesis of Parkinson's disease. Transl. Neurodegener. 8:23. doi: 10.1186/s40035-0190165-9

Papadopoulos, T., Rhee, H. J., Subramanian, D., Paraskevopoulou, F., Mueller, R., Schultz, C., et al. (2017). Endosomal phosphatidylinositol 3-phosphate promotes gephyrin clustering and gabaergic neurotransmission at inhibitory postsynapses. J. Biol. Chem. 292, 1160-1177. doi: 10.1074/jbc.M116.771592

Parent, C. A., Blacklock, B. J., Froehlich, W. M., Murphy, D. B., and Devreotes, P. N. (1998). G protein signaling events are activated at the leading edge of chemotactic cells. Cell 95, 81-91. doi: 10.1016/s0092-8674(00) 81784-5

Park, J.-Y., Paik, S. R., Jou, I., and Park, S. M. (2008). Microglial phagocytosis is enhanced by monomeric $\alpha$-synuclein, not aggregated $\alpha$-synuclein: implications for Parkinson's disease. Glia 56, 1215-1223. doi: 10.1002/glia.20691

Parkinson, J. (2002). An essay on the shaking palsy. 1817. J. Neuropsychiatry Clin. Neurosci. 14, 223-236; Discussion 222. doi: 10.1176/jnp.14.2.223

Parton, R. G., and del Pozo, M. A. (2013). Caveolae as plasma membrane sensors, protectors and organizers. Nat. Rev. Mol. Cell Biol. 14, 98-112. doi: $10.1038 / \mathrm{nrm} 3512$

Pavese, N., Gerhard, A., Tai, Y. F., Ho, A. K., Turkheimer, F., Barker, R. A., et al. (2006). Microglial activation correlates with severity in huntington disease: a clinical and PET study. Neurology 66, 1638-1643. doi: 10.1212/01. wnl.0000222734.56412.17

Phan, T. K., Williams, S. A., Bindra, G. K., Lay, F. T., Poon, I. K. H., and Hulett, M. D. (2019). Phosphoinositides: multipurpose cellular lipids with emerging roles in cell death. Cell Death Differ. 26, 781-793. doi: 10.1038/s41418-018-0269-2

Ping, Z., Xiaomu, W., Xufang, X., and Liang, S. (2019). Vinpocetine regulates levels of circulating TLRs in Parkinson's disease Patients. Neurol. Sci. 40, 113-120. doi: 10.1007/s10072-018-3592-y

Politis, M., Su, P., and Piccini, P. (2012). Imaging of microglia in patients with neurodegenerative disorders. Front. Pharmacol. 3:96. doi: 10.3389/fphar.2012. 00096

Popat, R. A., Van Den Eeden, S. K., Tanner, C. M., Kamel, F., Umbach, D. M., Marder, K., et al. (2011). Coffee, ADORA2A, and CYP1A2: the caffeine connection in Parkinson's disease. Eur. J. Neurol. 18, 756-765. doi: 10.1111/j. 1468-1331.2011.03353.x

Pourbadie, H. G., Sayyah, M., Khoshkholgh-Sima, B., Choopani, S., Nategh, M., Motamedi, F., et al. (2018). Early minor stimulation of microglial TLR2 And TLR4 receptors attenuates Alzheimer's disease-related cognitive deficit in rats: behavioral, molecular, and electrophysiological evidence. Neurobiol. Aging 70, 203-216. doi: 10.1016/j.neurobiolaging.2018.06.020

Prince, M., Guerchet, M., and Prina, M. (2013). Alzheimer's Disease International. Policy Brief for Heads of Government: The Global Impact of Dementia 2013-2050, London: Alzheimer's Disease International.

Puchaowicz, K., Tarnowski, M., Baranowska-Bosiacka, I., Chlubek, D., and Dziedziejko, V. (2014). P2X and P2Y receptors-role in the pathophysiology of the nervous system. Int. J. Mol. Sci. 15, 23672-23704. doi: 10.3390/ijms 151223672

Qi, Y., Cheng, X., Jing, H., Yan, T., Xiao, F., Wu, B., et al. (2019). Combination of schisandrin and nootkatone exerts neuroprotective effect in Alzheimer's disease mice model. Metab. Brain Dis. 34, 1689-1703. doi: 10.1007/s11011-01900475-4

Quintas, C., Pinho, D., Pereira, C., Saraiva, L., Goncalves, J., and Queiroz, G. (2014). Microglia $\mathrm{P}_{2} \mathrm{Y}_{6}$ receptors mediate nitric oxide release and astrocyte apoptosis. J. Neuroinflammation 11:141. doi: 10.1186/s12974-014-0141-3

Quintas, C., Vale, N., Gonçalves, J., and Queiroz, G. (2018). Microglia P2Y 13 receptors prevent astrocyte proliferation mediated by $\mathrm{P}_{1} \mathrm{Y}_{1}$ receptors. Front. Pharmacol. 9:418. doi: 10.3389/fphar.2018.00418

Raghu, P., Joseph, A., Krishnan, H., Singh, P., and Saha, S. (2019). Phosphoinositides: regulators of nervous system function in health and disease. Front. Mol. Neurosci. 12:208. doi: 10.3389/fnmol.2019.00208

Rai, S. N., Dilnashin, H., Birla, H., Singh, S. S., Zahra, W., Rathore, A. S., et al. (2019). The role of PI3K/Akt and ERK in neurodegenerative disorders. Neurotox. Res. 35, 775-795. doi: 10.1007/s12640-019-0003-y

Rangasamy, S. B., Jana, M., Roy, A., Corbett, G. T., Kundu, M., Chandra, S., et al. (2018). Selective disruption of TLR2-MyD88 interaction inhibits inflammation and attenuates Alzheimer's pathology. J. Clin. Invest. 128, 4297-4312. doi: 10.1172/JCI96209

Rech, J. C., Bhattacharya, A., Letavic, M. A., and Savall, B. M. (2016). The evolution of P2X7 antagonists with a focus on CNS indications. Bioorg. Med. Chem. Lett. 26, 3838-3845. doi: 10.1016/j.bmcl.2016.06.048

Renton, A. E., Majounie, E., Waite, A., Simón-Sánchez, J., Rollinson, S., Gibbs, J. R., et al. (2011). A hexanucleotide repeat expansion in C9ORF72 is the cause of chromosome 9p21-linked ALS-FTD. Neuron 72, 257-268. doi: 10.1016/j.neuron.2011.09.010

Richard, K. L., Filali, M., Prefontaine, P., and Rivest, S. (2008). Toll-like receptor 2 acts as a natural innate immune receptor to clear amyloid $\beta$ 1-42 and delay the cognitive decline in a mouse model of Alzheimer's disease. J. Neurosci. 28, 5784-5793. doi: 10.1523/JNEUROSCI.1146-08.2008

Rickert, P., Weiner, O. D., Wang, F., Bourne, H. R., and Servant, G. (2000). Leukocytes navigate by compass: roles of PI3K $\gamma$ and its lipid products. Trends Cell Biol. 10, 466-473. doi: 10.1016/s0962-8924(00)01841-9

Rietdijk, C., van Wezel, R., Garssen, J., and Kranveld, A. (2016). Neuronal tolllike receptors and neuro-immunity in Parkinson's disease, Alzheimer's disease and stroke. Neuroimmunol. Neuroinflammation 3, 27-37. doi: 10.20517/23478659.2015.28

Rodriguez, M. J., Martinez-Moreno, M., Ortega, F. J., and Mahy, N. (2013). Targeting microglial K(ATP) channels to treat neurodegenerative diseases: a mitochondrial issue. Oxid. Med. Cell. Longev. 2013:194546. doi: 10.1155/2013/194546

Rohatgi, R., Ho, H.-Y. H., and Kirschner, M. W. (2000). Mechanism of N-WASP activation by Cdc42 and phosphatidylinositol 4,5-bisphosphate. J. Cell Biol. 150, 1299-1310. doi: 10.1083/jcb.150.6.1299

Runnels, L. W., Yue, L., and Clapham, D. E. (2002). The TRPM7 channel is inactivated by PIP(2) hydrolysis. Nat. Cell Biol. 4, 329-336. doi: 10.1038/ ncb781

Saarikangas, J., Zhao, H., and Lappalainen, P. (2010). Regulation of the actin cytoskeleton-plasma membrane interplay by phosphoinositides. Physiol. Rev. 90, 259-289. doi: 10.1152/physrev.00036.2009

Sapp, E., Kegel, K. B., Aronin, N., Hashikawa, T., Uchiyama, Y., Tohyama, K., et al. (2001). Early and progressive accumulation of reactive microglia in the huntington disease brain. J. Neuropathol. Exp. Neurol. 60, 161-172. doi: 10.1093/jnen/60.2.161

Schafer, S. L., Lin, R., Moore, P. A., Hiscott, J., and Pitha, P. M. (1998). Regulation of type I interferon gene expression by interferon regulatory factor-3. J. Biol. Chem. 273, 2714-2720. doi: 10.1074/jbc.273.5.2714

Schappe, M. S., Szteyn, K., Stremska, M. E., Mendu, S. K., Downs, T. K., Seegren, P. V., et al. (2018). Chanzyme TRPm7 mediates the $\mathrm{Ca}(2+)$ influx essential for lipopolysaccharide-induced toll-like receptor 4 endocytosis and macrophage activation. Immunity 48, 59.e5-74.e5. doi: 10.1016/j.immuni.2017. 11.026

Schlam, D., Bagshaw, R. D., Freeman, S. A., Collins, R. F., Pawson, T., Fairn, G. D., et al. (2015). Phosphoinositide 3-kinase enables phagocytosis of large particles by terminating actin assembly through Rac/Cdc42 GTPase-activating proteins. Nat. Commun. 6:8623. doi: 10.1038/ncomms9623

Schlam, D., Bohdanowicz, M., Chatgilialoglu, A., Steinberg, B. E., Ueyama, T., Du, G., et al. (2013). Diacylglycerol kinases terminate diacylglycerol signaling during the respiratory burst leading to heterogeneous phagosomal nadph 
oxidase activation. J. Biol. Chem. 288, 23090-23104. doi: 10.1074/jbc.M113. 457606

Scott, C. C., Dobson, W., Botelho, R. J., Coady-Osberg, N., Chavrier, P., Knecht, D. A., et al. (2005). Phosphatidylinositol-4,5-bisphosphate hydrolysis directs actin remodeling during phagocytosis. J. Cell Biol. 169, 139-149. doi: $10.1083 /$ jcb. 200412162

Sebastião, A. M., Rei, N., and Ribeiro, J. A. (2018). Amyotrophic lateral sclerosis (ALS) and adenosine receptors. Front. Pharmacol. 9:267. doi: 10.3389/fphar. 2018.00267

Seeland, S., Kettiger, H., Murphy, M., Treiber, A., Giller, J., Kiss, A., et al. (2015). Atp-induced cellular stress and mitochondrial toxicity in cells expressing purinergic P2X7 receptor. Pharmacol. Res. Perspect. 3:e00123.doi: 10.1002/prp2.123

Sekar, S., and Taghibiglou, C. (2018). Elevated nuclear phosphatase and tensin homolog (PTEN) and altered insulin signaling in substantia nigral region of patients with Parkinson's disease. Neurosci. Lett. 666, 139-143. doi: 10.1016/j. neulet.2017.12.049

Shaw, A. C., Panda, A., Joshi, S. R., Qian, F., Allore, H. G., and Montgomery, R. R. (2011). Dysregulation of human toll-like receptor function in aging. Ageing Res. Rev. 10, 346-353. doi: 10.1016/j.arr.2010.10.007

Shieh, C.-H., Heinrich, A., Serchov, T., Van Calker, D., and Biber, K. (2014). P2X7-dependent, but differentially regulated release of IL-6, Ccl2, and TNF- $\alpha$ in cultured mouse microglia. Glia 62, 592-607. doi: 10.1002/glia.22628

Siddiqui, T. A., Lively, S., Vincent, C., and Schlichter, L. C. (2012). Regulation of podosome formation, microglial migration and invasion by $\mathrm{Ca}(2+)$ signaling molecules expressed in podosomes. J. Neuroinflammation 9:250. doi: 10.1186/1742-2094-9-250

Simard, A. R., Soulet, D., Gowing, G., Julien, J. P., and Rivest, S. (2006). Bone marrow-derived microglia play a critical role in restricting senile plaque formation in Alzheimer's disease. Neuron 49, 489-502. doi: 10.1016/j.neuron. 2006.01.022

Sims, R., Hill, M., and Williams, J. (2020). The multiplex model of the genetics of Alzheimer's disease. Nat. Neurosci. 23, 311-322. doi: 10.1038/s41593-0200599-5

Sims, R., Van Der Lee, S. J., Naj, A. C., Bellenguez, C., Badarinarayan, N., Jakobsdottir, J., et al. (2017). Rare coding variants in PLCG2, ABI3, and Trem2 implicate microglial-mediated innate immunity in Alzheimer's disease. Nat. Genet. 49, 1373-1384. doi: 10.1038/ng.3916

Sipe, G. O., Lowery, R. L., Tremblay, M., Kelly, E. A., Lamantia, C. E., and Majewska, A. K. (2016). Microglial P2Y12 is necessary for synaptic plasticity in mouse visual cortex. Nat. Commun. 7:10905. doi: 10.1038/ncomms10905

Smolders, S. M.-T., Kessels, S., Vangansewinkel, T., Rigo, J.-M., Legendre, P., and Brône, B. (2019). Microglia: brain cells on the move. Prog. Neurobiol. 178:101612. doi: 10.1016/j.pneurobio.2019.04.001

Solé-Domènech, S., Cruz, D. L., Capetillo-Zarate, E., and Maxfield, F. R. (2016). The endocytic pathway in microglia during health, aging, and Alzheimer's disease. Ageing Res. Rev. 32, 89-103. doi: 10.1016/j.arr.2016.07.002

Song, M., Jin, J., Lim, J. E., Kou, J., Pattanayak, A., Rehman, J. A., et al. (2011). Tlr4 mutation reduces microglial activation, increases a $\beta$ deposits and exacerbates cognitive deficits in a mouse model of Alzheimer's disease. J. Neuroinflammation 8:92. doi: 10.1186/1742-2094-8-92

Sosna, J., Philipp, S., Albay, R. III., Reyes-Ruiz, J. M., Baglietto-Vargas, D., Laferla, F. M., et al. (2018). Early long-term administration of the CSF1R inhibitor PLX3397 ablates microglia and reduces accumulation of intraneuronal amyloid, neuritic plaque deposition and pre-fibrillar oligomers in 5XFAD mouse model of Alzheimer's disease. Mol. Neurodegener. 13:11. doi: 10.1186/s13024-018-0244-x

Stokes, C. E., and Hawthorne, J. N. (1987). Reduced phosphoinositide concentrations in anterior temporal cortex of Alzheimer-diseased brains. J. Neurochem. 48, 1018-1021. doi: 10.1111/j.1471-4159.1987.tb05619.x

Stokes, L., Layhadi, J. A., Bibic, L., Dhuna, K., and Fountain, S. J. (2017). $\mathrm{P} 2 \mathrm{X} 4$ receptor function in the nervous system and current breakthroughs in pharmacology. Front. Pharmacol. 8:291. doi: 10.3389/fphar.2017.00291

Suh, B.-C., and Hille, B. (2005). Regulation of ion channels by phosphatidylinositol 4,5-bisphosphate. Curr. Opin. Neurobiol. 15, 370-378. doi: 10.1016/j.conb. 2005.05.005

Swiatkowski, P., Murugan, M., Eyo, U. B., Wang, Y., Rangaraju, S., Oh, S. B., et al. (2016). Activation of microglial P2Y12 receptor is required for outward potassium currents in response to neuronal injury. Neuroscience 318, 22-33. doi: 10.1016/j.neuroscience.2016.01.008

Tahara, K., Kim, H.-D., Jin, J. J., Maxwell, J. A., Li, L., and Fukuchi, K. (2006). Role of toll-like receptor signaling in a $\beta$ uptake and clearance. Brain 129, 3006-3019. doi: 10.1093/brain/awl249

Tai, Y. F., Pavese, N., Gerhard, A., Tabrizi, S. J., Barker, R. A., Brooks, D. J., et al. (2007). Imaging microglial activation in Huntington's disease. Brain Res. Bull. 72, 148-151. doi: 10.1016/j.brainresbull.2006.10.029

Takeda, K., and Akira, S. (2004). TLR signaling pathways. Semin. Immunol. 16, 3-9. doi: 10.1016/j.smim.2003.10.003

Takeda, K., Kaisho, T., and Akira, S. (2003). Toll-like receptors. Annu. Rev. Immunol. 21, 335-376. doi: 10.1146/annurev.immunol.21.120601.141126

Takenouchi, T., Sugama, S., Iwamaru, Y., Hashimoto, M., and Kitani, H. (2009). Modulation of the ATP-lnduced release and processing of IL-1 $\beta$ in microglial Cells. Crit. Rev. Immunol. 29, 335-345. doi: 10.1615/critrevimmunol.v29.i4.40

Takeuchi, O., Sato, S., Horiuchi, T., Hoshino, K., Takeda, K., Dong, Z., et al. (2002). Cutting edge: role of toll-like receptor 1 in mediating immune response to microbial lipoproteins. J. Immunol. 169, 10-14. doi: 10.4049/jimmunol. 169.1.10

Tan, M., Li, J., Ma, F., Zhang, X., Zhao, Q., and Cao, X. (2019). PLD3 rare variants identified in late-onset Alzheimer's disease affect amyloid- $\beta$ levels in cellular model. Front. Neurosci. 13:116. doi: 10.3389/fnins.2019.00116

Tanaka-Takiguchi, Y., Kinoshita, M., and Takiguchi, K. (2009). Septin-mediated uniform bracing of phospholipid membranes. Curr. Biol. 19, 140-145. doi: 10.1016/j.cub.2008.12.030

Tricker, E., and Cheng, G. (2008). With a little help from my friends: modulation of phagocytosis through tlr activation. Cell Res. 18, 711-712. doi: 10.1038/cr. 2008.78

Träger, U., Andre, R., Lahiri, N., Magnusson-Lind, A., Weiss, A., Grueninger, S., et al. (2014). HTT-lowering reverses Huntington's disease immune dysfunction caused by NFKB pathway dysregulation. Brain 137, 819-833. doi: 10.1093/brain/awt355

Tsukita, S., and Yonemura, S. (1997). Erm proteins: head-to-tail regulation of actin-plasma membrane interaction. Trends Biochem. Sci. 22, 53-58. doi: 10.1016/s0968-0004(96)10071-2

Tóth, A., Antal, Z., Bereczki, D., and Sperlágh, B. (2019). Purinergic signaling in Parkinson's disease: a multi-target system to combat neurodegeneration. Neurochem. Res. 44, 2413-2422. doi: 10.1007/s11064-019-02798-1

Ueyama, T., Lennartz, M. R., Noda, Y., Kobayashi, T., Shirai, Y., Rikitake, K., et al. (2004). Superoxide production at phagosomal cup/phagosome through $\beta$ I protein kinase $\mathrm{C}$ during $\mathrm{Fc} \gamma \mathrm{R}$-mediated phagocytosis in microglia. J. Immunol. 173, 4582-4589. doi: 10.4049/jimmunol.173.7.4582

Um, J. W., Kaufman, A. C., Kostylev, M., Heiss, J. K., Stagi, M., Takahashi, H., et al. (2013). Metabotropic glutamate receptor 5 is a coreceptor for Alzheimer a $\beta$ oligomer bound to cellular prion protein. Neuron 79, 887-902. doi: 10.1016/j. neuron.2013.06.036

van der Lee, S. J., Conway, O. J., Jansen, I., Carrasquillo, M. M., Kleineidam, L., Van Den Akker, E., et al. (2019). A nonsynonymous mutation in PLCG2 reduces the risk of Alzheimer's disease, dementia with lewy bodies and frontotemporal dementia, and increases the likelihood of longevity. Acta Neuropathol. 138, 237-250. doi: 10.1007/s00401-019-02026-8

Varma, R., Chai, Y., Troncoso, J., Gu, J., Xing, H., Stojilkovic, S. S., et al. (2009). Amyloid- $\beta$ induces a caspase-mediated cleavage of P2X4 to promote purinotoxicity. Neuromolecular Med. 11, 63-75. doi: 10.1007/s12017-0098073-2

Vawter, M. P., Dillon-Carter, O., Tourtellotte, W. W., Carvey, P., and Freed, W. J. (1996). TGF $\beta 1$ and TGF $\beta 2$ concentrations are elevated in Parkinson's disease in ventricular cerebrospinal fluid. Exp. Neurol. 142, 313-322. doi: 10.1006/exnr. 1996.0200

Vicinanza, M., Korolchuk, V. I., Ashkenazi, A., Puri, C., Menzies, F. M., Clarke, J. H., et al. (2015). PI(5)P regulates autophagosome biogenesis. Mol. Cell 57, 219-234. doi: 10.1016/j.molcel.2014.12.007

Vieira, O. V., Botelho, R. J., and Grinstein, S. (2002). Phagosome maturation: aging gracefully. Biochem. J. 366, 689-704. doi: 10.1042/BJ20020691

Vieira, O. V., Botelho, R. J., Rameh, L., Brachmann, S. M., Matsuo, T., Davidson, H. W., et al. (2001). Distinct roles of class I and class III phosphatidylinositol 3-kinases in phagosome formation and maturation. J. Cell Biol. 155, 19-25. doi: 10.1083/jcb.200107069 
Villar-Menéndez, I., Porta, S., Buira, S. P., Pereira-Veiga, T., Díaz-Sánchez, S., Albasanz, J. L., et al. (2014). Increased striatal adenosine A2A receptor levels is an early event in Parkinson's disease-related pathology and it is potentially regulated by miR-34b. Neurobiol. Dis. 69, 206-214. doi: 10.1016/j.nbd.2014. 05.030

Vincent, C., Siddiqui, T. A., and Schlichter, L. C. (2012). Podosomes in migrating microglia: components and matrix degradation. J. Neuroinflammation 9:190. doi: 10.1186/1742-2094-9-190

Visanji, N. P., Lang, A. E., and Kovacs, G. G. (2019). Beyond the synucleinopathies: $\alpha$ synuclein as a driving force in neurodegenerative comorbidities. Transl. Neurodegener. 8:28. doi: 10.1186/s40035-019-0172-x

Von Kügelgen, I., and Hoffmann, K. (2016). Pharmacology and structure of P2Y receptors. Neuropharmacology 104, 50-61. doi: 10.1016/j.neuropharm.2015. 10.030

Wake, H., Moorhouse, A. J., and Nabekura, J. (2011). Functions of microglia in the central nervous system-beyond the immune response. Neuron Glia Biol. 7, 47-53. doi: 10.1017/S1740925X12000063

Wallace, M. A., and Claro, E. (1993). Transmembrane signaling through phospholipase C in human cortical membranes. Neurochem. Res. 18, 139-145. doi: 10.1007/BF01474676

Walter, S., Letiembre, M., Liu, Y., Heine, H., Penke, B., Hao, W., et al. (2007). Role of the toll-like receptor 4 in neuroinflammation in Alzheimer's disease. Cell Physiol. Biochem. 20, 947-956. doi: 10.1159/000110455

Wan, T., Liu, T., Zhang, H., Tang, S., and Min, W. (2010). AIP1 functions as Arf6-GAP to negatively regulate TLR4 signaling. J. Biol. Chem. 285, 3750-3757. doi: 10.1074/jbc.M109.069385

Wang, S., Chu, C.-H., Stewart, T., Ginghina, C., Wang, Y., Nie, H., et al. (2015). $\alpha$-synuclein, a chemoattractant, directs microglial migration via $\mathrm{H}_{2} \mathrm{O}_{2}$ dependent Lyn phosphorylation. Proc. Natl. Acad. Sci. US A 112, E1926-E1935. doi: $10.1073 /$ pnas. 1417883112

Weeds, A. G., Gooch, J., Pope, B., and Harris, H. E. (1986). Preparation and characterization of pig plasma and platelet gelsolins. Eur. J. Biochem. 161, 69-76. doi: 10.1111/j.1432-1033.1986.tb10125.x

Weller, J., and Budson, A. (2018). Current understanding of Alzheimer's disease diagnosis and treatment. F1000res 7:F1000 Faculty Rev-1161. doi: 10.12688/f1000research.14506.1

Welliver, T. P., and Swanson, J. A. (2012). A growth factor signaling cascade confined to circular ruffles in macrophages. Biol. Open 1, 754-760. doi: 10.1242/bio.20121784

Wenk, M. R., and De Camilli, P. (2004). Protein-lipid interactions and phosphoinositide metabolism in membrane traffic: insights from vesicle recycling in nerve terminals. Proc. Natl. Acad. Sci. U S A 101, 8262-8269. doi: 10.1073/pnas.0401874101

West, M. A., Prescott, A. R., Eskelinen, E.-L., Ridley, A. J., and Watts, C. (2000). $\mathrm{Rac}$ is required for constitutive macropinocytosis by dendritic cells but does not control its downregulation. Curr. Biol. 10, 839-848. doi: 10.1016/s09609822(00)00595-9

Woods, L. T., Ajit, D., Camden, J. M., Erb, L., and Weisman, G. A. (2016). Purinergic receptors as potential therapeutic targets in Alzheimer's disease. Neuropharmacology 104, 169-179. doi: 10.1016/j.neuropharm.2015.10.031

World Alzheimer Report. (2015). The Global Impact of Dementia: An Analysis of Prevalence, Incidence, Cost and Trends. London: Alzheimer's Disease International.

Wu, C.-H., Fallini, C., Ticozzi, N., Keagle, P. J., Sapp, P. C., Piotrowska, K., et al. (2012). Mutations in the profilin 1 gene cause familial amyotrophic lateral sclerosis. Nature 488, 499-503. doi: 10.1038/nature11280

Wu, B., Kitagawa, K., Liu, B., Zhang, N. Y., Xiong, Z. M., and Inagaki, C. (2006). Attenuation of amyloid $\beta(A \beta)$-induced inhibition of phosphatidylinositol 4-kinase activity by A $\beta$ fragments, A $\beta 20-29$ and A $\beta 31-35$. Neurosci. Lett. 396, 148-152. doi: 10.1016/j.neulet.2005.11.026

Wu, B., Kitagawa, K., Zhang, N. Y., Liu, B., and Inagaki, C. (2004). Pathophysiological concentrations of amyloid $\beta$ proteins directly inhibit rat brain and recombinant human type II phosphatidylinositol 4-kinase activity. J. Neurochem. 91, 1164-1170. doi: 10.1111/j.1471-4159.2004.02805.x

Wu, C.-Y., Lin, M.-W., Wu, D.-C., Huang, Y.-B., Huang, H.-T., and Chen, C.L. (2014). The role of phosphoinositide-regulated actin reorganization in chemotaxis and cell migration. Br. J. Pharmacol. 171, 5541-5554. doi: $10.1111 /$ bph.12777
Wu, L.-J., Vadakkan, K. I., and Zhuo, M. (2007). ATP-induced chemotaxis of microglial processes requires $\mathrm{P} 2 \mathrm{Y}$ receptor-activated initiation of outward potassium currents. Glia 55, 810-821. doi: 10.1002/glia.20500

Xian, W., and Janmey, P. A. (2002). Dissecting the gelsolin-polyphosphoinositide interaction and engineering of a polyphosphoinositide-sensitive gelsolin C-terminal half protein. J. Mol. Biol. 322, 755-771. doi: 10.1016/s00222836(02)00841-0

Xie, F., Chen, S., Cen, Z. D., Chen, Y., Yang, D. H., Wang, H. T., et al. (2019). A novel homozygous SYNJ1 mutation in two siblings with typical Parkinson's disease. Parkinsonism Relat. Disord. 69, 134-137. doi: 10.1016/j.parkreldis. 2019.11.001

Xiong, Y., Sun, S., Teng, S., Jin, M., and Zhou, Z. (2018). $\mathrm{Ca}^{2+}$-dependent and $\mathrm{Ca}^{2+}$-independent ATP release in astrocytes. Front. Mol. Neurosci. 11:224. doi: 10.3389/fnmol.2018.00224

Yamamoto, M., Sato, S., Hemmi, H., Hoshino, K., Kaisho, T., Sanjo, H., et al. (2003a). Role of adaptor TRIF in the MYD88-independent toll-like receptor signaling pathway. Science 301, 640-643. doi: 10.1126/science.1087262

Yamamoto, M., Sato, S., Hemmi, H., Uematsu, S., Hoshino, K., Kaisho, T., et al. (2003b). Tram is specifically involved in the toll-like receptor 4-mediated MYD88-independent signaling pathway. Nat. Immunol. 4, 1144-1150. doi: $10.1038 /$ ni986

Yamamoto, M., Sato, S., Hemmi, H., Sanjo, H., Uematsu, S., Kaisho, T., et al. (2002). Essential role for tirap in activation of the signaling cascade shared by TLR2 and TLR4. Nature 420, 324-329. doi: 10.1038/nature01182

Yamasaki, R., Tanaka, M., Fukunaga, M., Tateishi, T., Kikuchi, H., Motomura, K. et al. (2010). Restoration of microglial function by granulocyte-colony stimulating factor in als model mice. J. Neuroimmunol. 229, 51-62. doi: 10.1016/j.jneuroim.2010.07.002

Yang, X., Lou, Y., Liu, G., Wang, X., Qian, Y., Ding, J., et al. (2017). Microglia P2Y6 receptor is related to Parkinson's disease through neuroinflammatory Process. J. Neuroinflammation 14:38. doi: 10.1186/s12974-017-0795-8

Yang, M., Lewinska, M., Fan, X., Zhu, J., and Yuan, Z. M. (2016). Prr14 is a novel activator of the PI3K pathway promoting lung carcinogenesis. Oncogene 35, 5527-5538. doi: 10.1038/onc.2016.93

Yang, J., Nie, J., Ma, X., Wei, Y., Peng, Y., and Wei, X. (2019). Targeting PI3K in cancer: mechanisms and advances in clinical trials. Mol. Cancer 18:26. doi: 10.1186/s12943-019-0954-x

Yang, H.-M., Yang, S., Huang, S.-S., Tang, B.-S., and Guo, J.-F. (2017). Microglial activation in the pathogenesis of Huntington's disease. Front. Aging Neurosci. 9:193. doi: 10.3389/fnagi.2017.00193

Yoshida, S., Hoppe, A. D., Araki, N., and Swanson, J. A. (2009). Sequential signaling in plasma-membrane domains during macropinosome formation in macrophages. J. Cell Sci. 122, 3250-3261. doi: 10.1242/jcs.053207

Yousefi, N., Sotoodehnejadnematalahi, F., Heshmati-Fakhr, N., Sayyah, M., Hoseini, M., Ghassemi, S., et al. (2019). Prestimulation of microglia through TLR4 pathway promotes interferon $\beta$ expression in a rat model of Alzheimer's disease. J. Mol. Neurosci. 67, 495-503. doi: 10.1007/s12031-018-1249-1

Yue, N., Huang, H., Zhu, X., Han, Q., Wang, Y., Li, B., et al. (2017). Activation of P2X7 receptor and NLRP3 inflammasome assembly in hippocampal glial cells mediates chronic stress-induced depressive-like behaviors. J. Neuroinflammation 14:102. doi: 10.1186/s12974-017-0865-y

Zanoni, I., Ostuni, R., Marek, L. R., Barresi, S., Barbalat, R., Barton, G. M., et al. (2011). CD14 controls the LPS-induced endocytosis of toll-like receptor 4. Cell 147, 868-880. doi: 10.1016/j.cell.2011.09.051

Zhang, S.-X., Duan, L.-H., He, S.-J., Zhuang, G.-F., and Yu, X. (2017). Phosphatidylinositol 3,4-bisphosphate regulates neurite initiation and dendrite morphogenesis via actin aggregation. Cell Res. 27, 253-273. doi: 10.1038/cr. 2017.13

Zhang, Y.-K., Liu, J.-T., Peng, Z.-W., Fan, H., Yao, A.-H., Cheng, P., et al. (2013). Different TLR4 expression and microglia/macrophage activation induced by hemorrhage in the rat spinal cord after compressive injury. J. Neuroinflammation 10:112. doi: 10.1186/1742-209410-112

Zhang, F. X., Kirschning, C. J., Mancinelli, R., Xu, X. P., Jin, Y., Faure, E., et al. (1999). Bacterial lipopolysaccharide activates nuclear factor-кb through interleukin-1 signaling mediators in cultured human dermal endothelial cells and mononuclear phagocytes. J. Biol. Chem. 274, 7611-7614. doi: 10.1074/jbc. 274.12 .7611 
Zhang, X., Wang, W.-A., Jiang, L.-X., Liu, H.-Y., Zhang, B.-Z., Lim, N., et al. (2017). Downregulation of RBO-PI4KIII $\alpha$ facilitates $A \beta_{42}$ secretion and ameliorates neural deficits in $\mathrm{A} \beta_{42}$-expressing Drosophila. J. Neurosci. 37:4928. doi: 10.1523/JNEUROSCI.3567-16.2017

Zhang, W., Wang, T., Pei, Z., Miller, D. S., Wu, X., Block, M. L., et al. (2005). Aggregated $\alpha$-synuclein activates microglia: a process leading to disease progression in Parkinson's disease. FASEB J. 19, 533-542. doi: 10.1096/fj.042751com

Zhang, Q., Wu, H.-H., Wang, Y., Gu, G.-J., Zhang, W., and Xia, R. (2016). Neural stem cell transplantation decreases neuroinflammation in a transgenic mouse model of Alzheimer's disease. J. Neurochem. 136, 815-825. doi: 10.1111/jnc. 13413

Zhao, Q., Yang, M., Ting, A. T., and Logothetis, D. E. (2007). PIP(2) regulates the ionic current of $\mathrm{P} 2 \mathrm{X}$ receptors And $\mathrm{P} 2 \mathrm{X}(7)$ receptor-mediated cell death. Channels 1, 46-55. doi: 10.4161/chan.3914

Zhou, Z., Hou, J., Mo, Y., Ren, M., Yang, G., Qu, Z., et al. (2020). Geniposidic acid ameliorates spatial learning and memory deficits and alleviates neuroinflammation via inhibiting HMGB-1 and downregulating TLR4/2 signaling pathway in APP/PS1 mice. Eur. J. Pharmacol. 869:172857. doi: 10.1016/j.ejphar.2019.172857

Zhou, C., Sun, X., Hu, Y., Song, J., Dong, S., Kong, D., et al. (2019). Genomic deletion Of TLR2 induces aggravated white matter damage and deteriorated neurobehavioral functions in mouse models of Alzheimer's disease. Aging 11, 7257-7273. doi: 10.18632/aging. 102260
Zhu, D., Bungart, B. L., Yang, X., Zhumadilov, Z., Lee, J. C., and Askarova, S. (2015). Role of membrane biophysics in Alzheimer'srelated cell pathways. Front. Neurosci. 9:186. doi: 10.3389/fnins.2015. 00186

Zhu, L., Zhong, M., Zhao, J., Rhee, H., Caesar, I., Knight, E. M., et al. (2013). Reduction of synaptojanin 1 accelerates $A \beta$ clearance and attenuates cognitive deterioration in an Alzheimer mouse model. J. Biol. Chem. 288, 32050-32063. doi: 10.1074/jbc.M113.504365

Zujovic, V., Benavides, J., Vigé, X., Carter, C., and Taupin, V. (2000). Fractalkine modulates TNF- $\alpha$ secretion and neurotoxicity induced by microglial activation. Glia 29, 305-315. doi: 10.1002/(sici)1098-1136(20000215)29:4<305::aidglia2 $>3.0 . \operatorname{co} ; 2-\mathrm{v}$

Conflict of Interest: The authors declare that the research was conducted in the absence of any commercial or financial relationships that could be construed as a potential conflict of interest.

Copyright (C) 2021 Phillips and Maguire. This is an open-access article distributed under the terms of the Creative Commons Attribution License (CC BY). The use, distribution or reproduction in other forums is permitted, provided the original author(s) and the copyright owner(s) are credited and that the original publication in this journal is cited, in accordance with accepted academic practice. No use, distribution or reproduction is permitted which does not comply with these terms. 